UNIVERSIDADE DE SÃO PAULO

Escola de Engenharia de São Carlos

Departamento de Engenharia de Transportes

Programa de Pós-Graduação em Engenharia de Transportes

ANABELE LINDNER

Métodos heurísticos de desagregação de dados de demanda por transportes através de simulação geoestatística

São Carlos

2019 

ANABELE LINDNER

Métodos heurísticos de desagregação de dados de demanda por transportes através de simulação geoestatística

Programa de Pós-Graduação em

Engenharia de Transportes da EESC-USP

Exemplar definitivo (corrigido). O exemplar original está disponível na CPG da EESC-USP.

São Carlos, 19/03/2019

Resolução CoPGr n 6018, de 13 de Outubro de 2011, Artigo $5^{\circ}$

Tese de doutorado apresentada à Escola de Engenharia de São Carlos (EESC/USP) como parte dos requisitos para a obtenção do título de Doutor em Ciências, Programa de Pós-Graduação em Engenharia de Transportes.

Área de concentração: Planejamento e Operação de Sistemas de Transportes.

Orientadora: Prof. Dra. Cira Souza Pitombo

São Carlos

2019 
AUTORIZO A REPRODUÇÃO TOTAL OU PARCIAL DESTE TRABALHO, POR QUALQUER MEIO CBONVENCIONAL OU ELETRÔNICO, PARA FINS DE ESTUDO E PESQUISA, DESDE QUE CITADA A FONTE.

Ficha catalográfica elaborada pela Biblioteca Prof. Dr. Sérgio Rodrigues Fontes da EESC/USP com os dados inseridos pelo(a) autor(a).

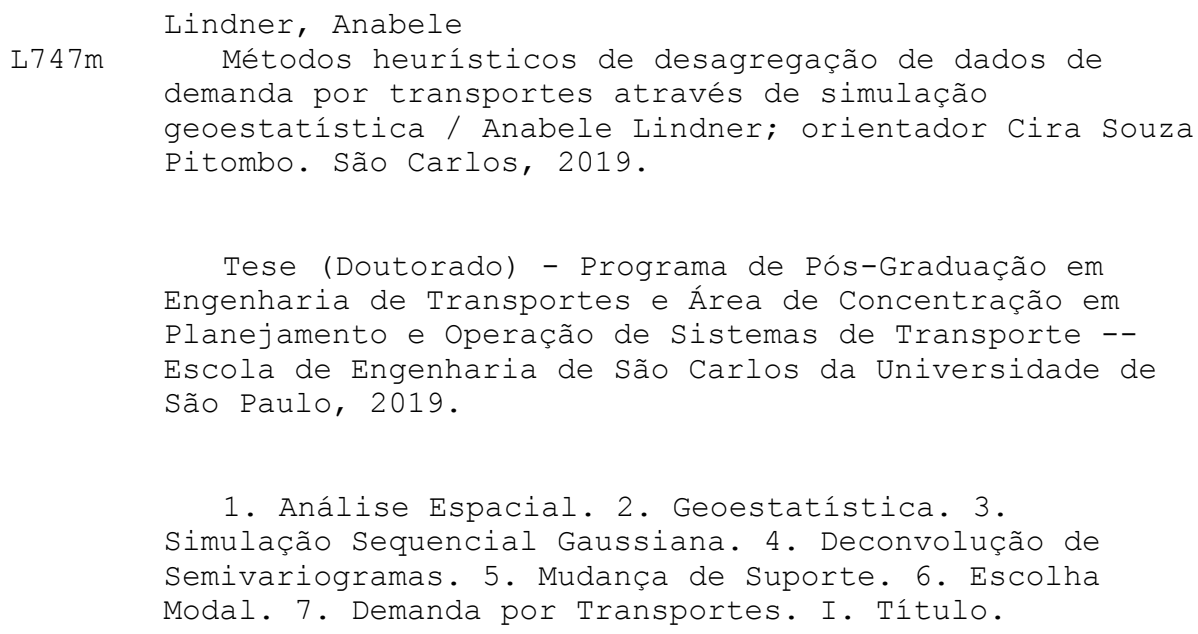

Eduardo Graziosi Silva - CRB - 8/8907 


\section{FOLHA DE JULGAMENTO}

Candidata: Engenheira ANABELE LINDNER.

Título da tese: "Métodos heurísticos de desagregação de dados de demanda por transportes através de simulação geoestatística".

Data da defesa: 19/02/2019.

Comissão Julgadora:

Profa. Associada Cira Souza Piłombo

(Orientadora)

(Escola de Engenharia de São Carlos/EESC)

Prof. Titular Antônio Nelson Rodrigues da Silva

(Escola de Engenharia de São Carlos/EESC)

Prof. Dr. Gustavo Garcia Manzato

(Universidade Estadual Paulista "Júlio de Mesquita Filho"/UNESP - Bauru)

Prof. Dr. Mauro José Alixandrini Junior

(Universidade Federal da Bahia/UFBA)

Prof. Dr. Jose Alberto Quintanilha

(Escola Politécnica/EP-USP)
Resultado:

Aprovada

APROVADA
APROVADA

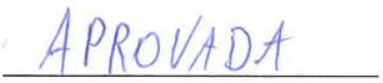

Coordenadora do Programa de Pós-Graduação em Engenharia de Transportes:

Profa. Associada Ana Paula Camargo Larocca

Presidente da Comissão de Pós-Graduação:

Prof. Associado Luis Fernando Costa Alberto 



\section{Agradecimentos}

Agradeço primeiramente a Deus, pelas oportunidades concebidas em minha vida e à força contemplada na jornada.

Agradeço à minha família, especialmente aos meus pais, pelos princípios ensinados, os quais permitiram que eu me tornasse uma pessoa perseverante.

Agradeço à Coordenação de Aperfeiçoamento de Pessoal de Nível Superior (CAPES) pelo apoio à pesquisa.

Agradeço à minha brilhante orientadora e amiga, Cira Souza Pitombo, que sempre acessível e com muito bom humor, confiou no meu potencial e me encorajou a seguir.

Agradeço ao Instituto de Geociências (IGc) da Universidade de São Paulo, em especial, ao Eduardo Takafuji, que, não somente esteve sempre disposto a me assistir academicamente, como também se tornou um grande amigo. Agradeço ao Professor Marcelo Monteiro Rocha e ao Matheus Andrade, sempre muito prestativos.

Agradeço à amiga Samille Santos Rocha, que se tornou minha companheira de projeto, de lutas e de vitórias neste caminho acadêmico. A Elaine Rodrigues Ribeiro pela grande amizade. Ao amicíssimo Diego Fernandes Neris, que me incentivou a fazer esta Pós Graduação e (continua) me inspirando com o seu sucesso. Aos solícitos amigos Rodrigo Barbosa e Silva e Rhaíssa Viana Sarot, que mesmo distantes, tiveram importância no desenvolvimento desta pesquisa.

Agradeço aos professores, colegas e funcionários do STT, em especial ao Samuel Marques, a Ana Hildebrand Vita, a Sabrina Dotta e à Professora Ana Paula Larocca, que foram, ao longo do doutoramento, essenciais.

Agradeço à banca examinadora, professores Antônio Nélson Rodrigues da Silva, Gustavo Garcia Manzato, Mauro José Alixandrini Júnior. Um agradecimento especial ao Professor José Alberto Quintanilha, pela colaboração, sugestões e disponibilidade. 



\section{Resumo}

LINDNER, A. Métodos heurísticos de desagregação de dados de demanda por transportes através de simulação geoestatística. 118p. Tese de Doutorado - Escola de Engenharia de São Carlos, Universidade de São Paulo. São Carlos, 2019.

Informações desagregadas de demanda por transportes são recursos essenciais ao correto planejamento urbano, especialmente no que se refere ao transporte público. Contudo, o acesso a estes dados é limitado, devido ao alto custo para coleta de pesquisas domiciliares e à confidencialidade de informações individuais. A presente tese de doutorado aborda esta problemática ao propor dois métodos heurísticos de desagregação de dados, através de simulação geoestatística. Propõe-se empregar, como um input aos procedimentos, informações com alta disponibilidade, como, por exemplo, os microdados, coletados pelo censo demográfico. A diferença principal entre os métodos é que o primeiro não necessita de valores de dados provenientes de Pesquisa Origem/Destino do município de São Paulo, área de estudo deste trabalho. Ambas as abordagens, que podem ser aplicadas a outros diferentes estudos de caso, compreendem um procedimento alternativo para deconvolução de semivariogramas, Simulação Sequencial Gaussiana e validação, considerando malhas regulares de diferentes suportes. Os mapas e métricas estatísticas gerados comprovam que é possível desagregar dados, associados a Áreas de Ponderação de Setores Censitários (Método Proposto 1 - MP1) e a Zonas de Tráfego (Método Proposto 2 - MP2), através dos procedimentos aplicados. Além disso, este trabalho apresenta contribuições metodológicas ao viabilizar: a geração de diversos cenários que reproduzam o comportamento espacial da variável; e o estudo da incerteza associada às simulações.

Palavras-chave: Análise Espacial, Geoestatística, Simulação Sequencial Gaussiana, Deconvolução de Semivariogramas, Escolha Modal, Demanda por Transportes. 



\section{Abstract}

LINDNER, A. Heuristic methods to disaggregate travel demand data using geostatistical simulation. 118p. PhD Dissertation - São Carlos School of Engineering, University of São Paulo. São Carlos, 2019.

Disaggregated data for travel demand are essential resources towards good urban planning, especially with regard to public transportation. However, the access to such data is limited due to high costs of collecting household data and due to individual information confidentiality. The present $\mathrm{PhD}$ dissertation addresses this issue by introducing two heuristic methods to disaggregate data using geostatistical simulation. It is proposed to employ, as input to the procedures, information with high availability, such as census microdata. The main difference between both methods rely on the fact that the first does not require data values of any Origin/Destination Survey of the São Paulo city, study area of this research. Both approaches, which can be applied to other different study cases, comprise an alternative procedure for semivariogram deconvolution, Sequential Gaussian Simulation and validation, using regular grids of various spatial scales. The resulting maps and statistical metrics corroborate that is possible to disaggregate data associated with a set of Census Tracts (Proposed Method 1 - MP1) and Traffic Analysis Zones (Proposed Method 2 - MP2). Besides, this dissertation presents relevant contributions as it enables: creating different scenarios to reproduce the spatial behavior of the study variable; and assessing the associated uncertainty.

Keywords: Spatial Analysis, Geostatistics, Sequential Gaussian Simulation, Semivariogram Deconvolution, Travel Mode Choice, Travel Demand. 



\section{Lista de Figuras}

Figura 3.1 - Parâmetros gráficos de um modelo teórico de semivariograma.

Figura 4.1 - Representação da área de estudo: município de São Paulo e ZTs.

Figura 4.2 - Áreas povoadas e mapa de uso do solo.

Figura 4.3 - Valores da variável de estudo associados às Zonas de Tráfego.

Figura 4.4 - Fluxograma do método proposto para deconvolução do semivariograma

Figura 4.5 - Fluxograma das etapas seguidas neste trabalho

Figura 5.1 - Georreferenciamento dos domicílios entrevistados pela Pesquisa O/D

Figura 5.2 - Valores sintéticos de taxa de domicílios de classes de renda baixa pelo total de domicílios.

Figura 5.3 - Valores sintéticos de taxa de viagens por transporte público. 64

Figura 5.4 - Histogramas dos dados sintéticos desagregados (médios) e da transformada gaussiana. 65

Figura 5.5 - Mapas variográficos da variável taxa de viagens por transporte público. 66

Figura 5.6 - Semivariogramas dos dados sintéticos criados a partir de oito sorteios (malha de $250 \mathrm{~m})$

Figura 5.7 - Semivariogramas experimentais das configurações de dados sintéticos para cada malha estudada e para os dados da Pesquisa O/D agregados por ZTs 69

Figura 5.8 - Semivariogramas experimentais e ajustados da transformada gaussiana dos dados sintéticos. 70

Figura 5.9 - Histogramas e semivariogramas dos dados da Pesquisa O/D associados a Zonas de Tráfego. 
Figura 5.10 - Histogramas dos dados domiciliares da Pesquisa O/D e da transformada gaussiana.

Figura 5.11 - Semivariogramas experimentais dos dados domiciliares para cada malha estudada e para os dados da Pesquisa O/D agregados por ZTs.

Figura 5.12 - Semivariogramas experimentais e ajustados da transformada gaussiana dos dados domiciliares. 74

Figura 5.13 - Gráficos de variabilidade (variância média vs. o número de realizações) para o MP1......... .76

Figura 5.14 - Análise estatística das realizações calculadas por SSG para o MP1 (Malha $250 \mathrm{~m})$. .77

Figura 5.15 - Análise estatística das realizações calculadas por SSG para o MP1 (Malha $1500 \mathrm{~m})$ 77

Figura 5.16 - Análise estatística das realizações calculadas por SSG para o MP2 (Malha $250 \mathrm{~m})$. 78

Figura 5.17 - Análise estatística das realizações calculadas por SSG para o MP2 (Malha $1500 \mathrm{~m})$ 78

Figura 5.18-MC1 (Malhas 250, 500, 1000 e $1500 \mathrm{~m}$ ). 79

Figura 5.19 - Análise estatística das realizações calculadas por SSG para o MC2 (Malha $250 \mathrm{~m})$. 80

Figura 5.20 - Análise estatística das realizações calculadas por SSG para o MC2 (Malha $1500 \mathrm{~m})$ 80

Figura 5.21 - Histograma dos valores e-type das 500 realizações para cada SSG. 82

Figura 5.22 - Quantidade de domicílios entrevistados por célula 83

Figura 5.23 - Histograma dos erros (desvios médios) dos valores e-type das 500 realizações para cada SSG. 


\section{Lista de Quadros}

Quadro 4.1 - Vantagens e desvantagens dos métodos propostos e de SSG tradicional..... 58

Quadro 5.1 - Resumo de resultados dos métodos propostos vs. métodos comparativos.... 87

\section{Lista de Tabelas}

Tabela 5.1 - Medidas estatísticas descritivas da variável de estudo para os grupos de informações utilizados.

Tabela 5.2 - Análise estatística univariada dos resultados

Tabela 5.3 - Análise estatística comparativa entre valores e-type. 84

Tabela 5.4 - Testes não paramétricos de distribuição com valores e-type 86 



\section{Lista de Acrônimos e Siglas}

\begin{tabular}{ll} 
AP & Área de Ponderação \\
IC & Intervalo de Confiança \\
KO & Krigagem Ordinária \\
KS & Krigagem Simples \\
MAUP & Problema da Unidade de Área Modificável \\
MC1 & Método Comparativo 1 \\
MC2 & Método Comparativo 2 \\
MP1 & Método Proposto 1 \\
MP2 & Método Proposto 2 \\
MZT & Macrozona de Tráfego \\
O/D & Origem/Destino \\
SSG & Simulação Sequencial Gaussiana \\
ZT & Zona de Tráfego \\
\hline
\end{tabular}





\section{Sumário}

1. INTRODUÇÃO

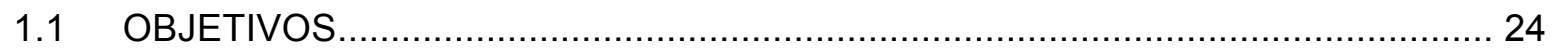

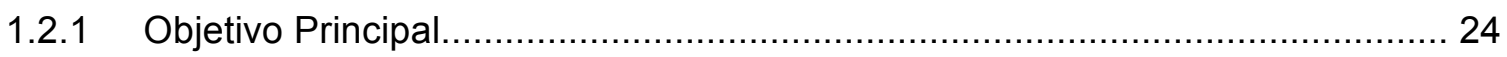

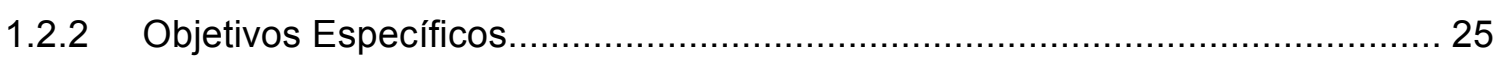

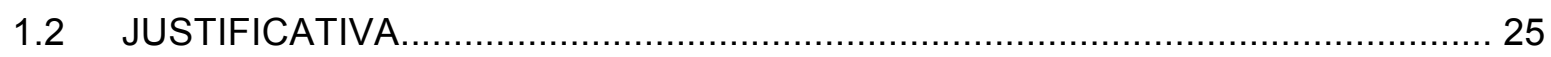

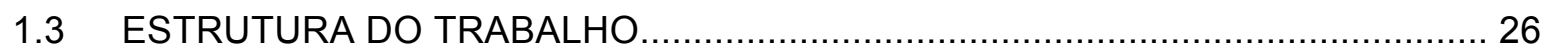

2. ANÁLISE ESPACIAL E DEMANDA POR TRANSPORTES 27

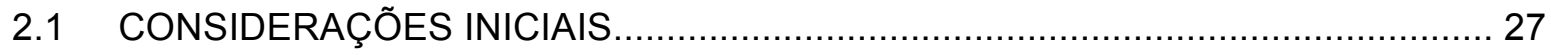

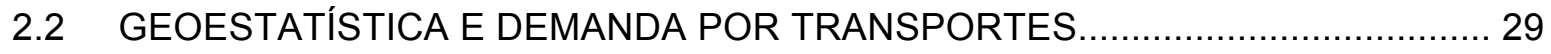

2.3 SUPORTE GEOGRÁFICO, MUDANÇA DE ESCALA E A GEOESTATÍSTICA...... 31

3. geoestatística

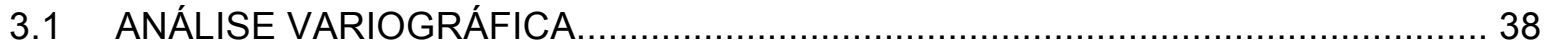

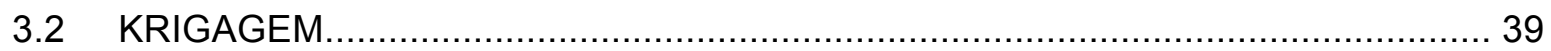

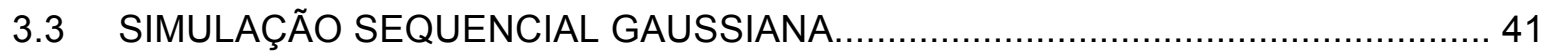

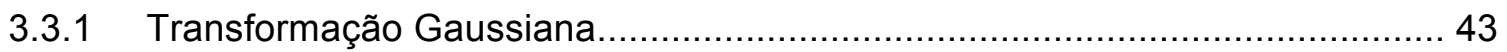

3.4 DECONVOLUÇÃO DE SEMIVARIOGRAMAS ............................................. 44

4. MATERIAIS E MÉTODO 49

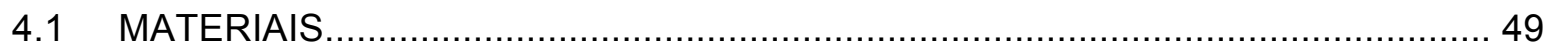

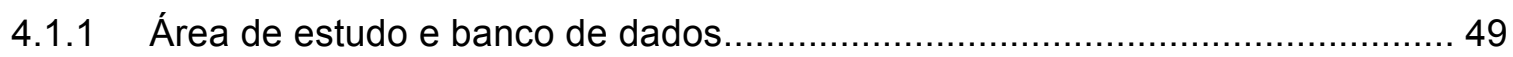

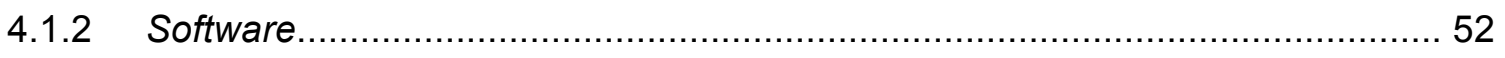


4.2 MÉTODO

4.2.1 Procedimento para deconvolução de semivariograma ............................... 53

4.2.2 Métodos Propostos e Métodos Comparativos................................................. 56

5. RESULTADOS E DISCUSSÕES

5.1 GERAÇÃO DE OITO CONFIGURAÇÕES DE DADOS SINTÉTICOS................... 62

5.2 ANÁLISE VARIOGRÁFICA E GERAÇÃO DE SEMIVARIOGRAMAS

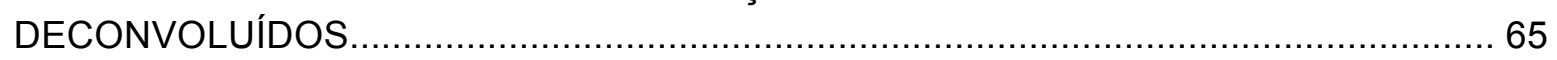

5.2.1 Configurações de dados sintéticos desagregados por malha........................6 67

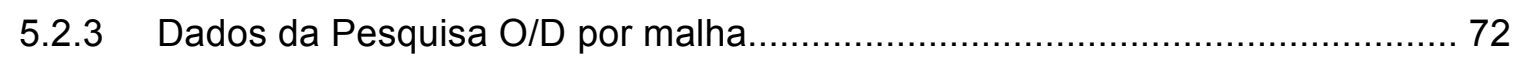

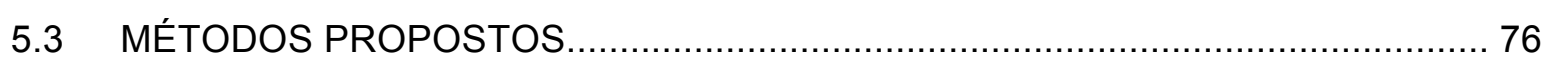

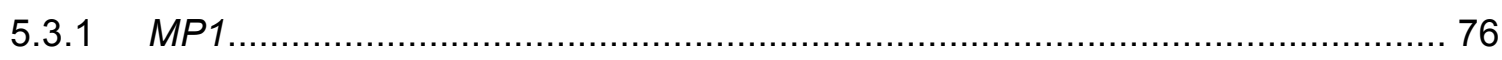

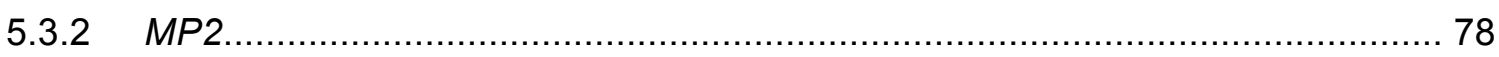

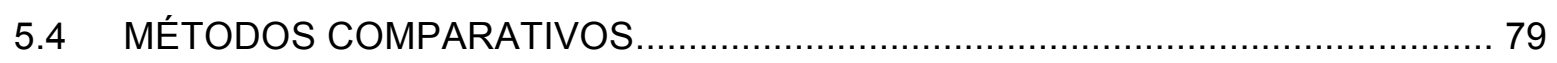

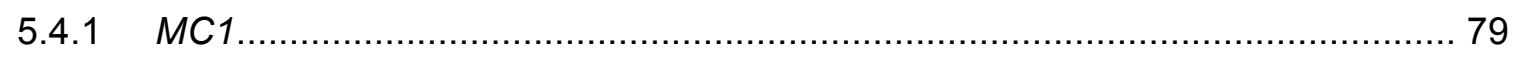

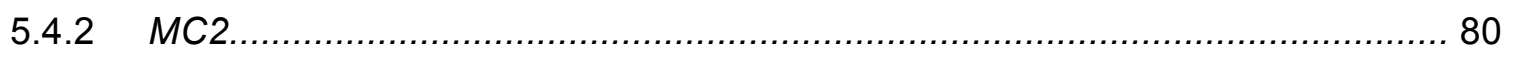

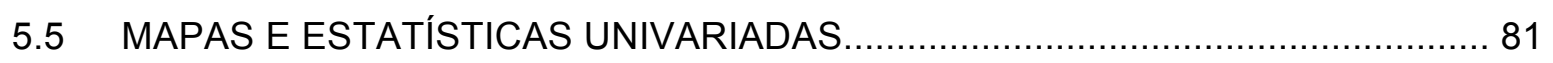

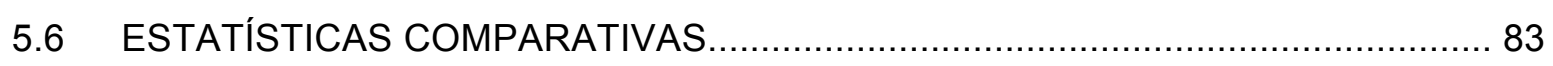

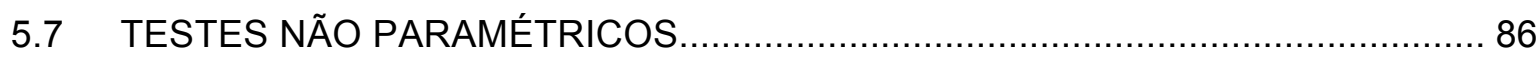

6. CONCLUSÕES E RECOMENDAÇÕES 89

6.1 PROBLEMÁTICAS, HIPÓTESES E OBJETIVOS: PRINCIPAIS CONCLUSÕES E

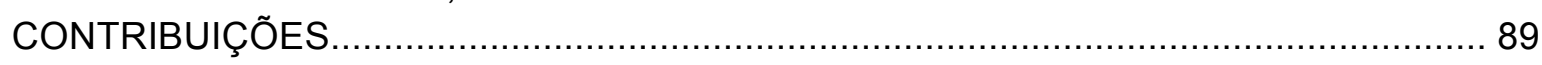

6.2 USO DA GEOESTATÍSTICA PARA DEMANDA POR TRANSPORTES............... 92

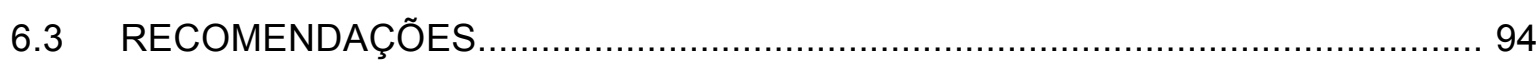

REFERÊNCIAS BIBLIOGRÁFICAS......................................................... 97 
Apêndice A - Semivariogramas dos dados sintéticos criados a partir de oito sorteios (Malha 500 metros). 107

Apêndice B - Semivariogramas dos dados sintéticos criados a partir de oito sorteios (Malha 1000 metros). 108

Apêndice $\mathrm{C}$ - Semivariogramas dos dados sintéticos criados a partir de oito sorteios (Malha 1500 metros). 109

Apêndice D - Gráficos de variabilidade (variância média vs. número de realizações calculadas) para cada SSG. 110

Apêndice E - Mapas resultantes da SSG para o MP1 (Malhas 500 e 1000 m)... 111

Apêndice F - Mapas resultantes da SSG para o MP2 (Malhas 500 e 1000 m) 112

Apêndice G - Mapas resultantes da SSG para o MC2 (Malhas 500 e 1000 m) 113

Anexo A - Mapa das Zonas de Tráfego do município de São Paulo. 115

Anexo B - Legenda das Zonas de Tráfego do município de São Paulo 116

Anexo C - Mapa das Áreas de Ponderação do município de São Paulo 117

Anexo D - Legenda das Áreas de Ponderação do município de São Paulo 118 



\section{Introdução}

No Capítulo 1 desta tese, uma introdução é feita, apresentando o problema da pesquisa, hipóteses, objetivos, justificativa do estudo e estrutura do texto.

A previsão de demanda por transportes é essencial para políticas de planejamento urbano. Os modelos clássicos para previsão de demanda, em geral, são fundamentados em Pesquisas Origem/Destino (O/D), cujos dados são coletados por amostras aleatórias de domicílios. No entanto, o processo de coleta de dados de tais pesquisas é moroso e requer grandes investimentos financeiros por parte dos órgãos responsáveis.

Além desta conjuntura, os modelos tradicionais não levam em conta fatores espaciais como variantes significativas para previsão da demanda por transportes. Contudo, ao longo dos anos, muitos estudos vêm corroborando a afirmação de que o comportamento individual relativo a viagens, principalmente associado à escolha modal, está diretamente relacionado à distribuição espacial das atividades do contexto urbano (CERVERO e RADISCH, 1996; KITAMURA et al., 1997). Além disso, os processos tradicionais de desagregação de dados e/ou obtenção de dados sintéticos por simulação, desconsideram a dependência espacial existente em dados de demanda por transportes.

Partindo-se do contexto de que variáveis de demanda por transportes são espacialmente dependentes e de que tal característica deve ser considerada para modelagem e desagregação de dados, este trabalho propõe o uso da Geoestatística. A Geoestatística compreende uma das técnicas de estatística espacial já utilizada por alguns autores nos estudos de planejamento de transportes (YOON et al., 2014; CHEN et al., 2015; MIURA, 2010; DA COSTA et al., 2013; ROCHA, 2014; LINDNER, 2015; PITOMBO et al., 2015a; PITOMBO et al., 2015b; LINDNER et al., 2016; ROCHA et al., 2017; MARQUES e PITOMBO, 2018). Esta técnica possibilita análises exploratórias e confirmatórias através da previsão do comportamento de uma variável espacialmente correlacionada. Além disso, o método permite que sejam modelados valores de uma variável em posições espaciais onde não há conhecimento prévio desta, ou seja, onde não houve amostragem. Diante do potencial geoestatístico nos estudos de Demanda por Transportes, esta tese visa utilizar a simulação geoestatística para propor um método de desagregação de dados.

A Simulação Sequencial Gaussiana (SSG) é a técnica mais popular de simulação geoestatística. Este método permite que sejam calculados modelos equiprováveis que 
reproduzam a correlação espacial e a distribuição de probabilidade de uma variável contínua (VERLY, 1993). Uma vez que são geradas diversas simulações, é possível calcular a incerteza associada e, consequentemente, tem-se parâmetros estatísticos, como intervalos de confiança e variância condicional.

Dessa forma, este trabalho confronta duas problemáticas:

- O acesso a informações desagregadas de demanda por transportes é restrito - devido ao alto custo para coleta de dados domiciliares e à confidencialidade de informações individuais; e

- Métodos tradicionais de simulação de dados e modelagem de demanda por transportes não levam em conta que existe associação espacial das variáveis ao tratar da desagregação de dados.

A partir destas questões, são identificadas as seguintes hipóteses:

- É possível gerar amostras desagregadas de dados de demanda por transportes, de modo a suprir a ausência de dados provenientes de pesquisa domiciliar ou individual; e

- É possível usar a Geoestatística, que considera a autocorrelação espacial, para desagregar dados de demanda por transportes.

\subsection{OBJETIVOS}

As subseções seguintes apresentam os objetivos principais e específicos explorados neste trabalho.

\subsubsection{Objetivo Principal}

Considerando o problema de indisponibilidade de dados domiciliares e o potencial da Geoestatística para estudos em Engenharia de Transportes, tem-se como objetivo principal: propor dois métodos heurísticos de desagregação de dados de demanda por transportes, através de procedimentos geoestatísticos. O Método Proposto 1 (MP1) baseiase na desagregação de dados associados a Áreas de Ponderação de Setores Censitários e não requer uso de distribuição populacional e de valores de dados advindos de Pesquisa O/D. O Método Proposto $2(M P 2)$ compreende a desagregação de dados associados a Zonas de Tráfego. 


\subsubsection{Objetivos Específicos}

Esta tese tem como objetivos secundários:

- Analisar os obstáculos enfrentados pela aplicação de modelos tradicionais e espaciais (encontrados na literatura atual) a dados de demanda por transportes;

- Propor um procedimento alternativo de deconvolução de semivariogramas para gerar dados sintéticos;

- Propor uma abordagem que combine a desagregação de dados e a Geoestatística para gerar mapas que representem os fenômenos espaciais de uma variável de demanda por transportes, levando em conta o/a: 1) Problema da Unidade de Área Modificável (MAUP); 2) não suavização dos resultados; 3) geração de valores críticos através de intervalos de confiança; e 4) incerteza associada.

\subsection{JUSTIFICATIVA}

Quando se faz um planejamento de transportes em uma cidade, é indispensável realizar uma adequada coleta de dados. Os modelos sequenciais Quatro Etapas, em geral, são baseados nas pesquisas domiciliares, que compõem a Pesquisa O/D. Contudo, países em desenvolvimento, como o Brasil, não costumam ter tais pesquisas disponíveis devido principalmente ao alto custo. Consequentemente, a eficiência do planejamento de sistemas de transportes é prejudicada.

Além disso, as informações desagregadas, quando existentes, não são disponibilizadas para garantir a confidencialidade dos dados individuais. Por outro lado, existem dados alternativos que possuem maior disponibilidade e maior frequência de atualização. Dados censitários, por exemplo, estão disponíveis a cada 10 anos. Uma diferença entre estas informações censitárias e as pesquisas domiciliares é referente à agregação espacial. Dados domiciliares têm a localização associada a um ponto no espaço, enquanto dados censitários são relacionados a áreas administrativas.

Percebe-se que dados desagregados possuem um nível de detalhamento maior quando comparados aos dados agregados, e, por isso, são mais interessantes à políticas de planejamento urbano.

Contudo, ao considerar os métodos de estimativa espacial e de desagregação, a unidade espacial ideal das informações não necessariamente é a mesma dos métodos tradicionais de demanda por transportes. Esse tema, conhecido na literatura como mudança 
de escala (ou suporte) - que trata da mudança na unidade de área de estudo; é abordado nesta pesquisa através da análise de desempenho de diversas malhas, que, apesar de desagregadas, ainda representam áreas, ao invés de pontos.

Conforme descrito brevemente no início deste capítulo introdutório, justifica-se utilizar a Geoestatística para estudos de caso de Demanda por Transportes. Logo, o projeto de doutorado, aqui proposto, objetiva a transformação de dados agregados em dados convenientes para o planejamento de transportes através de técnicas geoestatísticas, levando em conta o potencial da aplicação da Geoestatística e a carência de dados desagregados em países em desenvolvimento.

São destacadas como principais contribuições deste trabalho a:

(1) Obtenção de dados mais desagregados a partir de áreas irregulares (Áreas de Ponderação e Zonas de Tráfego), de modo a suprir a ausência de dados domiciliares e/ou individuais;

(2) Proposta de procedimento alternativo para deconvolução de semivariogramas a partir de dados obtidos mais facilmente (por exemplo, microdados do censo demográfico);

(3) Obtenção de diversos cenários, com valores simulados da variável de interesse, estabelecendo-se assim a distribuição de diversos valores possíveis e um mapa de intervalo de confiança.

\subsection{ESTRUTURA DO TRABALHO}

A tese de doutorado, aqui apresentada, é formada por seis capítulos, incluindo esta introdução. O segundo e terceiro capítulos guiam o leitor para o pleno entendimento deste trabalho. O segundo capítulo identifica e detalha a revisão de literatura relacionada aos temas centrais desta tese: demanda por transportes e análise espacial. Neste capítulo são apresentadas, com maior aprofundamento, as aplicações encontradas de procedimentos geoestatísticos e de mudança de suporte. O terceiro capítulo elucida o embasamento teórico acerca de técnicas geoestatísticas, nas quais esta tese se sustenta. No quarto capítulo são explanados os materiais, software e os métodos utilizados para a desagregação e reprodução de cenários para a variável de estudo de demanda por transportes, através de simulação geoestatística. O quinto capítulo apresenta os resultados obtidos ao seguir as etapas dos métodos propostos, bem como as principais discussões. O sexto capítulo expõe as conclusões e recomendações. 


\section{Análise Espacial e Demanda por Transportes}

O Capítulo 2 tem por intuito situar o leitor acerca das abordagens tradicionais, bem como apresentar técnicas de análise espacial aplicadas à área de Demanda por Transporte. Este capítulo visa guiar o leitor no entendimento das vantagens dos métodos geoestatísticos em comparação aos métodos clássicos exploratórios e confirmatórios. Adicionalmente, são apresentados conceitos e uma breve revisão da literatura sobre suporte geográfico na Geoestatística.

\subsection{CONSIDERAÇÕES INICIAIS}

A modelagem de demanda por transportes geralmente considera fatores explicativos como características individuais, viagens, o meio e as instalações em que se inserem (ORTÚZAR e WILLUMSEN, 2011). Alguns dos modelos tradicionais para estimativa de demanda estão relacionados aos modelos sequenciais Quatro Etapas. Tais modelos compreendem as etapas de: a) Geração de viagens; b) Distribuição de viagens, c) Escolha modal e d) Alocação de tráfego.

A presente tese tem como foco a escolha modal, que é normalmente subdividida em modelos determinísticos e probabilísticos, baseados na Econometria. Os modelos probabilísticos logísticos (e suas variações) são os modelos mais utilizados para a escolha modal. Como variáveis de interesse para esta etapa, são estimadas as probabilidades ou as escolhas discretas, que foram primeiramente estudadas por Ben-Akiva (1973), McFadden (1974) e Domencich e McFadden (1975).

A aplicação convencional de modelos logísticos para escolha modal é obtida através de variáveis independentes associadas a atributos socioeconômicos, ao custo e ao nível de serviço do modo. Contudo, informações relacionadas à localização das variáveis não são levadas em consideração na modelagem tradicional de demanda por transportes.

Ao longo dos anos, muitos estudos vêm corroborando a afirmação de que o comportamento individual relativo a viagens, principalmente associado à escolha modal, está diretamente relacionado à distribuição espacial das atividades do contexto urbano (CERVERO e RADISCH, 1996; KITAMURA et al., 1997). Fischer (2006) menciona os seguintes métodos da análise espacial para o campo das Ciências Sociais: o Método de 
Parcelas (Quadrat Method), Estimativas pela Densidade Kernel, o Método do Vizinho mais Próximo, a Análise da Função K, e medidas globais e locais de associação espacial.

Apesar dessas técnicas, as questões de análise espacial não são comumente identificadas e utilizadas nos modelos tradicionais de demanda por transportes. Pode-se dizer que os modelos clássicos não consideram aspectos espaciais na análise de demanda por transportes. Todavia, considerando os avanços tecnológicos e a disponibilidade de informações georreferenciadas, a análise espacial de demanda por transportes é vista como uma linha de estudo com grande potencial, sobretudo ao incluir efeitos espaciais em modelos matemáticos (PÁEZ e SCOTT, 2005; PÁEZ, 2007; PÁEZ et al., 2013).

Através de diferentes abordagens, alguns autores têm obtido resultados promissores ao acrescentar fatores espaciais em estudos que envolvem o comportamento associado às viagens (YAMADA e THILL, 2004; DUGUNDJI e WALKER, 2005; LOPES, 2005; XIE e YAN, 2013; KAYGISIZ et al., 2015). No contexto da análise de demanda por transportes, BenAkiva et al. (2004) propuseram estimar a alocação espacial através da combinação de estimativas por Kernel e de um modelo logit, demonstrando resultados eficientes ao considerar aspectos espaciais em modelos de demanda por transportes. Bhat e Zhao (2002) propuseram um modelo logit hierárquico misto, baseado em atividades, para incorporar fatores espaciais. Miyamoto et al. (2004) mostraram a eficácia e vantagens de um modelo logit misto ao combinar conceitos para especificar componentes espacialmente autocorrelacionadas e erros. Os resultados apontaram para eficácia e vantagens do método proposto. Recentemente, Páez et al. (2013) incorporaram um indicador espacial em modelos de escolha discreta para a previsão de viagens.

Ao comparar todos os estudos mencionados, que abordam aspectos espaciais no campo de Engenharia de Transportes, com a técnica geoestatística de estatística espacial, esta se destaca. A Geoestatística possibilita análises exploratórias e confirmatórias através da previsão de valores de uma variável espacialmente correlacionada. Isso permite que sejam estimados valores de uma variável não amostrada. Além disso, a Geoestatística se diferencia das demais técnicas de estatística espacial, pois utiliza o semivariograma (ou covariograma) como dado de entrada no método. Dessa forma, a estimativa/simulação não é realizada por uma simples interpolação espacial, mas sim, por um processo de krigagem. Além disso, os métodos geoestatísticos apresentam vantagens, pois permitem considerar os aspectos de direção de maior continuidade espacial da variável em estudo, através de uma análise de anisotropia espacial (MATHERON, 1963). 
Até o momento, foram constatadas poucas aplicações de métodos geoestatísticos em dados de transportes. Observa-se que, a maior parte dos artigos científicos está relacionada a estudos de engenharia de tráfego (DU e AULTMAN-HALL, 2006; BRAXMEIER et al., 2009; CIUFFO et al., 2011; MAZZELLA et al., 2011; ZOU et al., 2012), emissão veicular de gases (KASSTEELE e VELDERS, 2006; KASSTEELE e STEIN, 2006; PEARCE et al., 2009) e acidentes (MANEPALLI e BHAM, 2011; GUNDOGDU, 2014; MOLLA et al., 2014).

\subsection{GEOESTATÍSTICA E DEMANDA POR TRANSPORTES}

A abordagem geoestatística, aplicada a estudos relativos à demanda por transportes, é ainda recente e não foi suficientemente explorada na linha de pesquisa de planejamento de transportes (YOON et al., 2014; CHEN et al., 2015). Contudo, alguns estudos recentes mostraram o potencial da técnica ao realizar estimativas espaciais de variáveis de demanda por transportes através krigagens Ordinária, Universal, Indicativa e com Deriva Externa para estimar viagens urbanas e escolha modal (MIURA, 2010; DA COSTA et al., 2013; ROCHA, 2014; LINDNER, 2015; PITOMBO et al., 2015a; PITOMBO et al., 2015b; LINDNER et al., 2016; ROCHA et al., 2017). A aplicação da Geoestatística no campo de modelagem de demanda por transportes ainda requer muitos conhecimentos básicos, principalmente acerca das variáveis, que encontram obstáculos por envolverem questões de comportamento humano. Alguns trabalhos provenientes do estudo da Geoestatística na área de demanda por transportes são mencionados a seguir.

Teixeira (2003) relacionou aspectos socioeconômicos à geração de viagens através de técnicas geoestatísticas. Neste trabalho, foi aplicada a Krigagem Ordinária para a apresentação de um método para definir o zoneamento por áreas homogêneas, relacionadas ao planejamento de transportes, por meio de aspectos econômicos e de viagens da população, através dos setores censitários.

Pitombo e Sousa (2009) aplicaram conceitos geoestatísticos para analisar geração de viagens urbanas por modo de transporte e motivo de viagem. No trabalho, em que foram utilizadas as técnicas de Krigagem Ordinária e um banco de dados agregado por Zona de Tráfego, foram estimados valores das variáveis para 40.000 pontos. Nos trabalhos de Pitombo et al. (2010) e Pitombo et al. (2014) também foram previstos dados de geração de viagens de dados agregados pela Geoestatística, contudo, foi utilizada, além da Krigagem Ordinária, a Krigagem com Deriva Externa. 
Miura (2010) descreveu, em seu estudo, uma abordagem para a estimativa de tempo de viagem, através de Krigagem Universal. Os resultados demonstraram que as propriedades geoestatísticas de dados de tempo de viagem são tão favoráveis quanto os dados de malha viária.

Da Costa et al. (2013) estimaram a probabilidade da escolha modal através da Geoestatística por meio de dados desagregados, utilizando técnicas de Árvore de Decisão e Krigagem Ordinária. O trabalho de Pitombo et al. (2015b) propôs uma abordagem sequencial para estimar probabilidades de escolha modal através de Árvore de Decisão e posterior previsão espacial utilizando Krigagem Ordinária.

Rocha (2014) analisou a geração de viagens urbanas por transporte coletivo através da Geoestatística, por meio de Krigagens Ordinária e com Deriva Externa em um banco de dados agregado referente à Região Metropolitana de Salvador. Lindner et al. (2016) estimaram a produção de viagens por transporte público através de Krigagem Fatorial com Deriva Externa em dados agregados da cidade de São Paulo.

Pitombo et al. (2015a) propuseram um método de duas etapas para a estimação da escolha modal, através de um banco de dados domiciliar na cidade de São Carlos. Foram selecionados os atributos que mais influenciam na escolha modal por meio de Árvore de Decisão e, após a comparação da eficácia da Árvore de Decisão com um Modelo Multinomial Logístico, realizou-se uma Krigagem Ordinária para prever a escolha modal, a partir da localização espacial. Lindner e Pitombo (2018) apresentaram um método logístico misto que usufrui das vantagens da Krigagem Ordinária para calcular a escolha modal em uma superfície de estimativa.

Rocha et al. (2014; 2017) propuseram uma tentativa inicial de deconvolução de semivariogramas para melhorar a modelagem, sabendo que a Geoestatística manipula melhor dados contínuos no espaço. Estes trabalhos trataram de desagregar uma amostra de viagens por transporte público relacionada a Macrozonas de Tráfego (MZT) em uma malha quadricular regular, a fim de aprimorar estimativas por krigagem na Região Metropolitana de Salvador. Apesar de a técnica ser incipiente e de que poderiam existir valores equivalentes (devido ao fato de muitas quadrículas estarem locadas na mesma MZT), os autores apresentaram uma proposta que impulsiona medidas que solucionem uma questão importante em Demanda por Transportes: a pouca disponibilidade de dados desagregados, como os que são obtidos em Pesquisas Origem/Destino (O/D).

Os métodos de krigagem foram, até o momento, aplicados: a) a dados desagregados por indivíduo (MIURA, 2010; DA COSTA et al., 2013; PITOMBO et al., 2015a; PITOMBO et 
al., 2015b) e por domicílio (LINDNER, 2015; LINDNER e PITOMBO, 2018); e b) a dados agregados por setores censitários (TEIXEIRA, 2003) e por Zonas de Tráfego (PITOMBO e SOUSA, 2009; PITOMBO et al., 2010; PITOMBO et al., 2014; ROCHA, 2014; LINDNER et al., 2016). Apesar de os dados terem sido estimados para diferentes variáveis e diferentes níveis de agregação em demanda por transportes, as seguintes questões ainda necessitam de maior aprofundamento:

a) Qual o melhor nível de desagregação (suporte) para modelos espaciais?

b) É possível calcular estimativas/simulações coerentes considerando que as observações estão relacionadas a unidades com áreas, formas e tamanhos distintos?

c) Sabendo da diversidade de tipos de uso de solo em uma determinada área de estudo, os agrupamentos de observações devem ser apontados como empecilhos nas estimativas espaciais?

d) Visto que as técnicas de krigagem necessitam de dados com continuidade espacial, como é possível adaptar os dados de demanda por transportes para que áreas não habitadas não sejam um problema nos modelos geoestatísticos?

e) Qual o efeito que existe ao associar o valor de uma área ao seu respectivo centroide?

A presente tese dá continuidade à proposta de desagregação de dados e deconvolução de semivariogramas de Rocha et al. (2014; 2017), mas agora levando em consideração os entraves da aplicação da Geoestatística na área de Demanda por Transportes aqui mencionados. A Geoestatística é, aqui, abordada através da Simulação Sequencial Gaussiana, que permite gerar um conjunto de resultados alternativos equiprováveis que reproduzam os padrões espaciais, não apenas por uma única estimativa, como é feito pela krigagem.

\subsection{SUPORTE GEOGRÁFICO, MUDANÇA DE ESCALA E A GEOESTATÍSTICA}

Em uma grande proporção das análises de dados espaciais, os dados são espacialmente agregados. Alguns exemplos, mais práticos, incluem imagens de sensoriamento remoto - em que os pixels abrangem uma área (ao invés de um ponto); e os setores censitários - em que a contagem populacional é dada por unidades de área. No primeiro caso, a resolução da imagem é necessariamente finita. No segundo caso, considerando que existe a necessidade de manter o anonimato dos dados, as informações utilizadas são normalmente associadas a áreas, ao invés de indivíduos. Em qualquer 
circunstância em que os dados espaciais estão associados a uma área (agregados espacialmente), os resultados de uma análise são, em parte, uma função do tamanho e da forma das unidades de área. A forma das unidades de área é usualmente aleatória, podendo ser denominada pelo termo "modificável" (modifiable). O MAUP, definido por Openshaw (1984) como Modifiable Areal Unit Problem (Problema das Unidades de Áreas Modificáveis), compreende duas partes: um problema de escala - relacionado ao tamanho das unidades de área; e um problema de zoneamento - relacionado à forma das unidades de área (FOTHERINGHAM e WONG, 1991).

Pode-se dizer que a problemática de desagregação, vista em casos de Engenharia de Transportes, possui uma vertente que diverge quando comparada aos casos de Sensoriamento Remoto. Isso se deve ao fato de que, em Transportes, os dados agregados são referentes a Zonas de Tráfego (ZTs), Bairros, Cidades, e.g., ou seja, áreas irregulares e de tamanhos distintos, enquanto no caso de sensoriamento remoto, têm-se áreas regulares definidas por pixels, com mesmo tamanho e forma (ATKINSON, 2013).

Os modelos utilizados para as políticas de planejamento de transportes visam replicar o comportamento relativo a viagens, baseando-se em atributos socioeconômicos, por exemplo. Sabe-se que, quanto menor o nível de agregação, maior o detalhamento das informações. Por isso, informações relativas ao indivíduo são convenientes para os métodos tradicionais de planejamento urbano. No entanto, devido às questões de confidencialidade das informações individuais e ao alto investimento associado para a aquisição de tais dados, estas informações não estão facilmente disponíveis. A obtenção de dados desagregados de demanda por transportes é popularizada, na área do conhecimento, por técnicas de microssimulação. Guo e Bhat (2008) descrevem a microssimulação por meio de duas etapas. A primeira trata da criação de microdados associados aos agentes de interesse; enquanto a segunda visa simular e atualizar o comportamento e características destes agentes, a partir de modelos matemáticos e/ou modelos baseados em regras. A geração de microdados, i.e. dados sintéticos, é, comumente, sucedida por métodos de ajuste proporcional iterativo (IPF - Iterative Proportional Fitting), primeiramente explorados por Deming e Stephan (1940). Outras abordagens foram desenvolvidas para a geração de dados sintéticos e podem ser verificadas, com maior abrangência, no estudo do estado da arte publicado por Müller e Axhausen (2010). Nota-se que, apesar de o tema de microssimulação de dados ser bem consolidado na área de Demanda por Transportes, não foram constatados estudos que incluíssem a associação espacial das variáveis como elemento primordial de entrada aos métodos de microssimulação e obtenção de dados sintéticos. 
Além disso, ao analisar os métodos de desagregação espacial, observa-se que a unidade ideal das informações não necessariamente é a mesma dos modelos de demanda por transportes. Isso se deve ao fato de que cada unidade espacial deve ser representada por apenas um valor. E, contraditoriamente, as pesquisas tradicionais de transportes podem associar um ou mais valores a uma determinada localização espacial. Além disso, sabe-se que áreas próximas podem ter comportamento similar, fazendo com que as informações de determinadas regiões possam ser agregadas. E, apesar de o agrupamento de dados espaciais poder, inevitavelmente, causar alguma perda de informação ou enviesamento dos dados, pode-se ter benefícios na facilidade de entendimento de fenômenos espaciais ou até fornecer análises adicionais, que sejam mais importantes que o efeito negativo. Esse tema é conhecido na literatura como mudança de escala (suporte).

O suporte geográfico é definido como o tamanho, a geometria e a orientação do espaço em que uma observação é definida. O conceito de mudança de suporte de uma variável, por sua vez, envolve a criação de uma nova variável, relacionada à original, mas que tenha propriedades estatísticas e espaciais distintas (GOTWAY e YOUNG, 2002). Os métodos de mudança de suporte agregado para desagregado são bem reconhecidos na área de sensoriamento remoto como: super-resolution, sub-pixel mapping e downscaling. Nesta área de estudo, tem-se como objetivo obter uma imagem mais detalhada a partir de uma imagem com menor resolução.

Estudos relacionados a Sistemas de Informações Geográficas para Ciências Sociais, em geral, tratam da desagregação de dados demográficos por meio de diferentes interpolações espaciais (FLOWERDEW e GREEN, 1993; GOODCHILD et al., 1993). Normalmente, o problema verificado a tais estudos está associado à necessidade de compatibilização de informações associadas a diferentes níveis de agregação (FLOWERDEW e GREEN, 1993).

Um dos métodos mais simples para interpolação espacial, na Geografia, é o método de ponderação zonal, que mantém o volume total de dados e assume que a população é uniformemente distribuída nas zonas (GOODCHILD e LAM, 1980). Outras abordagens, como a interpolação picnofilática (TOBLER, 1979); métodos de interpolação de áreas baseada em pontos (Point-based areal interpolation) (LAM, 1983); interpolações determinísticas locais (CAMARGO et al., 2004); e krigagem (KRIGE, 1951); encontram obstáculos associados aos métodos. São assumidas densidades uniformes no espaço, que não consideram descontinuidades espaciais ocorridas pela existência de áreas não habitadas ou a população é associada a centroides de zonas (JEGA, 2015). Para tratar do problema de descontinuidade espacial, Mennis (2003) propôs utilizar dados de 
sensoriamento remoto como informação auxiliar para a desagregação através de mapas dasimétricos. Yamaguchi et al. (2018), ao compararem os métodos de interpolação: determinística local (interpoladores bilinear e vizinho mais próximo), por krigagem, por ponderação zonal, picnofilático e dasimétrico; notaram que, em geral, o método dasimétrico obteve maior desempenho de correlação com os dados de referência. Contudo, salienta-se que a aquisição de dados auxiliares é morosa e requer maiores investimentos financeiros.

O método de krigagem compreende parte da Geoestatística. Este método, por si, não considera a estrutura espacial do suporte mais desagregado, "alvo" da desagregação; mas sim, o suporte original das variáveis. Portanto, mesmo que seja considerado como método de desagregação, em consequência do procedimento de interpolação espacial, a krigagem deve estar associada a um semivariograma desagregado para que exista a compatibilidade dos suportes. Levando esta questão em consideração, o uso da Geoestatística para procedimentos de desagregação foi, efetivamente e inicialmente, aplicado a partir de Co-Krigagem Indicativa no estudo de Boucher e Kyriakidis (2006) e Atkinson et al. (2008) para mapeamento de imagens. Boucher e Kyriakidis (2006) utilizaram modelos de semivariograma desagregados, obtidos através de Simulação Sequencial Indicadora para os suportes "alvos", e dados reais para descrever a estrutura espacial em escalas desagregadas. Atkinson et al. (2008), por outro lado, aplicaram o método iterativo proposto por Journel e Huijbregts (1978) para deconvolução de semivariogramas e posterior uso em Co-Krigagem.

Geralmente, a Geoestatística é aplicada a casos cuja continuidade espacial é aparente, tais como temperatura, precipitação ou composição e propriedade dos solos, por exemplo. Apesar deste aspecto, observa-se, ao longo dos anos, a aplicação de modelos geoestatísticos a dados espacialmente discretos (CRONER e DE COLA, 2001; BOULOS, 2004; GOOVAERTS e JACQUEZ, 2004; GOOVAERTS, 2006; GOOVAERTS, 2008; GOOVAERTS, 2009). Áreas de contaminação, áreas de risco de mortalidade, e outras variáveis relacionadas à Saúde, que, antes eram detectadas por mapas temáticos ou mapas de Kernel, atualmente são modeladas e têm suas respectivas variâncias geradas através de técnicas de krigagem.

Os métodos geoestatísticos de mudança de suporte têm sido utilizados para criar mapas que auxiliam ao reduzir discrepâncias que podem surgir ao mapear os dados com suportes irregulares. Em 2008, Goovaerts propôs uma abordagem aplicável aos casos de demanda por transportes, ao utilizar a deconvolução (também denominada desregularização) de semivariogramas para obter maiores informações de estrutura espacial de dados de mortalidade por câncer, a partir de dados agregados contínuos associados a 
áreas irregulares. Através desta técnica, são solucionadas as questões relacionadas ao MAUP. A literatura atual mostra que os métodos de krigagem com mudança de suporte têm possibilidade de serem aplicados para diversas áreas do conhecimento, contudo, não existem muitos estudos que envolvam essas abordagens. A Krigagem Área-para-Ponto (também chamada de downscaling), popularizada por Kyriakidis (2004), a partir da teoria da Krigagem Área-para-Área, é aplicada a casos em que o suporte utilizado para o método é agregado, contudo, o suporte estimado é pontual. É importante salientar que os métodos de krigagem com mudança de suporte necessitam do cálculo de semivariogramas regularizados; o que faz com que sejam necessárias informações desagregadas como dados de entrada ao procedimento.

Outra abordagem geoestatística que deve ser considerada é a Simulação Sequencial Gaussiana (SSG). A SSG é uma técnica de simulação estocástica que visa gerar um conjunto de resultados alternativos que reproduzam os padrões espaciais, não apenas por uma única desagregação, como ocorre pela krigagem. Em outras palavras, nota-se que o principal objetivo da simulação estocástica é o de gerar diversas simulações que possam ser usadas para calcular a incerteza associada ao método de simulação espacial ou à deconvolução (GOOVAERTS, 1997; REMY et al., 2009). Além disso, a SSG permite que sejam feitas mudanças de suporte (GOOVAERTS, 2001) e que sejam evitados os efeitos de suavização, que ocorrem nas técnicas de krigagem (DEUTSCH e JOURNEL, 1998).

Recentemente, algoritmos de simulação estocástica gaussiana têm sido usados nos campos da hidrogeologia (PACHEPSKY e ACOCK, 1998; GOOVAERTS, 1999; VAN MEIRVENNE e GOOVAERTS, 2001; LEE et al., 2007; PARDO-IGÚZQUIZA e CHICAOLMO, 2008; YAO et al., 2013; BOLUWADE e MADRAMOOTOO, 2015; OMRAN, 2016; ZHANG et al., 2017), agricultura (GRIFO e DA SILVA, 2016) e petróleo (TAMAYO-MAS et al., 2016). Apesar de a técnica de SSG ser bem consolidada nas Ciências do Ambiente, as aplicações nas Ciências Sociais ainda são bem escassas. Trabalhos de Goovaerts (2008; 2009) mostraram que a técnica tem potencial na área da medicina geográfica - ao ser aplicada para dados de mortalidade por câncer - e pode ser promissora na área de Demanda por Transportes, visto que ambos os dados lidam com o MAUP.

Pode-se dizer que, até o momento, não foi constatado o desenvolvimento do tema de mudança de escala e da simulação geoestatística no campo de Demanda por Transportes, em especial, para escolha modal; uma vez que, não foram encontradas pesquisas que abrangessem os assuntos. Portanto, é pertinente destacar os aspectos inovadores da presente tese, visto que apresenta uma proposta que adota técnicas geoestatísticas, com potenciais vantagens ao serem aplicadas no campo de estudos de Transportes. 


\section{Geoestatística}

O Capítulo 3 versa sobre o referencial teórico acerca da Geoestatística. O capítulo descreve e conceitualiza processos de modelagem geoestatística e mudança de escala através de: (1) análise variográfica, (2) krigagem, (3) Simulação Sequencial Gaussiana, e (4) deconvolução de semivariogramas.

A Geoestatística foi desenvolvida por Matheron $(1963 ; 1965 ; 1971)$ como um método alternativo para explorar eventos em que os valores de uma determinada variável estão associados à sua respectiva localização espacial. Essa abordagem utiliza conceitos da estatística espacial e gera uma superfície contínua de valores de variáveis através de um banco de dados que pode ser espacialmente distribuído de forma regular ou não.

A abordagem geoestatística é interessante, pois permite caracterizar a dispersão espacial de um evento, analisando parâmetros de incerteza, determinando a variabilidade espacial e obtendo uma superfície contínua de estimação ou de simulações.

Matheron (1971) define a Geoestatística como a aplicação da teoria das variáveis regionalizadas, i.e., de variáveis que são espacialmente distribuídas, que apresentam estrutura espacial e que podem ser vistas como resultado de um processo estocástico. $O$ estudo de uma variável regionalizada geralmente envolve, pelo menos, dois aspectos geométricos: o campo geométrico (domínio) em que a variável é definida e o suporte geométrico em que cada observação da amostra da variável é definida (CHILĖS e DELFINER, 1999). O campo geométrico é onde a variação de uma variável regionalizada é considerada importante. Este espaço é delimitado pela metade do comprimento da linha na direção considerada (JOURNEL e HUIJBREGTS, 1978). O suporte geométrico, por sua vez, é descrito, por Matheron (1965) como o tamanho, a geometria e a orientação do espaço em que um valor de variável é coletado.

A Geoestatística diferencia-se das demais técnicas de estatística espacial, pois utiliza o semivariograma (ou covariograma) como dado de entrada no método. Dessa forma, a estimativa/simulação não é realizada por uma simples interpolação espacial, mas sim, por um processo de krigagem. Além disso, os métodos geoestatísticos apresentam vantagens, pois permitem considerar os aspectos de direção de maior continuidade espacial da variável em estudo, através de uma análise de anisotropia espacial (MATHERON, 1963). 
O presente trabalho introduz, nas seguintes seções, o desenvolvimento teórico dos conceitos geoestatísticos aqui utilizados: análise variográfica, krigagem, Simulação Sequencial Gaussiana (SSG) e deconvolução.

\subsection{ANÁLISE VARIOGRÁFICA}

A análise e modelagem da estrutura espacial de uma variável regionalizada tem como ferramenta primária o variograma experimental (GONÇALVES et al., 2001; SOUZA et al., 2004). O variograma condensa as informações obtidas pelas variáveis regionalizadas por meio de uma representação gráfica em que a ordenada é a esperança da variância entre pares de observações $(\gamma)$ e a abscissa é a distância entre estes pares $(h)$, também denominada lag.

A função do semivariograma foi originalmente desenvolvida por Matheron (1963) e é dada pela Equação 3.1, onde $N(h)$ é o conjunto de pares de valores $z(x)$ e $z(x+h)$ em posições $i$ e $i+h$, respectivamente.

$$
\gamma(h)=\frac{1}{2 N(h)} \sum_{i=1}^{n(h)}\left[z\left(x_{i}\right)-z\left(x_{i+h}\right)\right]^{2}
$$

Outra etapa da análise variográfica é a definição de um modelo teórico que se ajuste ao semivariograma experimental. A Figura 3.1 apresenta os parâmetros gráficos obtidos a partir de um modelo teórico experimental.

Figura 3.1 - Parâmetros gráficos de um modelo teórico de semivariograma

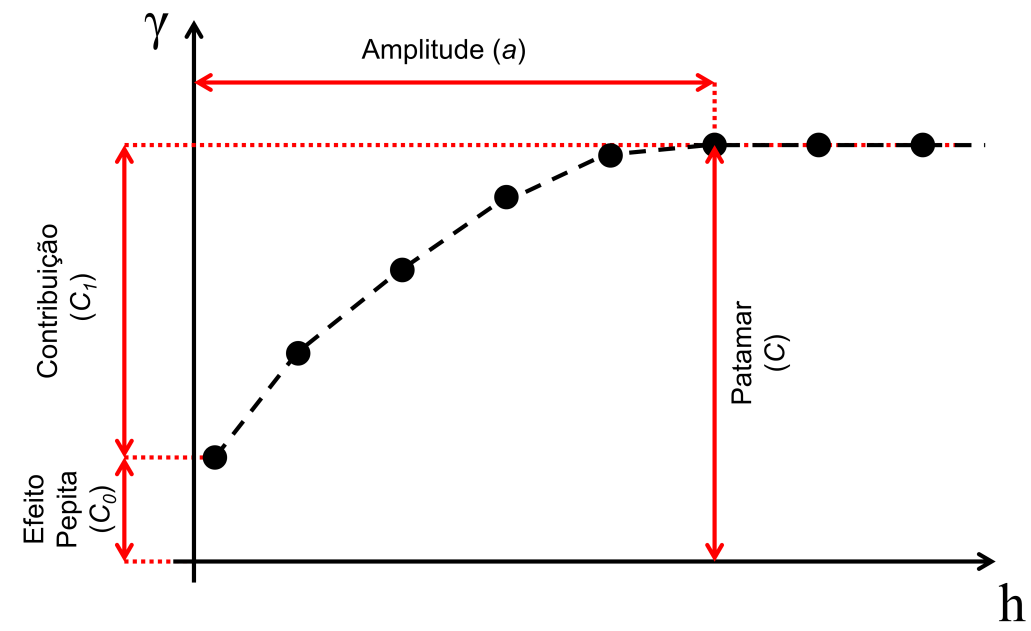

Adaptado de Wackernagel (2003) 
A determinação das direções principais é dada pela análise do comportamento espacial da variável considerando diversas direções. Dessa forma, aquelas direções, cujos semivariogramas apresentarem maiores diferenças e melhor estrutura, são definidas como a direção principal e a respectiva ortogonal.

Quando a estrutura espacial apresenta continuidade uniforme e independe da direção avaliada, o fenômeno é dito como isotrópico. Consequentemente, os semivariogramas, para todas as direções, são equivalentes. Caso contrário, o fenômeno é anisotrópico e entende-se que o comportamento estrutural varia. Para este caso, os semivariogramas devem ser avaliados para cada direção de maior e de menor continuidade.

Os modelos teóricos de um semivariograma podem ser de natureza: cúbica, esférica, exponencial, gaussiana, pentaesférica, lei de potência e efeito senoidal. Embora as sete curvas sejam convenientes a modelos de ajuste, as três curvas mais utilizadas na literatura são: exponencial, esférica e gaussiana, cujas expressões estão representadas nas Equações 3.2, 3.3 e 3.4, respectivamente (OLEA, 2006).

$$
\begin{gathered}
E x(h)=C\left(1-e^{-3 h / a}\right) \\
E s(h)=\left\{\begin{array}{lr}
C\left(\frac{3 h}{2 a}-\frac{1}{2}\left(\frac{h}{a}\right)^{3}\right), & 0 \leq|h|<|a| \\
C, & |a| \leq|h|
\end{array}\right. \\
G(h)=C\left(1-e^{-3(h / a)^{2}}\right)
\end{gathered}
$$

Onde, $C$ é o patamar do semivariograma, a é a amplitude e $h$ é o lag.

Uma vez definida a estrutura espacial, torna-se necessário verificar a hipótese intrínseca de estacionariedade de segunda ordem do semivariograma teórico. Dessa forma, a média dos valores do espaço geométrico deve permanecer constante, a covariância deve depender apenas da distância entre pares de observações e a variância deve ser finita (WACKERNAGEL, 2003).

\subsection{KRIGAGEM}

A krigagem é um método de estimativa utilizado na Geoestatística. A teoria foi desenvolvida por Georges Matheron na década de 1960, a partir do trabalho de Daniel G. Krige, da década de 1950. A técnica se trata de um processo de predição linear, pois suas 
estimativas são combinações lineares ponderadas por dados existentes (amostrados). A krigagem fornece, em geral, estimativas não tendenciosas e com variância mínima (LANDIM, 2003).

Os métodos de krigagem partem do pressuposto que pontos próximos no espaço tendem a ter valores mais parecidos do que pontos afastados e diferem-se dos demais interpoladores, pois são as únicas técnicas que reconhecem a anisotropia espacial. Esse pressuposto é garantido por uma ponderação intrínseca à abordagem. Além disso, essas técnicas assumem que os dados são estacionários de segunda ordem, ou seja, a variância é constante à translação (WACKERNAGEL, 2003).

A partir dos parâmetros gráficos do semivariograma (efeito pepita $\left(C_{o}\right)$, contribuição $\left(C_{1}\right)$ e amplitude $(a)$ ), é definido um modelo teórico que é, em conjunto com os dados, utilizado para a definição de pesos $\lambda_{i}$ (ponderadores) do sistema de krigagem. A função dos ponderadores é a de ditar a influência dos dados amostrais na estimação de novos valores. O estimador de krigagem é dado pela Equação 3.5.

$$
z^{*}\left(x_{0}\right)-m\left(x_{0}\right)=\sum_{j=1}^{n} \lambda_{j}\left[z\left(x_{j}\right)-m\left(x_{j}\right)\right]
$$

Onde $z^{*}\left(x_{0}\right)$ é o valor estimado em um local não amostrado $x_{0} ; m\left(x_{0}\right)$ é um valor inicial de média populacional em $x_{0} ; \lambda_{j}, j=1, \ldots, n$ são as ponderações aplicadas às $n$ observações (pontos amostrais); $z\left(x_{j}\right)$ são os valores de $n$ observações; $m\left(x_{j}\right), j=1, \ldots, n$ são os valores iniciais de média amostral nos locais com dados (CHILĖS e DELFINER, 1999).

As formas mais usuais de krigagem são a Krigagem Simples (KS) e a Ordinária (KO). A KS é utilizada quando se tem conhecimento prévio da média populacional. Essa média é assumida como estatisticamente constante para toda área de abrangência das amostras. A $\mathrm{KO}$, por sua vez, considera a média flutuante ou móvel por toda área. Dessa forma, para a $\mathrm{KO}$, a formulação pode ser simplificada, conforme a Equação 3.6.

$$
z^{*}\left(x_{0}\right)=\sum_{j=1}^{n} \lambda_{j} z\left(x_{j}\right)
$$

O sistema de krigagem é constituído por ponderadores com o objetivo de conduzir estimativas a erros nulos (não enviesamento universal) e à minimização da variância (otimização), conforme as restrições apresentadas na Equação 3.7. 


$$
\left\{\begin{array}{l}
\sum_{j=1}^{n} \lambda_{j} \gamma\left(x_{i}-x_{j}\right)+\mu=\gamma\left(x_{0}-x_{i}\right) \\
\sum_{j=1}^{n} \lambda_{j}=1
\end{array}\right.
$$

Sendo $\mu$ um multiplicador de Lagrange e para $i=1, n$. A solução para os ponderadores da KO pode ser dada pelo sistema matricial representado na Equação 3.8.

$$
\lambda_{j}=(G)^{-1} M
$$

Sendo $\lambda, G$ e $M$ as seguintes matrizes:

$$
\lambda=\left[\begin{array}{c}
\lambda_{1} \\
\lambda_{2} \\
\lambda_{3} \\
\ldots \\
\lambda_{n} \\
\mu
\end{array}\right], \quad G=\left[\begin{array}{ccccc}
\gamma\left(x_{1}, x_{1}\right) & \gamma\left(x_{1}, x_{2}\right) & \ldots & \gamma\left(x_{1}, x_{n}\right) & 1 \\
\gamma\left(x_{2}, x_{1}\right) & \gamma\left(x_{2}, x_{2}\right) & \ldots & \gamma\left(x_{2}, x_{n}\right) & 1 \\
\ldots & \ldots & \ldots & \ldots & 1 \\
\ldots & \ldots & \ldots & \ldots & 1 \\
\gamma\left(x_{n}, x_{1}\right) & \gamma\left(x_{n}, x_{2}\right) & \ldots & \gamma\left(x_{n}, x_{n}\right) & 1 \\
1 & 1 & 1 & 1 & 0
\end{array}\right], \quad M=\left[\begin{array}{c}
\gamma\left(x_{1}, x_{0}\right) \\
\gamma\left(x_{2}, x_{0}\right) \\
\ldots \\
\ldots \\
\gamma\left(x_{n}, x_{0}\right) \\
1
\end{array}\right] .
$$

Os ponderadores do estimador de krigagem resumem dois fatores: 1) o fator de distância estrutural entre amostras e o ponto a estimar; 2) o fator desagregação originado pela matriz de covariâncias entre as amostras, ou seja, quanto mais correlacionadas estiverem, maior a redundância e menor será o peso individual na construção do estimador (SOARES, 2006).

Os pesos são considerados dentro de uma área de atuação estabelecida por um elipsoide de raios determinados pelas amplitudes da direção principal e ortogonal.

\subsection{SIMULAÇÃO SEQUENCIAL GAUSSIANA}

A Simulação Sequencial Gaussiana (SSG) é um método de simulação estocástica, que corrige efeitos de suavização e permite explorar um campo de possibilidades de um fenômeno. Dessa forma, a simulação visa gerar um conjunto de resultados alternativos equiprováveis que reproduzam os padrões espaciais, não apenas por uma única estimativa, como é feito pela krigagem (VERLY, 1993; DEUTSCH e JOURNEL, 1998). 
Outra diferença entre a krigagem e a SSG trata da precisão de estimação. A krigagem utiliza a precisão local, ou seja, reproduz as médias locais, enquanto a SSG reproduz a precisão global, histogramas e variogramas (DEUTSCH e JOURNEL, 1998).

A SSG é um método sequencial. As simulações são realizadas através de um caminhamento aleatório de pontos, em que cada valor previamente simulado é utilizado como informação para simular novos pontos. Além de ter característica sequencial, a SSG pode ser condicional ou não. Uma simulação condicional constitui um método em que, ao final, manterá os valores amostrados nos resultados. Esses diferentes cenários gerados pela simulação são denominados realizações. Em resumo, o princípio da SSG propõe que sejam considerados: a) todos os dados disponíveis em uma determinada vizinhança, b) os dados originais e c) todos os valores simulados (ISAAKS, 1990).

Algumas condições são impostas à natureza da variável ao utilizar a SSG. A distribuição deve ser normal, com média igual a zero e variância igual a um. A segunda condição é a de que os dados transformados devem respeitar o formalismo multigaussiano. Como a multigaussianidade - que dita que qualquer combinação linear de uma variável deve possuir distribuição normal; é uma propriedade complexa de ser demonstrada, assume-se o teste de bigaussianidade (JEANNÉE et al. 2005). A subseção 3.3.1 detalha o procedimento de transformação gaussiana.

As realizações pela SSG são dadas em função das estimativas por krigagem simples somadas a um ruído, conforme Equação 3.9 (CHILÉS e DELFINER, 1999).

$$
z^{(l)}\left(x_{0}\right)=z^{*}\left(x_{0}\right)+\sigma \varepsilon
$$

Sendo $\varepsilon$ um termo aleatório entre 0 e 1 . Diante dos diversos tipos de krigagem, devese dar preferência ao algoritmo de Krigagem Simples (DEUTSCH e JOURNEL, 1998), pois este garante a reprodução do semivariograma.

O resultado da média de diversas realizações por SSG (conhecida pelo termo e-type) se aproxima do valor estimado pela krigagem e o resultado da variância das realizações tende à variância de krigagem (CHILÉS e DELFINER, 1999).

Em geral, as simulações têm como objetivo principal, além da geração de diversas realizações, o cálculo da incerteza associada. Este parâmetro é normalmente mensurado através da variância condicional entre as realizações. Para este trabalho, foi acrescentado o intervalo de confiança como medida estatística a ser gerada pelo método de simulação, uma vez que é relevante ao planejamento urbano ter posse de informações de áreas críticas. 
O método de SSG envolve duas vertentes estocásticas: 1) a simulação do termo aleatório da Equação 3.9, e 2) o método de simulação para definir o caminho aleatório que visite cada ponto da malha apenas uma vez. Estas questões são solucionadas pelo método de Monte Carlo.

Isaaks (1990) define o método de Monte Carlo como qualquer método que utiliza números aleatórios para fornecer uma solução a um problema. Esta abordagem pode ser aplicada a problemas determinísticos ou probabilísticos. Contudo, é apenas através de modelos probabilísticos que a Geoestatística é capaz de fornecer soluções consistentes para a escolha de números aleatórios que simulem os processos físicos estocásticos do problema original.

Neste trabalho, a SSG é precedida de procedimentos de mudança de escala, de modo que, ao final, sejam geradas diversas realizações para informações desagregadas.

\subsubsection{Transformação Gaussiana}

Visto que, na prática, as variáveis de transportes não costumam possuir distribuições normais, com média zero e desvio padrão igual a um, os dados devem ser submetidos a uma transformada gaussiana para que sejam utilizados na SSG.

O processo de transformar a distribuição de uma variável em uma distribuição gaussiana segue o primeiro passo de ordenar valores crescentes para categorizar a primeira classe como $k_{1}=1$ e a n-ésima classe como $k_{n}=n$. A etapa seguinte se trata do cálculo da proporção das classes pela divisão de cada uma pelo número total $(n)$ - ou por $n+1$ (JOURNEL e HUIJBREGTS, 1978). Os quartis da variável de estudo são calculados usando esta divisão e os escores da distribuição normal padrão de acordo com a Equação 3.10.

$$
y\left(k_{i}\right)=G^{-1}\left(\frac{k_{i}}{n+1}\right)
$$

Em que $y\left(k_{i}\right)$ é o escore, $G^{-1}$ é a função gaussiana inversa e $k_{i} / n+1$ é o quartil para $k_{i}=1, n$ (DEUTSCH e JOURNEL, 1998).

Vale ressaltar que, ao final do processo de simulação, é necessário realizar a transformação para a variável de origem (backtransforming). 


\subsection{DECONVOLUÇÃO DE SEMIVARIOGRAMAS}

No campo das Ciências Sociais, técnicas como a deconvolução são, muitas vezes, necessárias na aplicação da Geoestatística, pois as informações disponíveis podem estar associadas a áreas (ou volumes). Além disso, comumente, as unidades geográficas têm formas e tamanhos muito diferentes (MAUP - Problema de Unidade de Área Modificável). Desta maneira, é importante salientar o obstáculo do cálculo e da aplicação direta de tais informações a semivariogramas e a processos de krigagem, uma vez que estes processos não permitem assumir que os centroides dos polígonos representem uma variável corretamente (GOOVAERTS, 2008).

Outro problema comum é a combinação de amostras obtidas por diferentes suportes espaciais. Por isso, devido às características dos dados das Ciências Sociais, a mudança de suporte tem como objetivo tornar possível a estimação de valores de uma variável em pontos ou blocos (células de uma malha) diferentes daqueles que foram observados (GOOVAERTS, 2011; GELFAND et al., 2001).

Além disso, ao tratar da mudança de escala, em especial da desagregação, na Geoestatística, deve-se levar em conta que métodos de krigagem não consideram a estrutura espacial do suporte mais desagregado, "alvo" da desagregação; mas sim, do suporte original das variáveis. Portanto, técnicas de deconvolução se tornam fundamentais para manter a compatibilidade das informações.

A deconvolução de semivariogramas, definida por Journel e Huijbregts (1978), visa calcular um semivariograma pontual (ou associado a áreas menores) a partir de um semivariograma experimental agregado.

A deconvolução de um semivariograma encontra, de forma iterativa, um modelo de semivariograma com suporte pontual ideal que minimize a diferença entre o semivariograma regularizado e o modelo de semivariograma com suporte agregado. Mais especificamente, depois de definir um semivariograma pontual inicial, o modelo teoricamente regularizado é computado e comparado com o semivariograma agregado. A partir da comparação dos dois modelos, os parâmetros do semivariograma pontual são ajustados para minimizar a diferença estatística. Esse procedimento é repetido até que o critério de parada seja satisfeito (GOOVAERTS, 2008).

Os dados com suporte pontual $z(x)$ não estão sempre disponíveis e, na maioria das vezes, os dados disponíveis $z_{v}(x)$ estão definidos apenas em um suporte $v(x)$ com centroide $x$, sendo $v$ o suporte - definido como ponto, volume ou área de uma amostra, como no caso 
deste estudo. Conforme Journel e Huijbregts (1978), a grade $z_{v}(x)$ dessa amostra é o valor médio da grade pontual $z(u)$ no suporte $v(x)$, de acordo com a Equação 3.11.

$$
z_{v}(x)=\frac{1}{v} \int_{v(x)} z(u) d u
$$

Dessa forma, o valor médio $z_{v}(x)$ é dito como a regularização da variável de suporte pontual $z(u)$ no suporte $v(x)$.

Sendo a variável de suporte pontual $z(u)$ um valor observado de uma função aleatória estacionária de segunda $\operatorname{ordem}^{1} Z(u)$, com esperança $m$ e variograma $2 \gamma(h)$; a regularização do ponto de uma função aleatória $Z(u)$ em um suporte $v(x)$ é, também, uma função aleatória denotada por $Z_{v}(x)$ e escrita conforme a Equação 3.12.

$$
Z_{v}(x)=\frac{1}{v} \int_{v(x)} Z(u) d u
$$

Assim, a função aleatória regularizada $Z_{v}(x)$ de uma função aleatória estacionária de segunda ordem com suporte pontual possui:

(i) esperança igual à esperança do suporte pontual $m$,

(ii) semivariograma $\gamma_{v}(h)$ definido conforme a Equação 3.13.

$$
\gamma_{v}(h)=\frac{1}{2} \mathrm{E}\left\{\left[Z_{v}(x+h)-Z_{v}(x)\right]^{2}\right\}
$$

O problema é, então, derivar esse semivariograma regularizado $\gamma_{v}(h)$ a partir do $\gamma(h)$. Para isso, uma maneira fácil é considerar a Equação 3.13 do semivariograma regularizado como a variância da estimativa da grade média $Z_{v}(x)$ através da grade média $Z_{v}(x+h)$ separada pelo vetor $h$. Essa estimativa de variância é dada pela fórmula geral de semivariograma (Equação 3.14).

$$
\gamma_{v}(h)=\bar{\gamma}(v(x), v(x+h))-\frac{1}{2} \bar{\gamma}(v(x), v(x))-\frac{1}{2} \bar{\gamma}(v(x+h), v(x+h))
$$

\footnotetext{
1 Uma variável é estacionária de segunda ordem caso a média seja constante e o segundo momento exista, ou seja, a covariância entre dois pares quaisquer $Z(x)$ e $Z(x+h)$, separados por $h$, exista e dependa somente de $h$.
} 
Sabendo que o semivariograma $\gamma(h)$ é estacionário, os últimos dois termos da Equação 3.14 são iguais e, então, obtém-se a Equação 3.15 (JOURNEL e HUIJBREGTS, 1978).

$$
\gamma_{v}(h)=\bar{\gamma}\left(v, v_{h}\right)-\bar{\gamma}(v, v)
$$

Sendo $v_{h}$ o suporte $v$ transladado do $v$ para o vetor $h ; \bar{\gamma}\left(v, v_{h}\right)$ o valor médio do modelo de semivariograma pontual $\gamma(u)$ quando uma das extremidades do vetor $u$ descreve o suporte $v$ e a outra extremidade descreve independentemente o suporte transladado $v_{h}$. Dessa forma, pode-se dizer que $\bar{\gamma}\left(v, v_{h}\right)$ representa a variância espacial entre blocos e $\bar{\gamma}(v, v)$ representa a variância intra-blocos. O semivariograma modelado pode ser estimado para qualquer suporte regular $v$, inclusive o pontual, através da Equação 3.15. Dessa forma, diz-se que o método proposto por Journel e Huijbregts (1978) envolve a regularização do modelo, e não dos dados (ATKINSON e TATE, 2000).

Até este ponto, assume-se que os suportes sejam os mesmos. Contudo, em muitos casos, inclusive para o presente estudo, em que são utilizadas diversas Zonas de Tráfego, têm-se suportes com diferentes tamanhos e formas. Para solucionar esse entrave do método proposto por Journel e Huijbregts (1978), Goovaerts (2008) sugeriu uma expressão geral (Equação 3.16).

$$
\gamma_{v}(h)=\bar{\gamma}\left(v, v_{h}\right)-\bar{\gamma}_{h}(v, v)
$$

Em que o valor do semivariograma intra-bloco $\bar{\gamma}_{h}(v, v)$ varia como uma função do vetor $h$ de separação, dado que o tamanho dos blocos (células) varia em função da distância entre eles. Goovaerts (2008) demonstrou, através de semivariogramas teóricos de suporte agregado, desagregado e regularizado, que suportes menores tendem a produzir valores de variância maiores quando comparados aos valores de semivariograma agregados, da mesma forma que para o semivariograma regularizado. Para isso, o método de deconvolução é interessante, pois aproxima, de forma sistemática, os semivariogramas de diferentes suportes. Todavia, ressalta-se que a deconvolução tradicional necessita de informações desagregadas que, neste presente trabalho, são tratadas como indisponíveis.

A inferência de um semivariograma de suporte pontual a partir de dados agregados não é tão simples quando o procedimento de regularização. Para casos em que interessa calcular um suporte pontual, a partir de um suporte amostrado pequeno, o semivariograma experimental de dados agregados pode ser tratado como um estimador para o pontual. 
Contudo, para o caso da área de Demanda por Transportes, assim como em estudos de Medicina Geográfica e Ciências Sociais (GOOVAERTS, 2009), os blocos (células de uma malha) possuem áreas relativamente grandes. Nestas situações, Journel e Huijbregts (1978) propuseram um método geral de deconvolução:

- Definir um modelo de semivariograma pontual a partir da inspeção de um modelo agregado $\hat{\gamma}_{V}(h)$ e estimar os parâmetros gráficos (patamar, amplitude, contribuição);

- Computar o modelo teórico regularizado $\gamma_{V}(h)$ usando a aproximação dada pela Equação 3.16 e comparar com o modelo agregado $\hat{\gamma}_{V}(h)$; e

- Ajustar os parâmetros do semivariograma pontual para aproximar o modelo regularizado com o modelo agregado $\hat{\gamma}_{V}(h)$.

Percebe-se que a abordagem proposta por Journel e Huijbregts (1978) aponta para um modelo de otimização de semivariograma, em que o objetivo se torna aproximar modelos de semivariogramas. Baseado nisso, Goovaerts (2008) propôs um método que diminui, de forma iterativa, os desvios entre os semivariogramas regularizado e agregado a partir do método dos mínimos quadrados. Esse método já foi aplicado por Goovaerts (2008), Park (2013) e Fosu et al. (2016) e deu origem a um aplicativo do programa SpaceStat 4 da empresa Biomedware.

A aplicação do procedimento de deconvolução de semivariogramas é justificada pela vantagem associada à solução do MAUP. Apesar disso, o método necessita de informações refinadas, uma vez que utiliza semivariogramas regularizados (que, por sua vez, são obtidos através de informações intra e entre blocos). Dessa forma, este trabalho se propõe a elaborar um método de deconvolução alternativo de dados e de semivariogramas a partir de bases prontamente acessíveis, respeitando questões de confidencialidade das informações e a redução dos custos de coleta de dados.

Conforme descrito no capítulo seguinte, os dois métodos partem de dados agregados por unidades de área: (1) Áreas de Ponderação de Setores Censitários - Método Proposto 1, e (2) Zonas de Tráfego - Método Proposto 2. O papel da deconvolução de semivariogramas, neste caso, é considerar a estrutura espacial dos dados mais desagregados (caracterizada pelos semivariogramas teóricos) na Simulação Sequencial Gaussiana. Sendo assim, para as simulações, são considerados os valores de dados agregados, associados aos semivariogramas deconvoluídos (desagregados), a partir do procedimentos propostos. O Capítulo 4 detalha os procedimentos metodológicos seguidos na presente pesquisa. 


\section{Materiais e Método}

Uma vez que, nos Capítulos 2 e 3, foi discutido o referencial teórico necessário para o entendimento das atividades deste trabalho, o Capitulo 4 descreve os materiais e o método. Foram utilizados, como banco de dados, os microdados de 2010 e a Pesquisa Origem/Destino de 2007 da área de estudo, explanada a seguir, e como pacotes computacionais: o IBM SPSS 22, o ESRI ArcGIS Platform 10.1, SGeMS 3.0 e os pacotes geoestatísticos em $R$ (maptools, geoR, gstat). As etapas metodológicas também são descritas, posteriormente aos materiais.

\subsection{MATERIAIS}

Esta seção apresenta a área de estudo, os bancos de dados e os pacotes computacionais utilizados para este trabalho.

\subsection{1 Área de estudo e banco de dados}

A área de estudo está locada no sudeste do Brasil. São Paulo é o município mais populoso do país, compreendendo uma área de $1.521 \mathrm{~km}^{2}$ e aproximadamente 11,2 milhões de pessoas, de acordo com o último censo demográfico (IBGE, 2010). O município possui o maior PIB brasileiro (IBGE, 2010) e conta com o maior sistema de transporte público do Brasil, atualmente deslocando mais de nove milhões de passageiros por dia útil (SPTRANS, 2018). A Figura 4.1 apresenta a localização da Região Metropolitana de São Paulo, da cidade de São Paulo e das respectivas Zonas de Tráfego (ZTs).

Figura 4.1 - Representação da área de estudo: município de São Paulo e Zonas de Tráfego
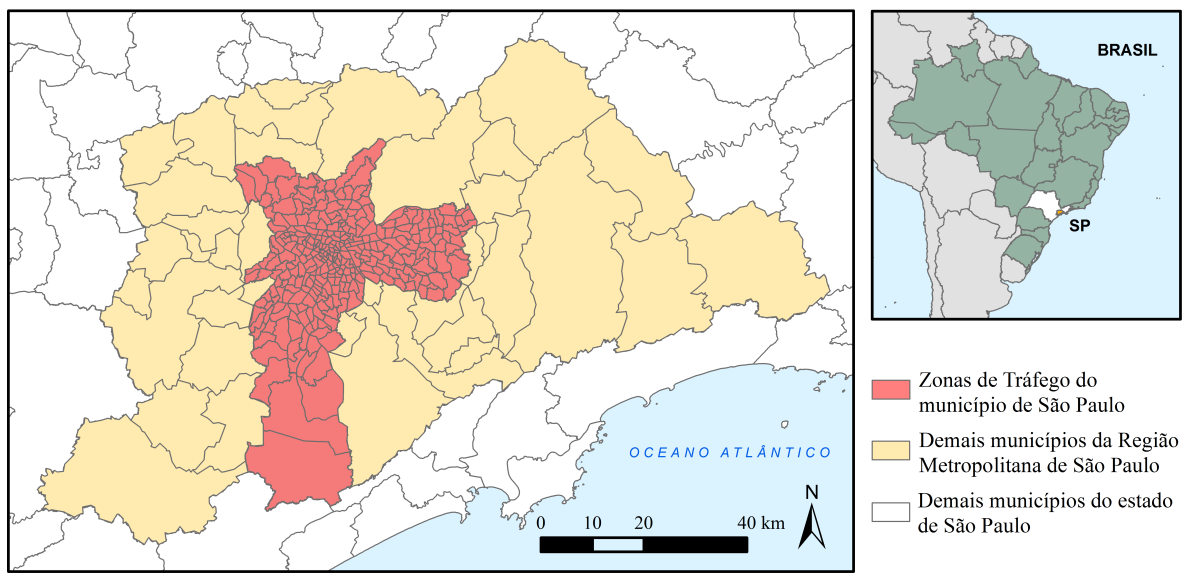
Os limites das ZTs foram estabelecidos pela Companhia do Metropolitano de São Paulo (METRÔ, 2007) considerando os setores censitários de 2000, o mapa de zoneamento de 1997, as instalações urbanas, as barreiras físicas, as áreas de proteção ambiental, o município e os bairros da cidade de São Paulo. Os Anexos A e B contêm o mapa e a designação das respectivas ZTs da Pesquisa Origem/Destino (O/D) de 2007.

Por se tratar de uma área com intensa aglomeração urbana, o município de São Paulo abrange regiões com alta densidade demográfica. Uma vez que a cidade possui em média 74 habitantes por hectare (IBGE, 2010), a Figura 4.2 sugere uma classificação de áreas não habitadas plausível a partir dos dados de densidade demográfica disponibilizados pela Emplasa (2002). A Figura 4.2 também apresenta um mapa de uso do solo, que permite corroborar a classificação sugerida, por este trabalho, para áreas não habitadas. Nota-se que a região de extremo norte e, em maior área, a região de extremo sul possuem uso do solo (e densidade populacional) que não demanda por um sistema de transporte público urbano tão complexo como na parte central do município.

Figura 4.2 - Áreas povoadas e mapa de uso do solo (GeoSampa, 2010)
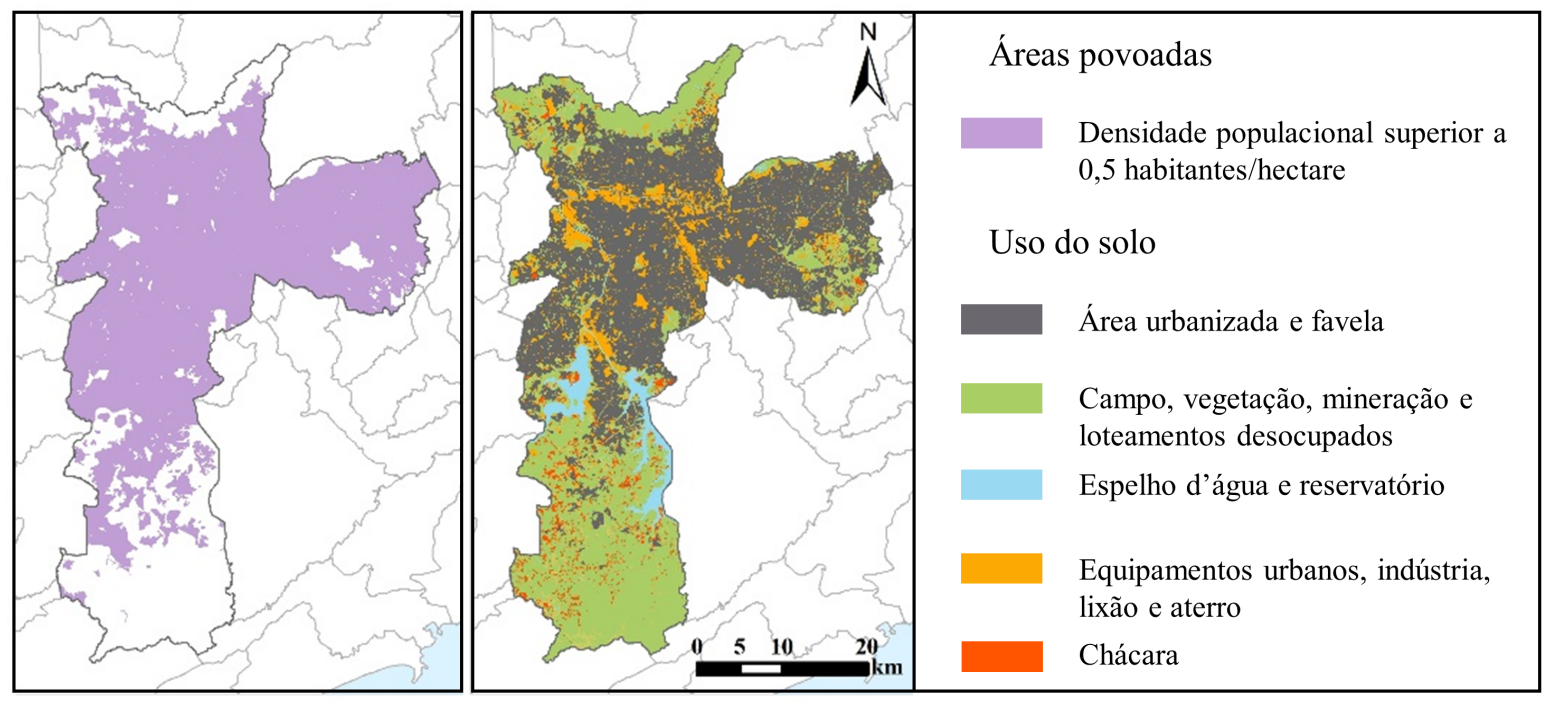

Este trabalho visa empregar técnicas de análise espacial geoestatística que permitam inferir sobre o comportamento relativo a viagens, especialmente com relação às viagens produzidas por transporte público em diferentes unidades de área.

Os bancos de dados empregados nesta pesquisa provêm de duas fontes: IBGE (2010) e Metrô (2007), que disponibilizaram os microdados socioeconômicos e a Pesquisa O/D, respectivamente. Os microdados do município de São Paulo, provenientes do IBGE (2010), são disponibilizados em formato ASCII, necessitando de uma ferramenta para decodificação dos registros. As variáveis dos microdados estão associadas a 172.627 
domicílios, não georreferenciados, em 310 Áreas de Ponderação (APs), conforme os Anexos C e D. A Pesquisa O/D, conduzida pelo Metrô (2007) na Região Metropolitana de São Paulo, por sua vez, possui um total de 196.699 registros de viagens associados a 30.000 domicílios entrevistados. As informações de viagens por transporte público de 15.759 domicílios foram selecionadas e agregadas em 320 ZTs (Anexos A e B), considerando apenas o município de São Paulo, para que os dados fossem utilizados nos métodos propostos MP1 e MP2. Dessa forma, essa base possui 320 registros. Os dados da Pesquisa O/D foram também agregados por diferentes malhas para validar os métodos propostos, através dos métodos comparativos MC1 e MC2. Os métodos propostos e comparativos (MP1, MP2, MC1 e MC2) são explanados na Seção 4.2.

A variável de estudo é a taxa de viagens produzidas por transporte público em relação ao total de viagens produzidas por unidade de área. A Figura 4.3 apresenta os valores da variável associados às 320 ZTs (valores domiciliares agregados por ZT). Para a agregação, considerou-se o modo principal de cada domicílio, sendo o transporte público referente a viagens por ônibus, metrô e trem.

Figura 4.3 - Valores da variável de estudo associados às Zonas de Tráfego (Metrô, 2007)

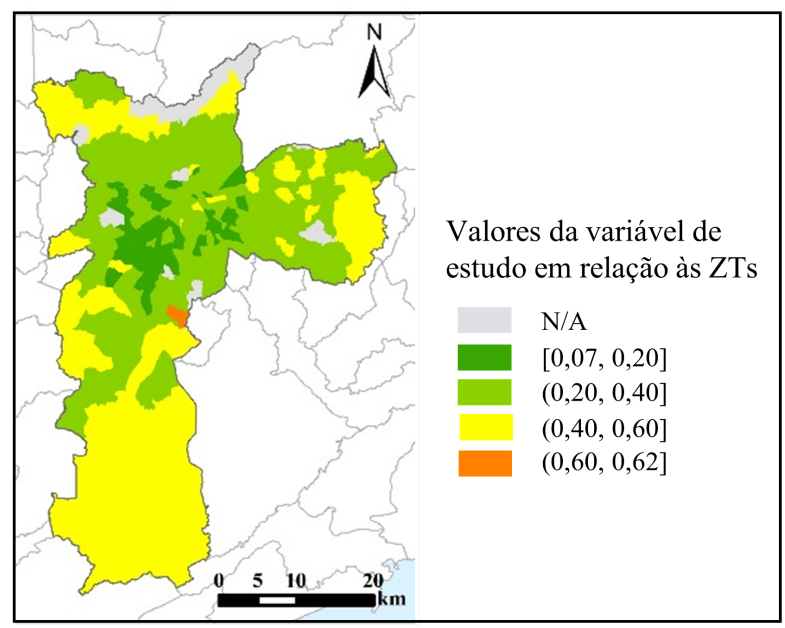

Nota-se que, as ZTs do extremo sul - em que, na Figura 4.2, sugerem baixo adensamento urbano; na Figura 4.3, por outro lado, apontam para maiores taxas de uso de transporte público. Isso pode ser explicado pelo efeito de utilizar um único valor para representar uma área com grande extensão. Consequentemente, são realizadas interpretações errôneas acerca do comportamento associado a viagens. Além disso, as ZTs possuem comportamentos bastante homogêneos quando comparadas entre si. Esse efeito de suavização de dados ocorre, pois os dados são agregados, o que acarreta perda de informações. 
Esta tese se propõe a desagregar informações como estas (associadas a ZTs, e a APs) e a transformá-las em dados relacionados a células quadriculares uniformes de diferentes malhas. Contudo, tem-se, como input ao Método Proposto 1 (MP1), informações socioeconômicas e um modelo de regressão para estimar viagens a partir destes dados. Esse artifício de inferir a demanda por transportes de forma desagregada, com base em dados menos robustos, com menor custo de aquisição e sem riscos de disseminação de informações individuais - que devem, rigorosamente, ser tratadas como confidenciais; demonstra um dos aspectos promissores desta pesquisa.

\subsubsection{Software}

A decodificação dos microdados e a análise estatística (tanto univariada, como comparativa) foram auxiliadas pela plataforma IBM SPSS 22. A preparação de dados espaciais e a reprodução de mapas foi realizada pela plataforma ESRI ArcGIS 10.1. As técnicas geoestatísticas (cálculo e ajuste de semivariogramas, Simulação Sequencial Gaussiana, transformação gaussiana e back-transforming) foram processadas através do programa SGeMS 3.0. Pacotes geoestatísticos em $R$ (maptools, geoR, gstat) auxiliaram na tomada de decisão de direções principais de continuidade.

\subsection{MÉTODO}

Este trabalho objetiva propor métodos heurísticos de desagregação de dados através de um procedimento alternativo para deconvolução de semivariogramas e de Simulação Sequencial Gaussiana (SSG) para obtenção de mapas desagregados de demanda por transportes, a partir de dados socioeconômicos e de transportes relacionados a Áreas de Ponderação (APs) e a Zonas de Tráfego (ZTs).

Foram propostas duas abordagens, mencionadas como: Método Proposto 1 (MP1) e Método Proposto 2 (MP2). Visando a validação da aplicação das abordagens propostas, foram utilizados dois métodos comparativos: Método Comparativo 1 (MC1) e Método Comparativo 2 (MC2). Uma vez que, ambas abordagens propostas (MP1 e MP2) utilizam o mesmo procedimento de deconvolução, este é, primeiramente, detalhado na próxima subseção. 


\subsubsection{Procedimento para deconvolução de semivariograma}

O procedimento proposto, neste trabalho, para deconvolução de semivariogramas é uma das contribuições metodológicas, além de ser um dos objetivos secundários. Através dos dados agregados por ZTs, bem como dos semivariogramas teóricos associados às ZTs, é possível calcular valores médios de simulações, utilizando a SSG. No entanto, neste caso, seriam considerados como dados de entrada, dados exclusivamente agregados; tanto da distribuição populacional (dados observados, associados aos centroides das ZTs) quanto da estrutura espacial (semivariogramas teóricos, também relativos aos centroides de ZTs).

O processo para deconvolução variográfica propicia a entrada, na aplicação da SSG, de características da estrutura espacial de dados mais desagregados (por malhas regulares), a partir dos semivariogramas teóricos, obtidos para cada um dos suportes analisados (relativos a unidades de áreas menores e homogêneas, quando comparadas às Zonas de Tráfego).

A Figura 4.4 resume parte dos procedimentos de desagregação dos dados e a proposta de deconvolução do semivariograma, adotados nesta tese. As etapas são designadas pelos algarismos arábicos (1) a (7) e os bancos de dados são denominados pelas letras $(A)$ e $(B)$.

A priori, deve-se atentar para a manipulação das variáveis, tendo em vista que cada banco de dados possui agregações espaciais distintas. Dessa forma, torna-se necessário compatibilizar as informações disponíveis. Uma vez que cada fonte de informações possui características singulares, cada caso deve ser tratado de forma particular. Para este trabalho, notou-se que ambos os bancos de dados - (A) e (B), conforme a Figura 4.4; possuíam informações de renda por domicílio. Sabe-se que, na área de estudo da Região Metropolitana de São Paulo, domicílios com rendas menores possuem maior tendência a utilizar transporte público, enquanto rendas domiciliares altas apontam para modos motorizados individuais (LINDNER, 2015).

A transformação da renda domiciliar em uma variável compatível com a mudança de escala se deu pela consideração do número de domicílios com renda salarial baixa para cada unidade de área (suporte) considerada. A classificação de domicílios de classe social $C$, aqui utilizada como limite superior para a definição de domicílio de renda baixa, foi definida conforme o critério ABEP (2010) para domicílios com renda média de R\$1541.

Para a Etapa (1) realizou-se o processo de calibração de um modelo que estimasse a taxa de viagens produzidas por transporte público pelo total de viagens produzidas em 
cada suporte a partir da taxa de domicílios de baixa renda pelo número total de domicílios pelo mesmo suporte. Esse processo foi obtido através dos dados agregados por ZT (A), provenientes da Pesquisa O/D (METRÔ, 2007).

Figura 4.4 - Fluxograma do método proposto para deconvolução do semivariograma

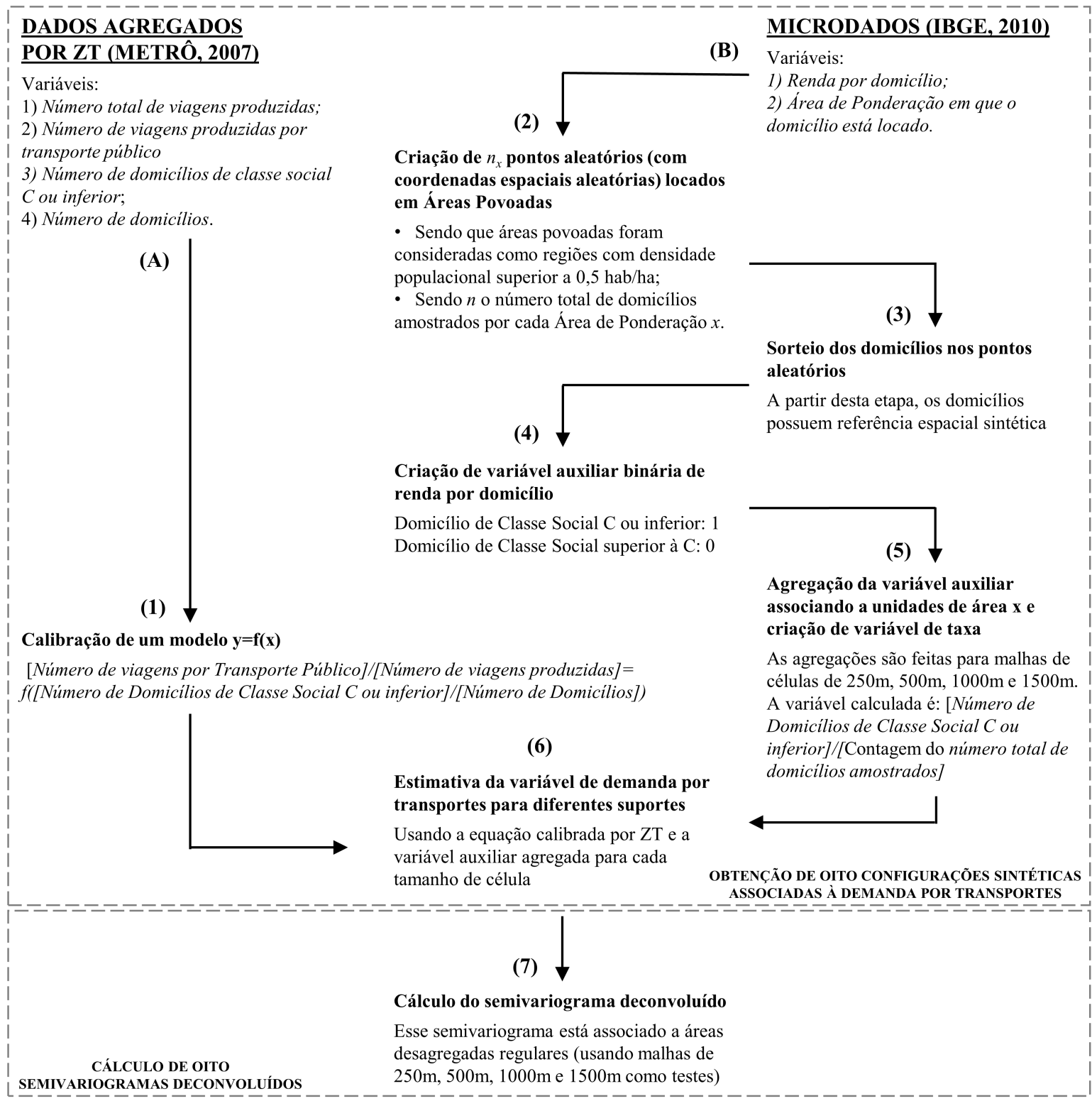

A partir dos microdados (B), foram extraídas as variáveis de renda e Área de Ponderação (AP) (vide Anexo C) em que cada domicílio estava locado. O IBGE (2010) define a AP como sendo um agrupamento mutuamente exclusivo de setores censitários adjacentes, cuja amostra tenha, no mínimo, 400 domicílios. A cada AP, foi identificado o respectivo número de domicílios amostrados pelo censo demográfico - Etapa (2). 
Sabendo que os microdados, divulgados pelo IBGE (2010), não fornecem as posições espaciais de cada observação da amostra (georreferenciamento) - em função da questão de confidencialidade das informações individuais; este trabalho propôs o sorteio da posição espacial aleatória para cada domicílio condicionado à respectiva AP - Etapa (3). Esta etapa de criação de dados desagregados, associados a posições espaciais sintéticas (dados sintéticos), é realizada por meio de sorteios aleatórios em regiões habitadas da área de estudo.

A renda domiciliar foi transformada na variável auxiliar binária - Etapa (4). Caso o domicílio fosse de classe social $\mathrm{C}$ ou inferior, seria classificado com o valor um. Caso o domicílio fosse de classe social superior à $\mathrm{C}$, seria classificado com o valor zero. Ao final da Etapa (4), tem-se domicílios, com localizações espaciais sintéticas, associados aos valores um ou zero. Este processo foi fundamental para quantificar o número de domicílios de baixa renda em cada célula das malhas analisadas - Etapa (5).

A escolha das malhas analisadas foi baseada na observação do comportamento da variável, através da análise da estrutura espacial, da distância mínima média entre os centroides das ZTs e também com base nos resultados apresentados pelo trabalho de mestrado de LINDNER (2015) - que mostrou que o nível de desagregação pontual, referente a domicílios, apresenta valores altos de efeito pepita para dados de demanda por transportes.

Ao final, utilizou-se, como variável independente, a taxa de domicílios de baixa renda pelo número total de domicílios em cada unidade de área estudada. Para a Etapa (6), essa variável serviu como variável independente para o cálculo da variável objeto de estudo (taxa de viagens por transporte público pelo total de viagens produzidas) através do modelo calibrado na Etapa (1). Esse processo de obtenção de dados foi repetido oito vezes, dando origem a oito configurações de dados sintéticos.

Ao final, foram calculados os semivariogramas experimentais deconvoluídos das configurações de dados sintéticos e avaliou-se a possibilidade de uso da média dos resultados obtidos - Etapa (7).

Os métodos propostos MP1 e MP2 utilizam a deconvolução alternativa de semivariogramas para a SSG. A diferença é que enquanto o MP1 tem dados sintéticos como input à SSG, o MP2 utiliza as informações agregadas por ZT da Pesquisa O/D. Ambos os procedimentos são descritos, detalhadamente, nas subseções seguintes. 


\subsubsection{Métodos Propostos e Métodos Comparativos}

A Figura 4.5 sintetiza as etapas seguidas nos métodos propostos (MP1 e MP2) e nos métodos comparativos (MC1 e MC2). As etapas são designadas pelos algarismos romanos (i) a (v) e as informações utilizadas são denominadas pelas letras (a) a (d).

Figura 4.5 - Fluxograma das etapas seguidas neste trabalho

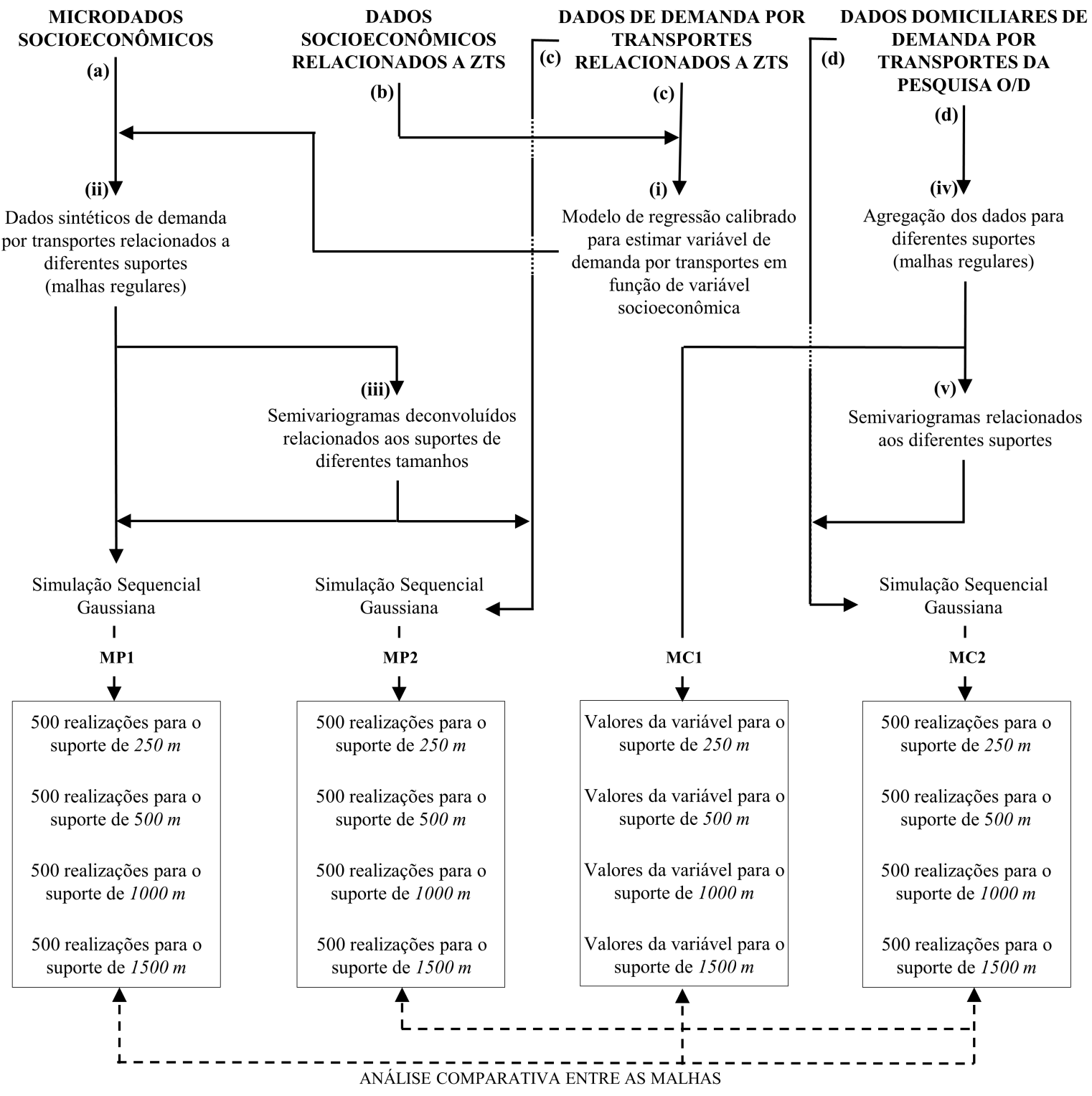

Os microdados socioeconômicos (a) provêm do IBGE (2010). Os dados domiciliares de demanda por transportes (d) e os dados socioeconômicos (b) e de demanda por transportes (c) relacionados a ZTs são provenientes da Pesquisa O/D (METRÔ, 2007).

Vale ressaltar que os procedimentos metodológicos manipulam três grupos de informações para as SSGs (MP1, MP2 e MC2): a) dados sintéticos desagregados por 
malha; b) dados da Pesquisa O/D associados a ZTs; e c) dados da Pesquisa O/D desagregados por malha.

\subsubsection{Método Proposto 1 (MP1)}

Partindo-se do pressuposto que não existe a disponibilidade de dados desagregados de demanda por transportes, uma forma de obtê-los é através de um modelo calibrado por regressão - Etapa (i). Este modelo deve estimar a variável de demanda por transportes (taxa de viagens por transporte público pelo total de viagens produzidas) a partir de variáveis socioeconômicas disponíveis (como a renda e o número de domicílios por unidade de área).

A etapa de criação de dados desagregados associados a posições espaciais sintéticas (dados sintéticos) - Etapa (ii), a partir de informações associadas a Áreas de Ponderação (APs) de Setores Censitários, é realizada conforme apresentado na Subseção 4.2.1. Em seguida, esses dados são agregados para cada malha testada (malhas com espaçamento de 250, 500, 1000 e 1500 metros).

Por conseguinte, são calculados semivariogramas deconvoluídos associados aos suportes desagregados das oito configurações sintéticas - Etapa (iii), também de acordo com a Subseção 4.2.1. Ao final, são calculadas 500 realizações (simulações) - valor este escolhido de forma a estabilizar a variabilidade entre as simulações; através de Simulação Sequencial Gaussiana (SSG), utilizando os valores médios das oito configurações de dados sintéticos e os semivariogramas deconvoluídos dos valores médios.

É relevante observar que o MP1 apresenta a vantagem de necessitar apenas de uma equação calibrada para a variável de demanda por transportes e não utiliza os dados desagregados da Pesquisa O/D como entrada à simulação.

\subsubsection{Método Proposto $2(M P 2)$}

O MP2 utiliza o semivariograma deconvoluído médio (iii), cujo procedimento foi detalhado na Subseção 4.2.1, e os dados de demanda por transportes associados a ZTs (c). São calculadas 500 realizações através de SSG para as malhas de suporte 250, 500, 1000 e 1500 metros. Salienta-se que o MP2 é baseado nos bancos de dados agregados e desagregados do IBGE (2010) e da Pesquisa O/D (METRÔ, 2007). 
O Quadro 4.1 resume as principais características dos dois métodos propostos e da aplicação direta de SSG.

Visando analisar as vantagens de aplicar os Métodos Propostos em relação à simples aplicação de simulação aos dados da Pesquisa $O / D$, associados às ZTs; comparativamente, é descrito, também, o uso da Simulação Sequencial Gaussiana (SSG). Neste caso mais simples, tanto os dados da variável, quanto os semivariogramas, são provenientes de dados agregados. Consequentemente, os valores desagregados calculados (por malhas), obtidos pelas simulações, trazem características apenas dos dados agregados.

Este trabalho não apresenta os resultados da aplicação direta de SSG a dados da Pesquisa Origem/Destino, associados a Zonas de Tráfego, uma vez que viola o pressuposto da Geoestatística sobre suportes homogêneos para semivariogramas.

Quadro 4.1 - Vantagens e desvantagens dos métodos propostos e de SSG tradicional

\begin{tabular}{|c|c|c|c|c|}
\hline & Descrição & Input & Vantagens & Desvantagens \\
\hline$\stackrel{\Sigma}{\Sigma}$ & $\begin{array}{l}\text { Desagregação de } \\
\text { dados associados a } \\
\text { APs para malhas } \\
\text { homogêneas. }\end{array}$ & $\begin{array}{l}\text { 1) Microdados } \\
\text { socioeconômicos } \\
\text { agregados por APs; } \\
\text { 2) Modelo calibrado; } \\
\text { 3) Semivariograma } \\
\text { deconvoluído. }\end{array}$ & $\begin{array}{l}\text { 1) Considera a dependência } \\
\text { espacial entre os valores da } \\
\text { variável; } \\
\text { 2) Considera semivariogramas de } \\
\text { dados desagregados a partir do } \\
\text { processo de deconvolução; } \\
\text { 3) Não requer uso de dados } \\
\text { provenientes de Pesquisa O/D. }\end{array}$ & $\begin{array}{l}\text { 1) Localização espacial sintética } \\
\text { de domicílios de microdados (não } \\
\text { amostrados). }\end{array}$ \\
\hline$\stackrel{\mathfrak{N}}{\Sigma}$ & $\begin{array}{l}\text { Desagregação de } \\
\text { dados associados a } \\
\text { ZTs para malhas } \\
\text { homogêneas. }\end{array}$ & $\begin{array}{l}\text { 1) Dados da Pesquisa } \\
\text { O/D agregados por ZT; } \\
\text { 2) Modelo calibrado; } \\
\text { 3) Semivariograma } \\
\text { deconvoluído. }\end{array}$ & $\begin{array}{l}\text { 1) Considera a dependência } \\
\text { espacial entre os valores da } \\
\text { variável; } \\
\text { 2) Considera semivariogramas de } \\
\text { dados desagregados a partir do } \\
\text { processo de deconvolução. }\end{array}$ & $\begin{array}{l}\text { 1) Requer dados provenientes de } \\
\text { Pesquisa O/D; } \\
\text { 2) Sofre maiores efeitos do } \\
\text { MAUP (Problema de Unidade de } \\
\text { Área Modificável), dado que } \\
\text { utiliza dados associados a } \\
\text { centroides de ZTs na SSG. }\end{array}$ \\
\hline 心 & $\begin{array}{l}\text { Desagregação de } \\
\text { dados associados a } \\
\text { unidades de área } \\
\text { maiores e irregulares } \\
\text { para malhas } \\
\text { regulares. }\end{array}$ & $\begin{array}{l}\text { 1) Dados da Pesquisa } \\
\text { O/D agregados por ZT; } \\
\text { 2) Semivariogramas } \\
\text { associados aos } \\
\text { centroides das ZTs. }\end{array}$ & $\begin{array}{l}\text { 1) Considera a dependência } \\
\text { espacial entre os valores da } \\
\text { variável. }\end{array}$ & $\begin{array}{l}\text { 1) Requer dados provenientes de } \\
\text { Pesquisa O/D; } \\
\text { 2) Sofre maiores efeitos do } \\
\text { MAUP, dado que utiliza dados } \\
\text { associados a centroides de ZTs; } \\
\text { 3) Não respeita o pressuposto da } \\
\text { Geoestatística de suportes } \\
\text { homogêneos para cálculo e } \\
\text { ajuste de semivariogramas. }\end{array}$ \\
\hline
\end{tabular}




\subsubsection{Métodos Comparativos}

Os métodos comparativos, por outro lado, são exclusivamente derivados da Pesquisa O/D. Inicialmente, os dados domiciliares são agregados para as quatro malhas estudadas - Etapa (iv). Os valores da variável de estudo em cada célula representam os valores comparativos para o MC1. O MC2 gera, a partir dos dados resultantes do MC1, 500 simulações geoestatísticas por SSG, utilizando os semivariogramas obtidos pelos próprios dados da Pesquisa O/D, conforme a Etapa (v), e os dados (d).

A análise estatística comparativa dos resultados para os métodos propostos versus os métodos comparativos segue quatro critérios. A primeira abordagem é a inspeção visual dos resultados espaciais gerados pela SSG e representados pelos mapas e-type (média das simulações), de intervalo de confiança, de mediana e de variância. O segundo critério trata de analisar as estatísticas univariadas. A terceira métrica avalia o desempenho dos métodos propostos em relação aos métodos comparativos através dos parâmetros de desvio médio, desvio médio absoluto, erro quadrático médio, raiz do erro quadrático médio, erro percentual médio, erro percentual médio absoluto e correlação de Pearson. A quarta avaliação aplica testes não paramétricos para duas amostras independentes (método proposto versus método comparativo), analisando a hipótese nula de que as distribuições são equivalentes. Além destas métricas, é importante averiguar as estatísticas espaciais através da análise variográfica dos dados da Pesquisa O/D e dos dados sintéticos para da malha.

O intervalo de confiança (IC), assim como a variância, é uma medida vantajosa no âmbito de Demanda por Transportes, tendo em vista que é conveniente aos analistas e engenheiros de transportes estarem munidos de informações sobre áreas críticas e sobre a incerteza de métodos de simulação. O IC é calculado considerando que a variância da população é desconhecida, de acordo com a Equação 4.1 .

$$
I C=\bar{X} \pm \Delta=\bar{X} \pm t_{\alpha / 2} \frac{s}{\sqrt{n}}
$$

Em que $\bar{X}$ é a média de todos os valores amostrados, $t_{\alpha / 2}$ é o valor crítico considerando a significância $\alpha, s$ é o desvio padrão e $n$ é o número de valores amostrados.

Como esta tese compara os procedimentos metodológicos (MP1 vs. MC1; MP1 vs. MC2; MP2 vs. MC1; MP2 vs. MC2), as configurações de dados sintéticos geradas versus os dados desagregados da Pesquisa O/D e as análises variográficas dos dados utilizados; o Capítulo 5 expõe os resultados de forma distinta ao que é apresentado nos itens das Figuras 4.4 e 4.5. É, também, levado em consideração que alguns pressupostos associados 
à SSG devam ser analisados no decorrer do trabalho, conforme detalhado no Capítulo 3, sobre Geoestatística. Para melhor entendimento dos outputs e das decisões tomadas, os resultados são apresentados respeitando a seguinte ordem:

Geração de oito configurações de dados sintéticos

Análise variográfica e geração de semivariogramas deconvoluídos

Dados sintéticos desagregados por malha

Dados da Pesquisa O/D associados a ZTs

Dados da Pesquisa O/D desagregados por malha

Métodos Propostos

$M P 1$ (SSG)

MP2 (SSG)

Métodos Comparativos

MC1

MC2 (SSG)

Mapas e Estatísticas Univariadas

Estatísticas Comparativas

Testes não Paramétricos 


\section{Resultados e Discussões}

O Capítulo 5 descreve e formaliza a discussão dos resultados obtidos através dos métodos propostos e explanados no Capítulo 4. São apresentados os resultados da criação de oito configurações de dados sintéticos, da análise variográfica, da geração de semivariogramas deconvoluídos, dos métodos propostos, dos métodos comparativos e das estatísticas analisadas.

A Figura 5.1 apresenta as coordenadas dos domicílios entrevistados na Pesquisa Origem/Destino (O/D), conduzida pelo Metrô (2007).

Figura 5.1 - Georreferenciamento dos domicílios entrevistados pela Pesquisa O/D (Metrô, 2007)

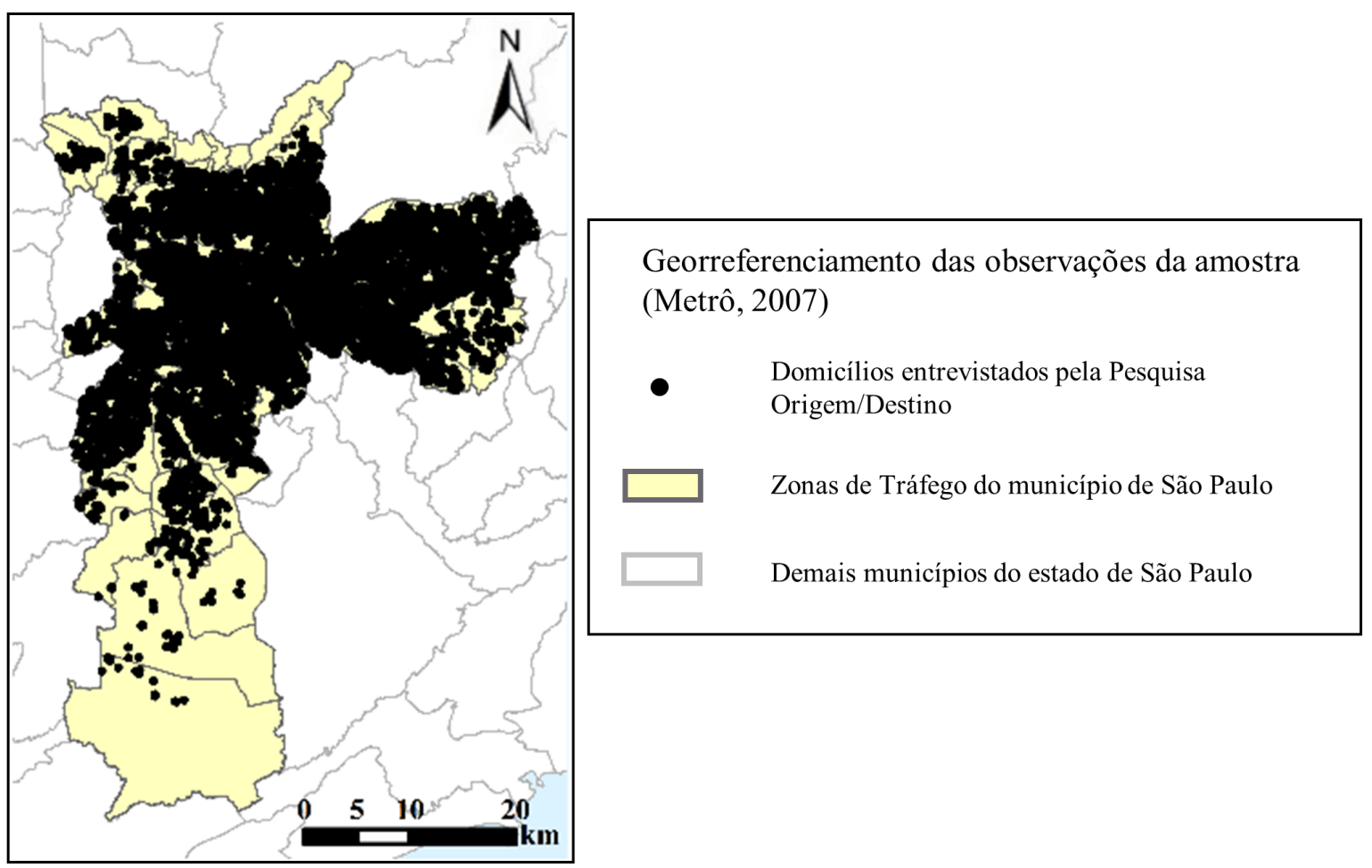

Nota-se que houve Zonas de Tráfego (ZTs) com nenhum domicílio entrevistado: Jaraguá (ID 113), Vista Alegre (ID 119), Parque Anhembi (ID 130), Reserva da Cantareira (ID 140), ETA Guaraú (ID 143), Cantareira (ID 146), USP Leste I e II (IDs 173 e 174), Parque do Carmo (ID 212), Parque do Estado (ID 232), Congonhas (ID 254) e Cidade Universitária (ID 317), conforme o Anexo A e B. Analogamente, podem existir outras áreas que também não são habitadas e, portanto, não deveriam ser representadas por um valor médio da respectiva $\mathrm{ZT}$. Além disso, pode ocorrer o inverso, regiões com intensa atividade urbana podem ser representadas por valores suavizados. Essas desvantagens analisadas 
pelos dados agregados de demanda por transportes são tratadas aqui pela desagregação das informações disponíveis.

Adicionalmente, como este trabalho intenciona empregar informações menos custosas e que respeitem a confidencialidade dos dados, a variável de estudo de demanda por transportes é calculada através de uma equação calibrada com base em informações socioeconômicas acessíveis.

A seção seguinte apresenta os resultados obtidos pela geração de configurações de dados sintéticos e pela inferência da variável de demanda de transportes.

\subsection{GERAÇÃO DE OITO CONFIGURAÇÕES DE DADOS SINTÉTICOS}

A densidade populacional de áreas habitadas foi considerada para o sorteio dos domicílios dos microdados. Foram utilizadas as variáveis domiciliares de renda e a Área de Ponderação (AP) em que cada domicílio está locado. Observou-se que, dos 172.627 domicílios que forneceram informações sobre renda, 66.562 domicílios (39\%) possuíam renda inferior a $R \$ 1.541$.

A partir das informações sobre a quantidade de domicílios amostrados $(n)$ em cada uma das 310 APs, foram gerados, aleatoriamente e de forma condicional às regiões habitadas, $n$ pontos em cada AP, através de oito configurações diferentes. O Anexo $C$ apresenta as APs e o Anexo $D$ contém o detalhamento do número de pontos aleatórios criados em cada AP. Em média, foram gerados, aproximadamente, 557 pontos por AP. Com base nisso, foram criadas variáveis binárias auxiliares de renda por domicílio, sendo os domicílios de classe baixa associados ao valor um e os demais ao valor igual a zero.

Considerando as diferentes malhas, o somatório dos valores foi agregado por cada unidade de área estudada (250, 500, 1000 e 1500 metros). Ao final, foram contabilizados: o total de domicílios amostrados e o total de domicílios com classe de renda baixa para cada célula.

Por conseguinte, calculou-se a taxa de domicílios de baixa renda pelo total de domicílios. A Figura 5.2, apresenta os valores médios das oito configurações para a taxa de domicílios de classe de renda baixa pelo total de domicílios em cada malha estudada. 
Figura 5.2 - Valores sintéticos de taxa de domicilios de classes de renda baixa pelo total de domicílios

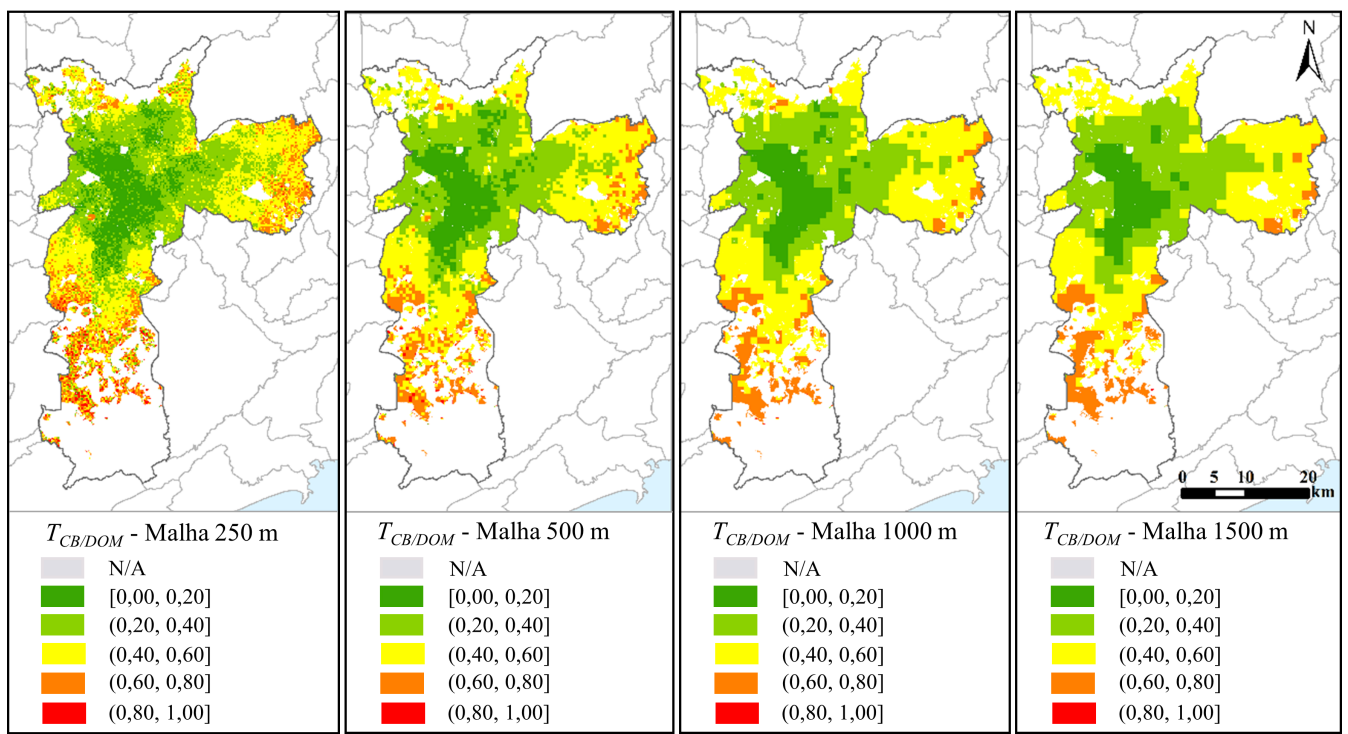

Esses dados são mencionados como dados sintéticos, uma vez que a posição espacial foi criada aleatoriamente com base na suposição de habitação. A Equação 5.1 apresenta a função do modelo de calibração, que objetiva calcular a taxa de viagens por transporte público pelo total de viagens produzidas, sabendo-se que o IBGE não fornece informações relativas às viagens urbanas. $O$ modelo é baseado na variável independente ilustrada na Figura 5.2.

$$
\begin{gathered}
\frac{T P}{V P}=f\left(\frac{C B}{D O M}\right) \\
\therefore T_{T P / V P}=f\left(T_{C B / D O M}\right)
\end{gathered}
$$

Sendo, TP o número de viagens produzidas por transporte público, VP o número total de viagens produzidas, $C B$ o número de domicílios de classe de renda baixa, $D O M$ o número total de domicílios.

Ao final, consideram-se duas variáveis de taxa, em que $T_{T P N P}$ é a variável de estudo e $T_{C B / D O M}$ é a variável independente. O modelo calibrado é representado pela Equação 5.2. Para o cálculo deste modelo, foram utilizados os dados da Pesquisa O/D agregados por ZT. Desta base, foram extraídas informações de renda acerca de 15.759 domicílios, em que 23\% (3.702 domicílios) podem ser considerados de baixa renda. Essa porcentagem difere da proporção de domicílios de baixa renda dos microdados do IBGE. Com isso, presume-se que diferentes amostragens tenham sido feitas a ambas as bases de dados. 


$$
T_{T P / V P}=\beta f\left(T_{C B / D O M}\right)
$$

Sendo o coeficiente de regressão $(\beta)$ significante estatisticamente $(\operatorname{sig}=0,00)$ e igual a 1,056. A equação calibrada apresentou um coeficiente de determinação de 0,815 .

Ao aplicar este modelo calibrado aos dados sintéticos, foram obtidos os valores da variável de estudo em diferentes células para cada uma das quatro malhas. A geração de dados sintéticos foi processada oito vezes, dando origem a oito diferentes configurações espaciais da variável de demanda por transportes. Optou-se pelo uso de valores médios levando-se em conta as oito configurações obtidas, por malha regular.

As médias das taxas de viagens produzidas por transporte público pelo total de viagens produzidas são apresentadas na Figura 5.3.

Figura 5.3 - Valores sintéticos de taxa de viagens por transporte público pelo total de viagens produzidas

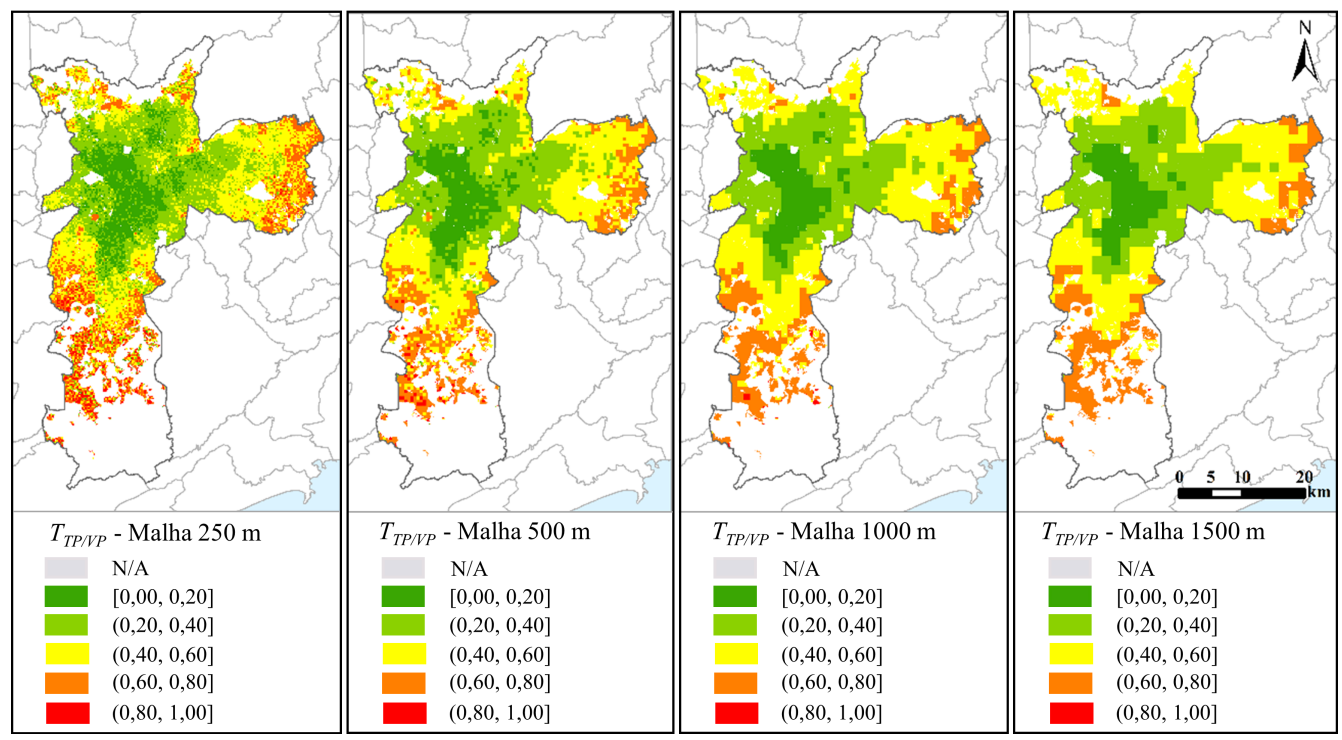

A Figura 5.4 apresenta uma análise das frequências dos valores médios das configurações de dados sintéticos e da respectiva transformada gaussiana, instrumento fundamental para a Simulação Sequencial Gaussiana (SSG).

Salienta-se que, as malhas mais agregadas possuem menos observações em comparação às malhas mais refinadas. Contudo, as malhas mais desagregadas têm maiores quantidades de: a) células sem registros, que provocam descontinuidades espaciais e b) células que contabilizam poucos domicílios para o cálculo da variável independente. É importante avaliar a limitação do nível de desagregação de dados através dos resultados do método para as diferentes malhas. 
A suficiência de oito configurações de dados sintéticos é demonstrada na próxima seção, que averigua os aspectos geoestatísticos, através da análise variográfica.

Figura 5.4 - Histogramas dos dados sintéticos desagregados (médios) e da transformada gaussiana
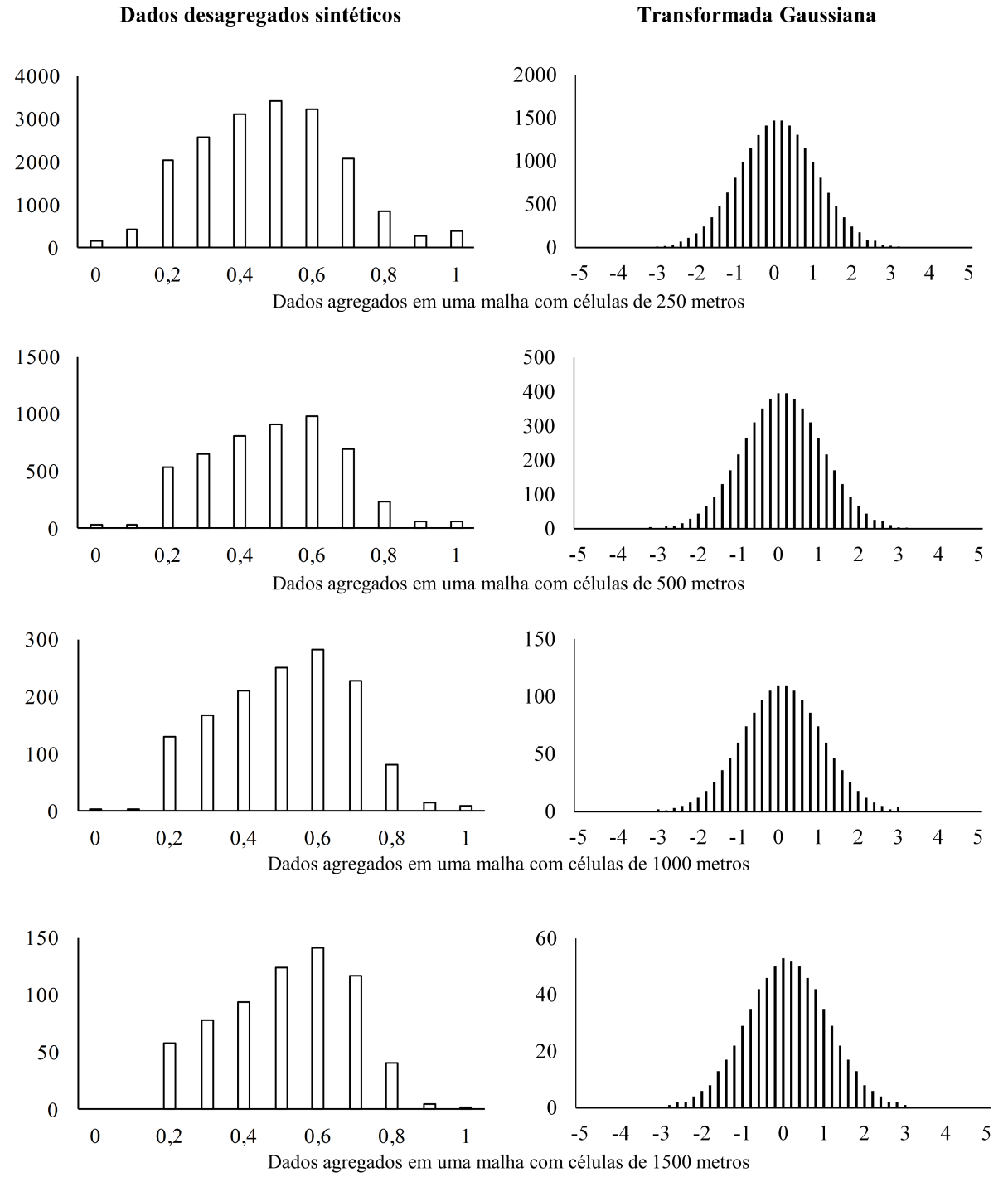

\subsection{ANÁLISE VARIOGRÁFICA E GERAÇÃO DE SEMIVARIOGRAMAS DECONVOLUÍDOS}

A Figura 5.5 apresenta a análise variográfica da variável de estudo: taxa de viagens produzidas por transporte público pelo total de viagens por unidade de área, através de mapas variográficos.

A análise variográfica é uma etapa da modelagem geoestatística que investiga a estrutura espacial de uma variável regionalizada. Para aplicá-la, deve-se, primeiramente, atestar que as variáveis de estudo são, de fato, regionalizadas. Ou seja, devem ser 
espacialmente distribuídas, resultado de um processo estocástico e apresentar estrutura espacial (MATHERON, 1963).

À vista disso, os valores esperados das variâncias entre os pares foram representados espacialmente, considerando a distância de corte de $60 \mathrm{~km}$, o caso omnidirecional e os três tipos de informações aqui utilizadas (configurações de dados sintéticos por malhas, dados associados aos centroides das ZTs, e dados da Pesquisa O/D, associados às quatro malhas avaliadas), conforme a Figura 5.5.

Figura 5.5 - Mapas variográficos da variável taxa de viagens por transporte público

(a)

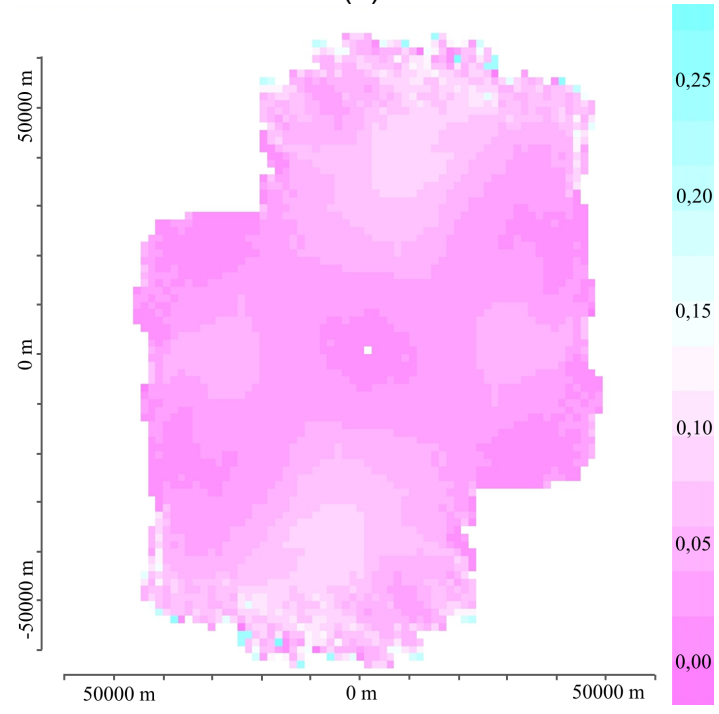

(b)

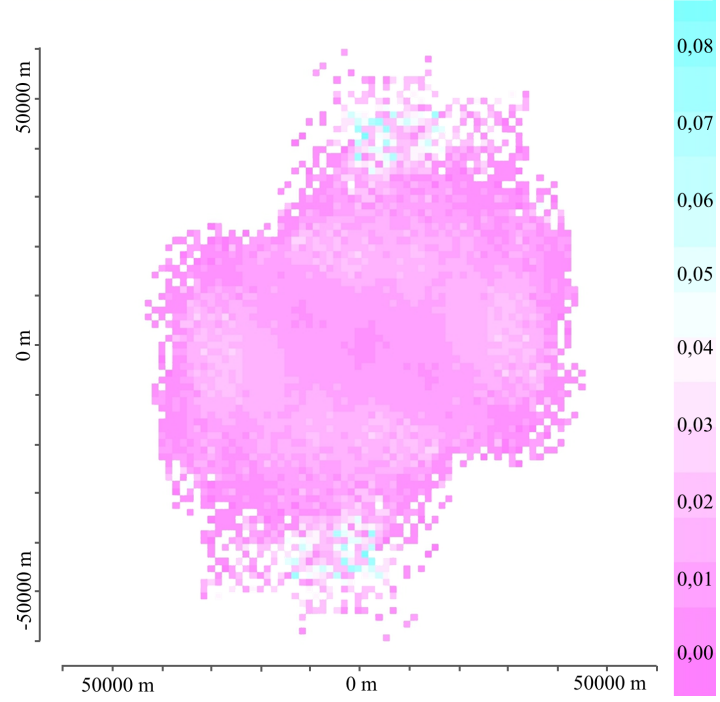

(c)

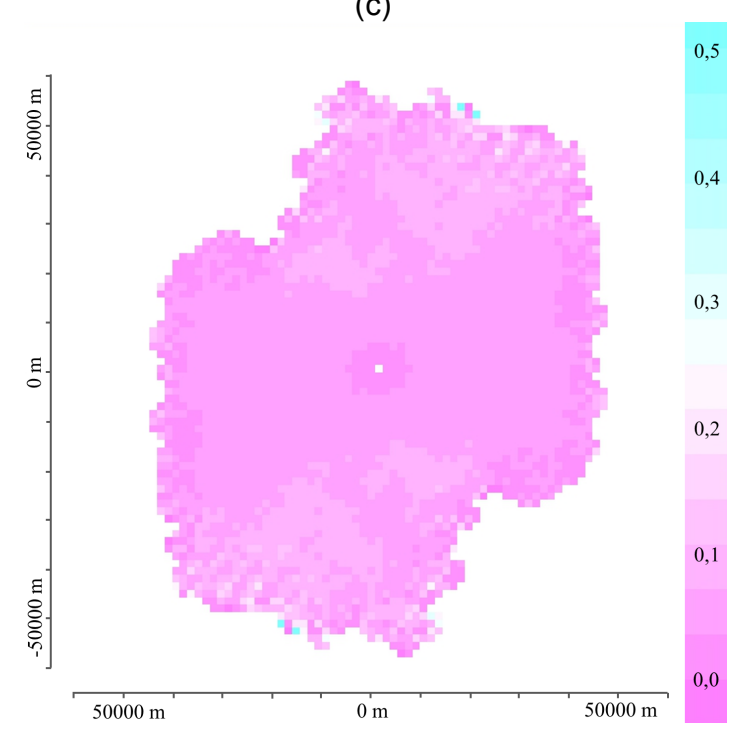

Legenda: (a) dados sintéticos criados associados à malha de $1500 \mathrm{~m}$; (b) dados das Zonas de Tráfego (Metrô, 2007) considerando a distância euclidiana de 1400 m; e (c) dados da Pesquisa O/D associados à malha de 1500 m (Metrô, 2007). 
A Figura 5.5 (b) apresenta o mapa variográfico considerando um lag de 1400 metros, que trata da distância euclidiana entre os centroides das ZTs. Com isso, tem-se um critério máximo para desagregação nesta tese. Ao utilizar malhas mais agregadas que 1400 metros, o propósito de desagregação é negligenciado. Contudo, para este trabalho, considera-se um suporte máximo de 1500 metros, a fim de avaliar também o efeito da regularização das informações.

As Figuras 5.5 (a), (b) e (c) indicam a existência de estrutura espacial. Em todos os casos, nota-se maior tendência de variabilidade na direção aproximada de $0^{\circ}$ (Norte-Sul), e, por conseguinte, maior continuidade espacial em $90^{\circ}$ (Leste-Oeste), sendo essa, portanto a direção principal. A tolerância angular utilizada para os cálculos foi de $15^{\circ}$. Esta tolerância permite que sejam abrangidas todas as disparidades entre as direções principais analisadas para os três grupos de informações, conforme as Figuras 5.5 (a), (b) e (c).

As subseções seguintes exploram as relações geoestatísticas para os três grupos de informações utilizados: 1) configurações de dados sintéticos associados às quatro malhas avaliadas, 2) dados da Pesquisa O/D associados a ZTs e 3) dados da Pesquisa O/D associados às quatro malhas avaliadas. O último conjunto de dados é proveniente da agregação dos dados domiciliares da Pesquisa O/D em cada uma das quatro unidades de áreas utilizadas.

\subsubsection{Configurações de dados sintéticos desagregados por malha}

Para fins de análise, foram calculados os semivariogramas omnidirecionais das oito configurações de dados sintéticos para a malha de 250 metros (Figura 5.6). Tendo em vista que existe a possibilidade de os dados sintéticos possuírem diferentes comportamentos para diversas direções, o semivariograma omnidirecional permite que sejam avaliadas, de maneira uniforme, todas as disparidades e similaridades entre as oito configurações.

Os demais semivariogramas das configurações dos dados sintéticos (para as malhas $500 \mathrm{~m}, 1000 \mathrm{~m}$ e $1500 \mathrm{~m}$ ) podem ser encontrados nos Apêndices A, B e C, respectivamente. Os semivariogramas são considerados análogos até o espaço geométrico de 40 quilômetros. Dada a similaridade do comportamento espacial dos modelos, foram utilizadas as médias como semivariogramas deconvoluídos no MP1 e MP2. 
Figura 5.6 - Semivariogramas dos dados sintéticos criados a partir de oito sorteios (malha de $250 \mathrm{~m}$ )

Semivariogramas omnidirecionais para oito sorteios dos microdados (IBGE, 2010)
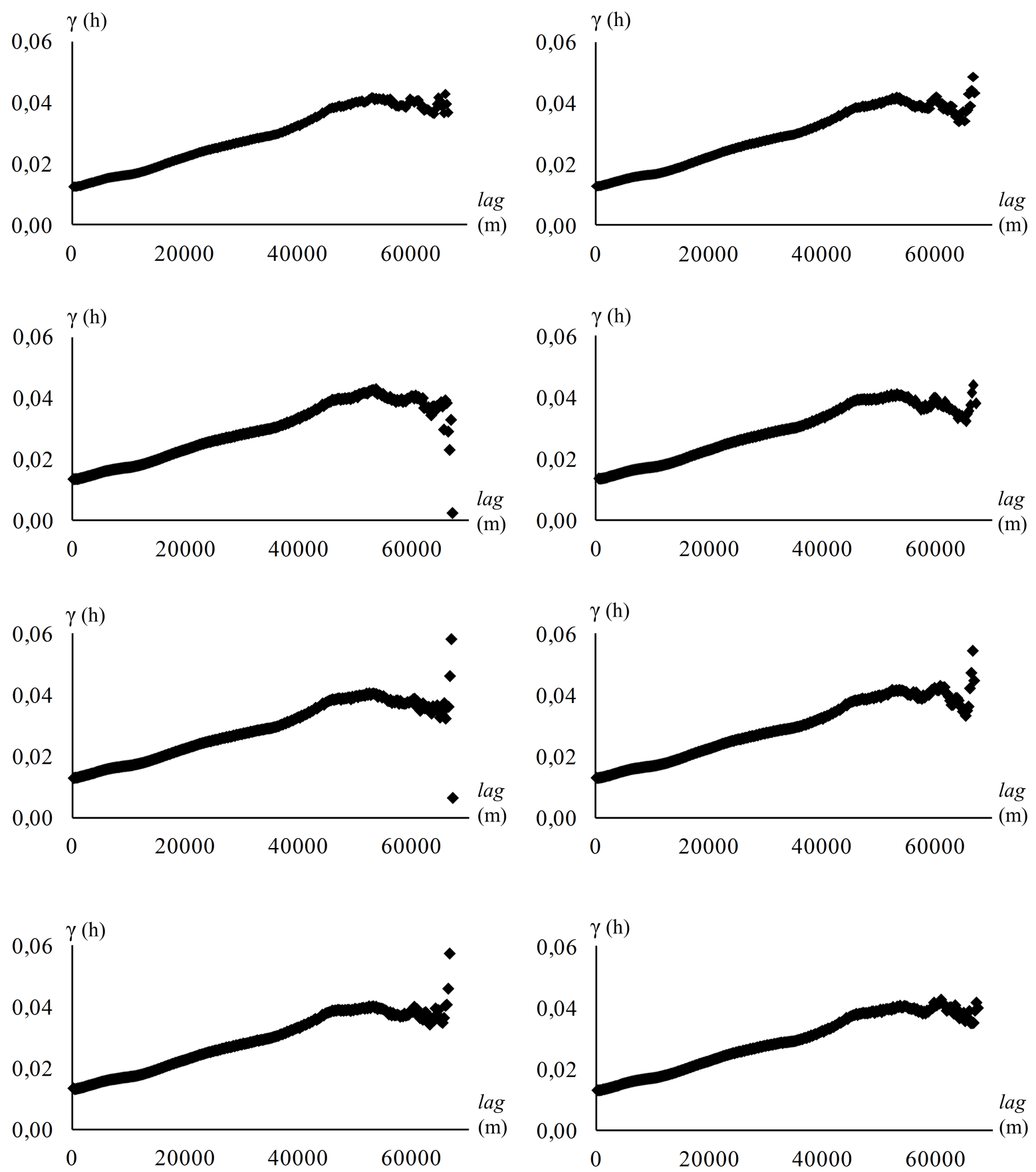

Dados agregados em uma malha com células de 250 metros

A Figura 5.7 apresenta os semivariogramas médios para cada malha. Para o dado de entrada no MP1, foram calculados os valores médios da variável em cada célula das configurações de dados sintéticos. 
Figura 5.7 - Semivariogramas experimentais das configurações de dados sintéticos para cada malha estudada e para os dados da Pesquisa O/D agregados por ZTs
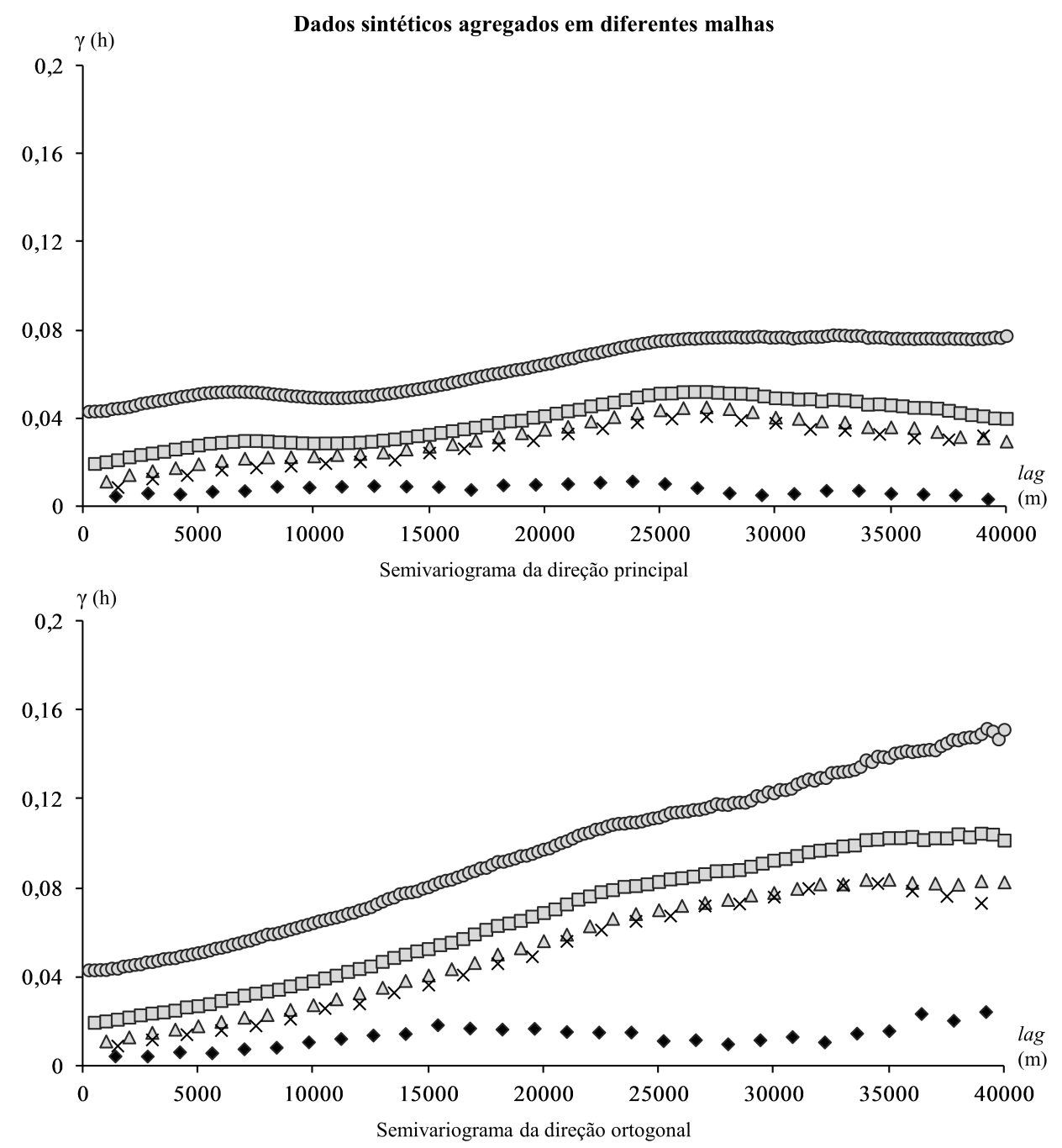

$$
\begin{array}{lrl}
\begin{array}{l}
\text { Dados sintéticos agregados em uma malha com } \\
\text { células de } 250 \text { metros }
\end{array} & \Delta \begin{array}{l}
\text { Dados sintéticos agregados em uma malha com } \\
\text { células de } 1000 \text { metros }
\end{array} \\
\begin{array}{l}
\square \text { Dados sintéticos agregados em uma malha com } \\
\text { células de } 500 \text { metros }
\end{array} & \times \begin{array}{l}
\text { Dados sintéticos agregados em uma malha com } \\
\text { células de } 1500 \text { metros }
\end{array} \\
& \quad \text { Dados agregados da Zona de Tráfego (Metrô, 2007) }
\end{array}
$$

A Figura 5.7 revela que quanto mais agregado o suporte, menor a variância entre pares de pontos. No entanto, percebe-se que a variância para os dados associados a ZTs apresentam grandezas inferiores, mesmo sendo o tamanho de lag inferior ao da malha de 1500 metros. Isso indica que existe maior perda de informação ao agregar dados associando a áreas irregulares.

Também através da Figura 5.7, é possível constatar que, à medida em que são considerados suportes muito desagregados (ou seja, malhas com suportes inferiores a 250 metros, para o presente estudo de caso), os semivariogramas violam a hipótese intrínseca de estacionariedade de segunda ordem. Ou seja, observa-se que, principalmente para o 
semivariograma ortogonal, não existe limite na variância e, desta forma, o semivariograma possui tendências espaciais. Isso indica que existe uma limitação metodológica no processo de desagregação. Tendo em vista esse fato, justifica-se o critério de uso da malha mais desagregada como possuindo tamanho de 250 metros.

A Figura 5.8 apresenta os semivariogramas experimentais e ajustados para os valores da transformada gaussiana dos dados provenientes da Pesquisa O/D agregados por malha e por ZTs.

Figura 5.8 - Semivariogramas experimentais e ajustados da transformada gaussiana dos dados sintéticos
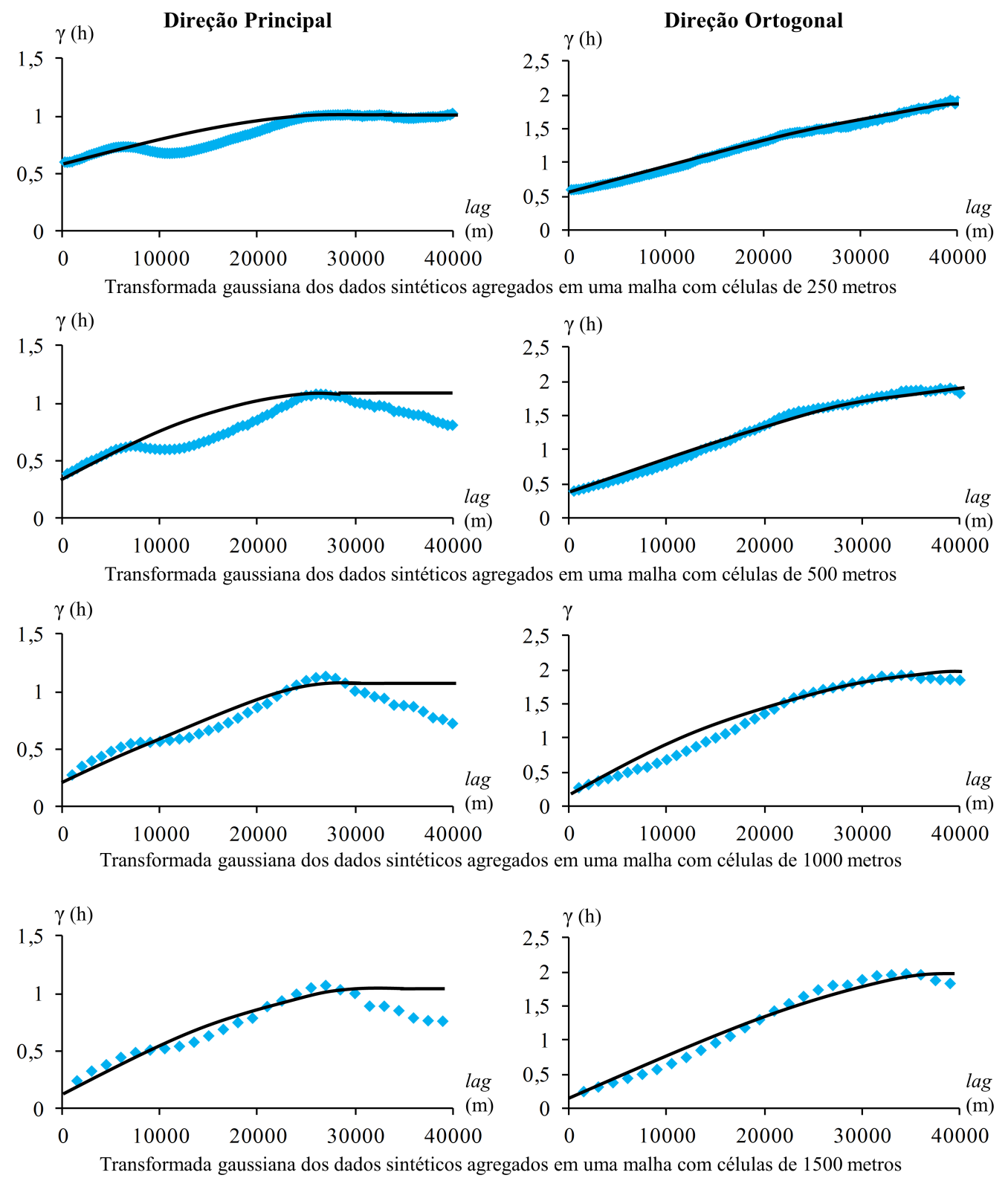

Semivariograma experimental _ـ Semivariograma ajustado (modelo esférico) 
Os semivariogramas experimentais e ajustados para os valores da transformada gaussiana (Figura 5.8) mostram que os modelos teóricos se aproximam mais de curvas esféricas e que existe estrutura espacial melhor definida nos suportes mais agregados. Isto é, o semivariograma da direção ortogonal para o suporte de 250 metros, por exemplo, não possui estacionariedade. À medida em que são utilizados suportes maiores, os modelos teóricos são melhor acomodados.

5.2.2 Dados da Pesquisa O/D associados a ZTs

A Figura 5.9 apresenta os histogramas e os semivariogramas dos dados associados a ZTs e das respectivas transformadas gaussianas.

Figura 5.9 - Histogramas e semivariogramas dos dados da Pesquisa O/D associados a Zonas de Tráfego
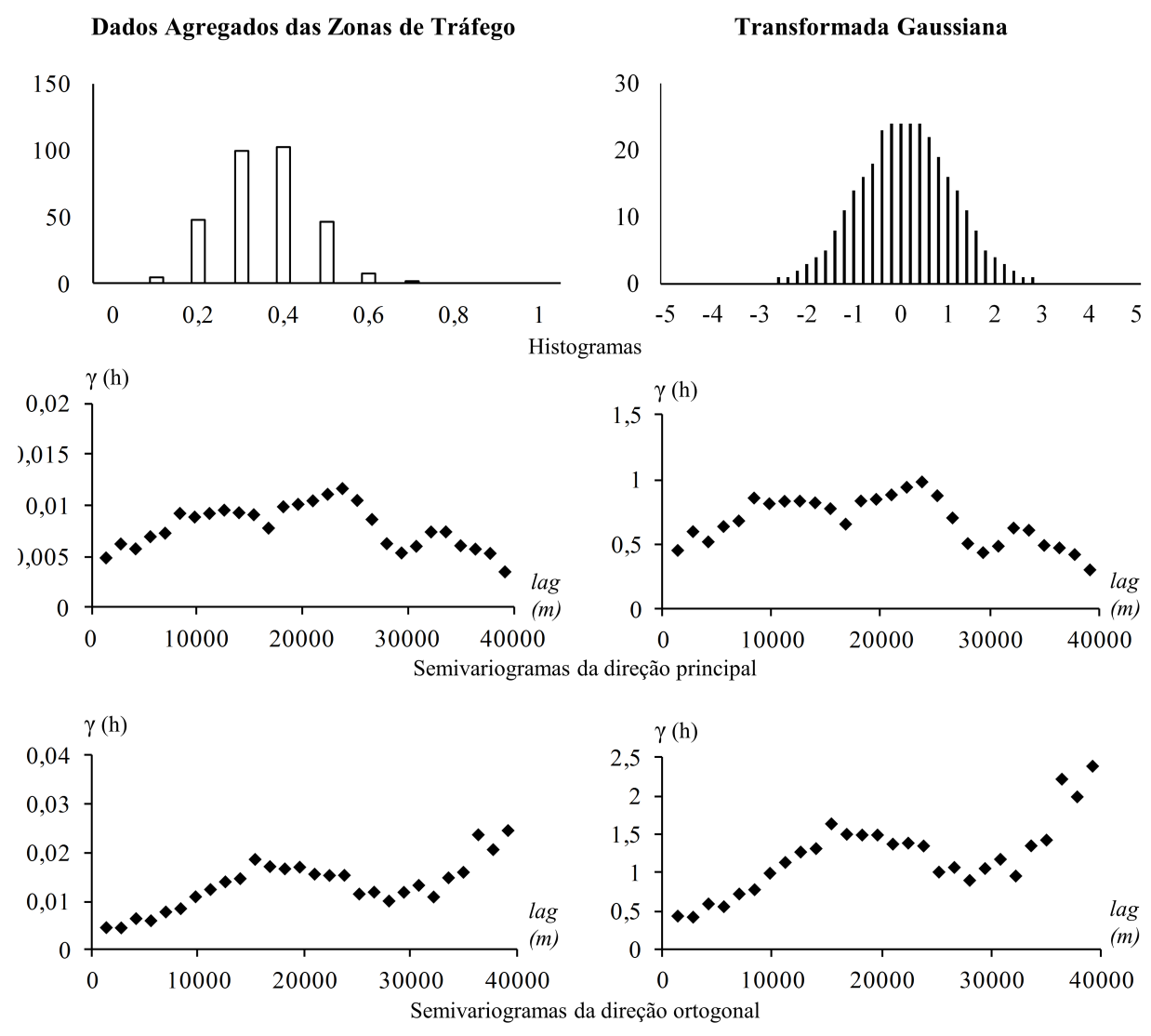

Nota-se, pelo histograma da variável de estudo, que não existem valores extremos (0 ou 1), novamente remetendo ao problema de suavização dos dados. O lag, utilizado para o cálculo dos semivariogramas, refere-se à distância euclidiana entre os centroides das ZTs (1400 m). Os semivariogramas mostram que, à medida em que as distâncias entre os pares aumentam, aumenta a variabilidade dos valores, até uma distância próxima a 20 quilômetros (amplitude). 


\subsubsection{Dados da Pesquisa O/D por malha}

Os dados desagregados (domiciliares) da Pesquisa O/D foram utilizados neste trabalho com o intuito de prover meios de validar as abordagens propostas. Os dados foram agregados por quatro malhas e os histogramas dos valores agregados e das respectivas transformadas gaussianas são mostrados na Figura 5.10.

Figura 5.10 - Histogramas dos dados domiciliares da Pesquisa O/D e da transformada gaussiana

Dados desagregados da Pesquisa O/D
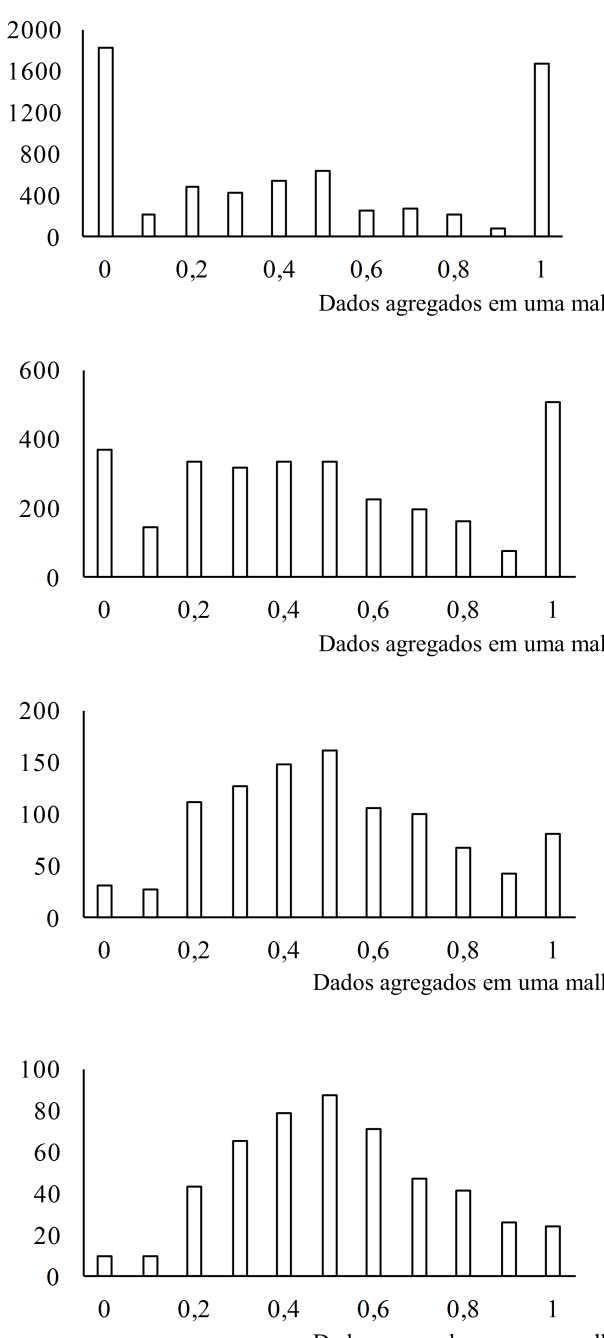

Dados agregados em uma malha com células de 1500 metros
Transformada Gaussiana
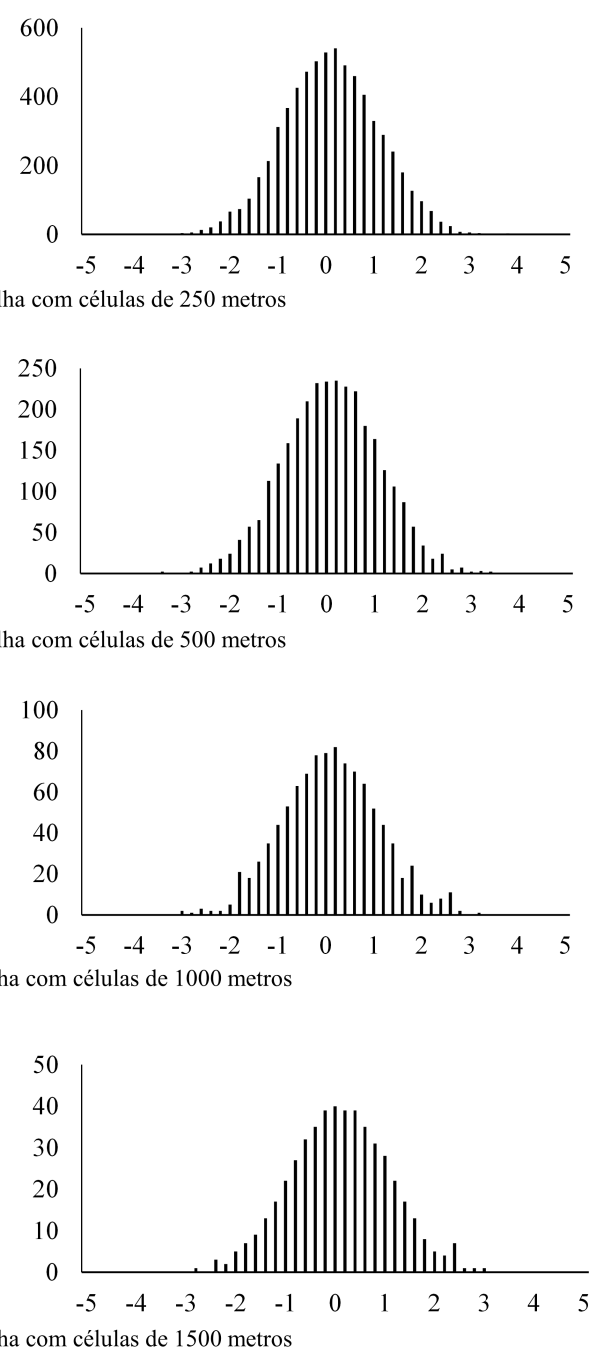

Os histogramas para as malhas de suporte 250 e 500 metros apresentam grande quantidade de taxas nulas e valores iguais a 1. Isso ocorre, pois os dados foram agregados por unidades de área com, muitas vezes, apenas um domicílio. A normalidade é verificada com maior nitidez em malhas de suporte maior que 1000 metros.

A Figura 5.11 apresenta os semivariogramas experimentais dos dados da Pesquisa O/D agregados a partir dos dados domiciliares, para cada malha estudada. Novamente, 
percebe-se que as variâncias entre pares de observações são maiores nos suportes mais desagregados.

Figura 5.11 - Semivariogramas experimentais dos dados domiciliares para cada malha estudada e para os dados da Pesquisa O/D agregados por ZTs
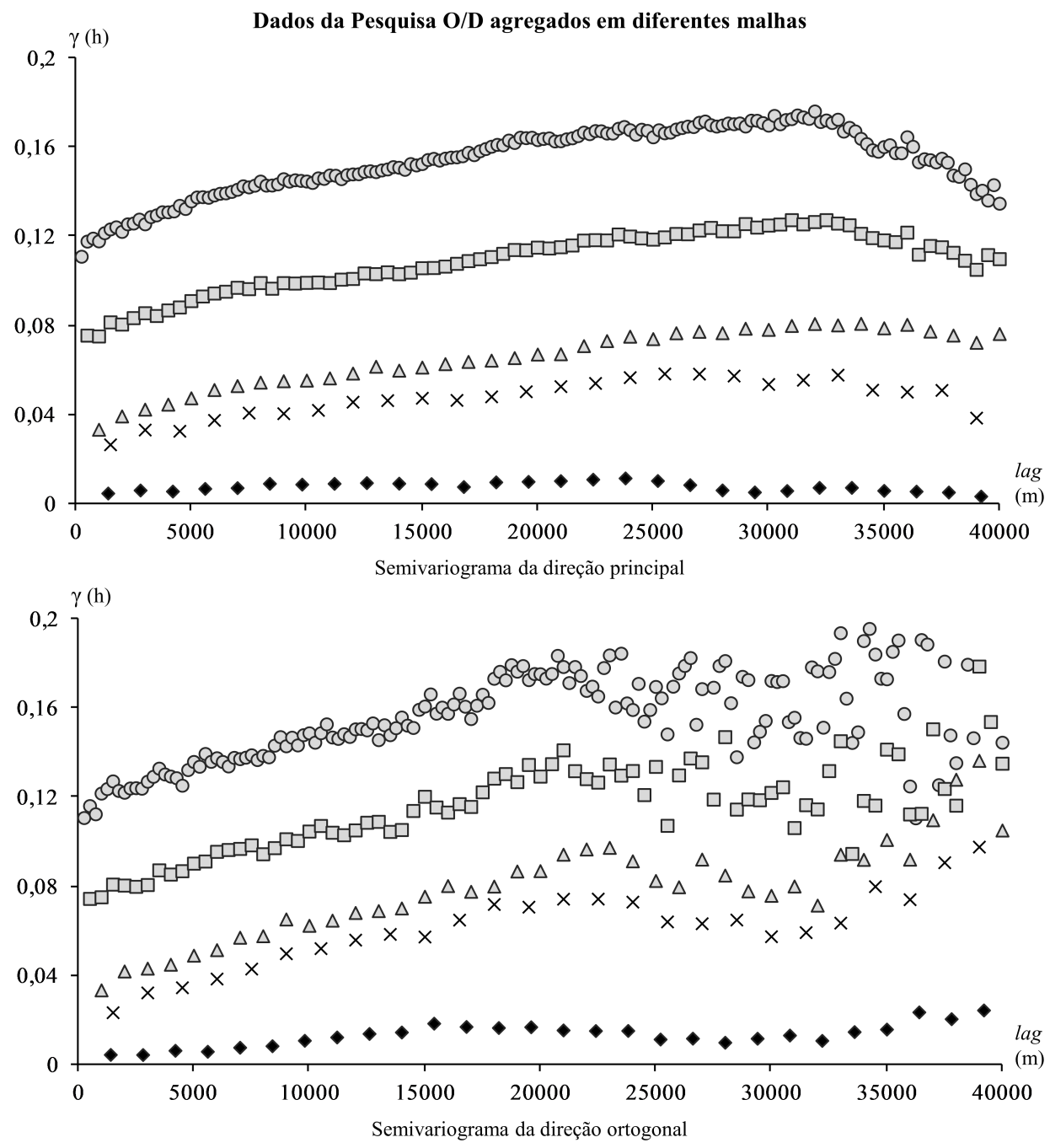

\footnotetext{
O Dados da Pesquisa O/D agregados em uma malha com células de 250 metros

$\triangle$ Dados da Pesquisa O/D agregados em uma malha com células de 1000 metros

Dados da Pesquisa O/D agregados em uma malha

$\times$ Dados da Pesquisa O/D agregados em uma malha com células de 1500 metros

- Dados agregados da Zona de Tráfego (Metrô, 2007)
}

Outro aspecto relevante é observado na grandeza das variâncias quando comparadas aos valores dos semivariogramas dos dados sintéticos. Os dados da Pesquisa O/D associados a diferentes suportes regulares produzem maiores variâncias.

Ao comparar estes resultados (provenientes da Pesquisa O/D e associados a diferentes malhas) com os semivariogramas dos dados da Pesquisa O/D associados a ZTs, tem-se maior desvio ainda, tendo em vista que as variâncias são maiores do que as obtidas pelos dados sintéticos. Essa observação é interessante, pois demonstra que a associação 
de dados sintéticos a áreas regulares é mais conveniente do que a agregação dos próprios dados domiciliares da Pesquisa O/D a áreas irregulares, uma vez que esta acarreta maior perda de informação espacial. Na Figura 5.12 estão representados os semivariogramas experimentais e ajustados, considerando a transformada gaussiana dos dados da Pesquisa Origem/Destino, agregados por malhas regulares.

Figura 5.12 - Semivariogramas experimentais e ajustados da transformada gaussiana dos dados domiciliares
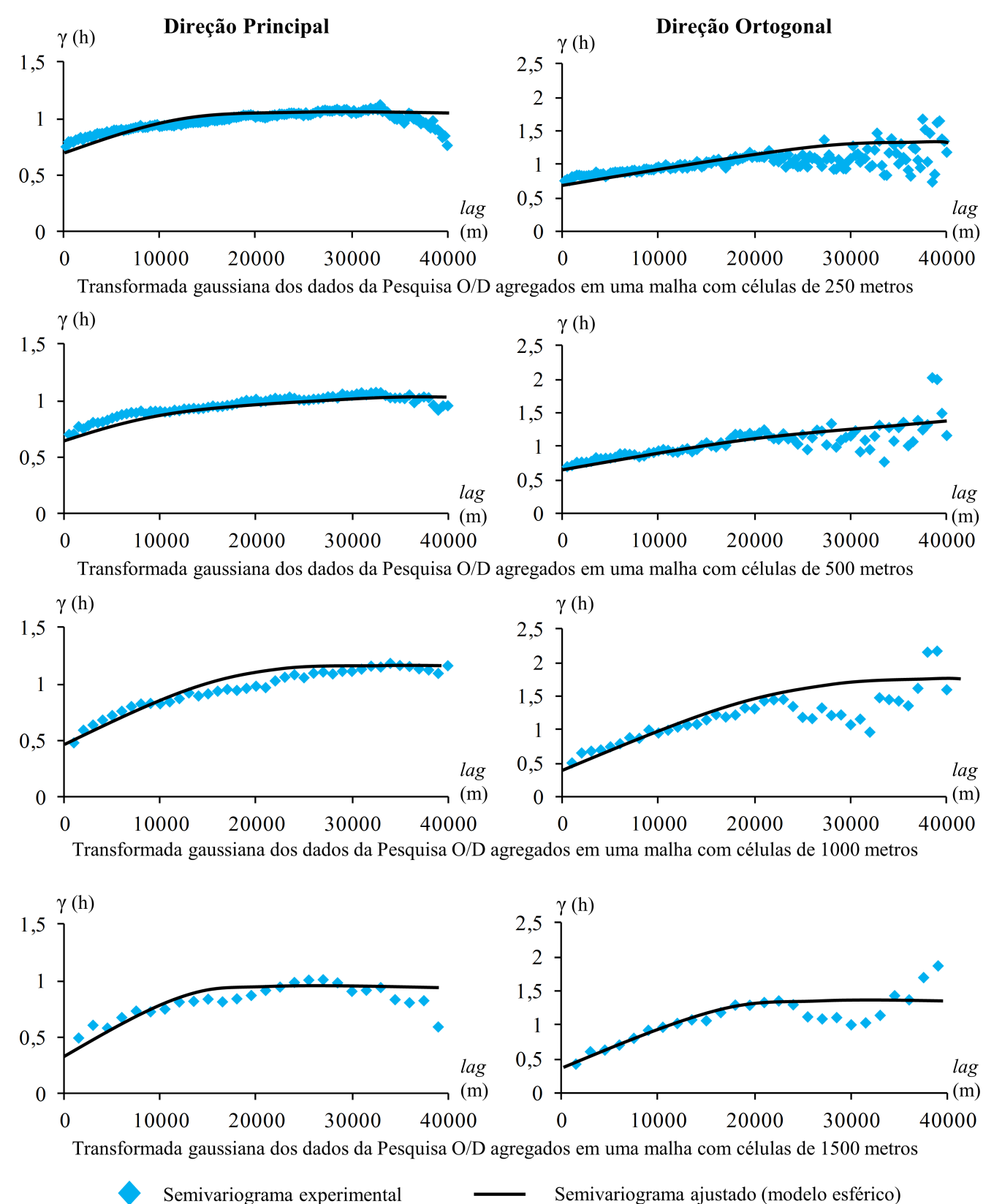

Os semivariogramas experimentais e ajustados da transformada gaussiana dos dados da Pesquisa O/D, agregados por malhas regulares, apresentaram estrutura bem 
definida para todas as malhas. O modelo teórico utilizado foi o esférico, variando o patamar e a amplitude para cada caso estudado, conforme a Figura 5.12.

Em geral, os valores calculados nos semivariogramas ortogonais para as malhas mais desagregadas, considerando distâncias lag entre pares de observações acima de 20 quilômetros, se apresentaram mais dispersos do que os valores dos semivariogramas da direção principal. Isso mostra que o eixo Norte-Sul do município de São Paulo constitui um padrão bem definido de estacionariedade de semivariograma em função de grandes distâncias entre observações.

A Tabela 5.1 sumariza as estatísticas descritivas dos grupos de informações utilizados neste trabalho.

Tabela 5.1 - Medidas estatísticas descritivas da variável de estudo para os grupos de informações utilizados

\begin{tabular}{|c|c|c|c|c|c|c|c|c|c|}
\hline \multirow[b]{2}{*}{$\begin{array}{l}\text { Malha } \\
\text { (m) }\end{array}$} & \multirow[b]{2}{*}{ Dado } & \multirow{2}{*}{$\begin{array}{c}\# \\
\text { Registros* }\end{array}$} & \multicolumn{7}{|c|}{ Medida Estatística } \\
\hline & & & Média & $\begin{array}{l}\text { Desvio } \\
\text { Padrão }\end{array}$ & Mínimo & $\begin{array}{c}\text { Primeiro } \\
\text { Quartil }\end{array}$ & Mediana & $\begin{array}{c}\text { Terceiro } \\
\text { Quartil }\end{array}$ & Máximo \\
\hline \multirow{2}{*}{250} & Domiciliar & 6619 & 0,44 & 0,39 & 0 & 0 & 0,35 & 1 & 1 \\
\hline & Sintético & 18563 & 0,43 & 0,20 & 0 & 0,28 & 0,43 & 0,57 & 1 \\
\hline \multirow{2}{*}{500} & Domiciliar & 2999 & 0,46 & 0,33 & 0 & 0,18 & 0,41 & 0,70 & 1 \\
\hline & Sintético & 4990 & 0,44 & 0,19 & 0 & 0,30 & 0,45 & 0,58 & 1 \\
\hline \multirow{2}{*}{1000} & Domiciliar & 1002 & 0,47 & 0,26 & 0 & 0,26 & 0,44 & 0,64 & 1 \\
\hline & Sintético & 1378 & 0,46 & 0,18 & 0 & 0,32 & 0,47 & 0,60 & 1 \\
\hline \multirow{2}{*}{1500} & Domiciliar & 503 & 0,47 & 0,24 & 0 & 0,29 & 0,46 & 0,62 & 1 \\
\hline & Sintético & 659 & 0,47 & 0,17 & 0,10 & 0,33 & 0,48 & 0,60 & 1 \\
\hline irregular & $\begin{array}{l}\text { Domiciliar } \\
\text { por ZT }\end{array}$ & 308 & 0,30 & 0,10 & 0,07 & 0,23 & 0,30 & 0,37 & 0,62 \\
\hline
\end{tabular}

Os dados domiciliares provenientes da Pesquisa O/D (METRÔ, 2007) possuem menor número de registros em comparação aos dados sintéticos gerados neste trabalho. Outro ponto importante é observado nos valores extremos dos dados irregulares (dados domiciliares agregados por ZT), uma vez que estes possuem valores mínimos para as taxas de viagens por transporte público iguais a $7 \%$ e valores máximos iguais a $62 \%$. Enquanto isso, os dados sintéticos e dados domiciliares, agregados pelas unidades de área estudadas, possuem valores mínimos de $0 \%$ e máximos de $100 \%$. Apesar disso, nota-se que os dados domiciliares, em geral, apresentam grande variabilidade, tendo em vista que os valores de desvio padrão são superiores aos vistos para os dados sintéticos.

Até esta subseção, foram apresentados os métodos de tratamento de dados para obtenção das bases utilizadas nos métodos propostos e comparativos, explanados nas seções seguintes. 


\subsection{MÉTODOS PROPOSTOS}

As subseções seguintes apresentam os resultados obtidos pela SSG de cada método proposto MP1 e MP2. Vale ressaltar que esses resultados representam a variável de estudo, em razão do processo de backtransforming, que permitiu converter a distribuição gaussiana - transformada gaussiana - na distribuição original da variável.

\subsubsection{MP1}

Para o MP1, foram calculadas 500 realizações, por malha regular, através dos semivariogramas deconvoluídos e dos dados sintéticos (valores médios das configurações de dados sintéticos). A Figura 5.13 apresenta os resultados de variância média entre os valores de cada célula em função do número de realizações (malhas 250 e 1500 metros). Estes gráficos de variabilidade permitem avaliar se o número de realizações é suficiente para representar os resultados obtidos.

Figura 5.13 - Gráficos de variabilidade (variância média vs. o número de realizações) para o MP1
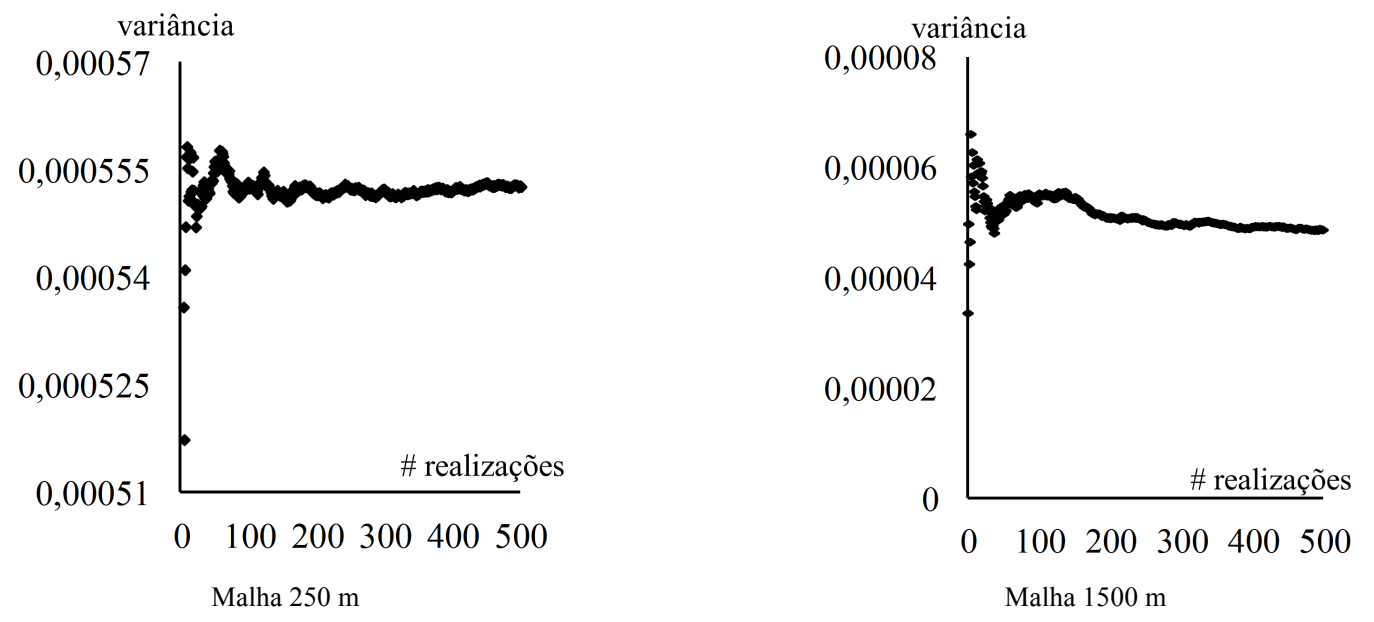

Para este estudo de caso, o cálculo de 500 realizações é visto como um número conservador, uma vez que as variâncias se mostram suficientemente constantes a partir de 300 realizações. O Apêndice $D$ contém as demais análises de variâncias médias em função do número de realizações para todos os casos avaliados neste trabalho. As Figuras $5.14 \mathrm{e}$ 5.15 apresentam os mapas estatísticos resultantes da aplicação da SSG ao MP1 para as malhas de suporte 250 e 1500 metros, respectivamente.

Para fins de análise, foram apresentados os resultados para as malhas com maior e menor agregação. Os demais resultados encontram-se no Apêndice E. 
Figura 5.14 - Análise estatística das realizações calculadas por SSG para o MP1 (Malha 250 m)

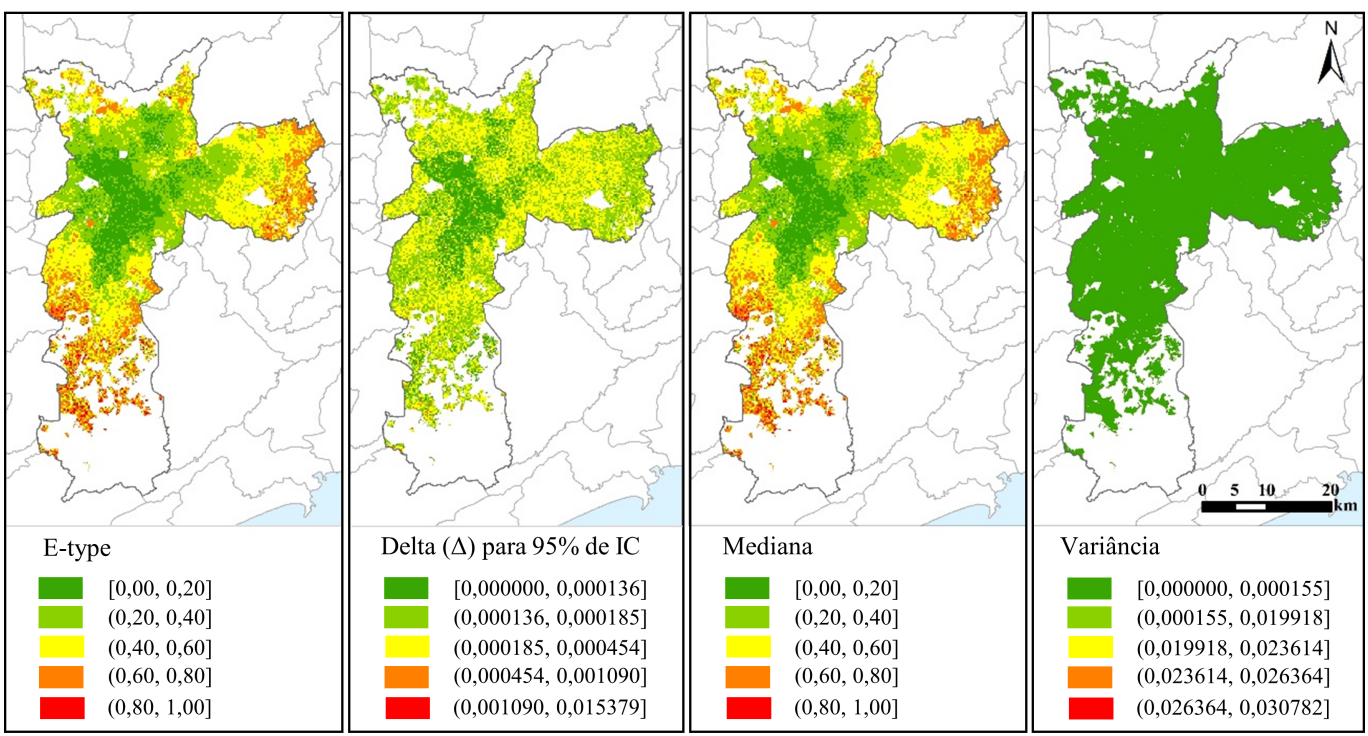

Figura 5.15 - Análise estatística das realizações calculadas por SSG para o MP1 (Malha 1500 m)

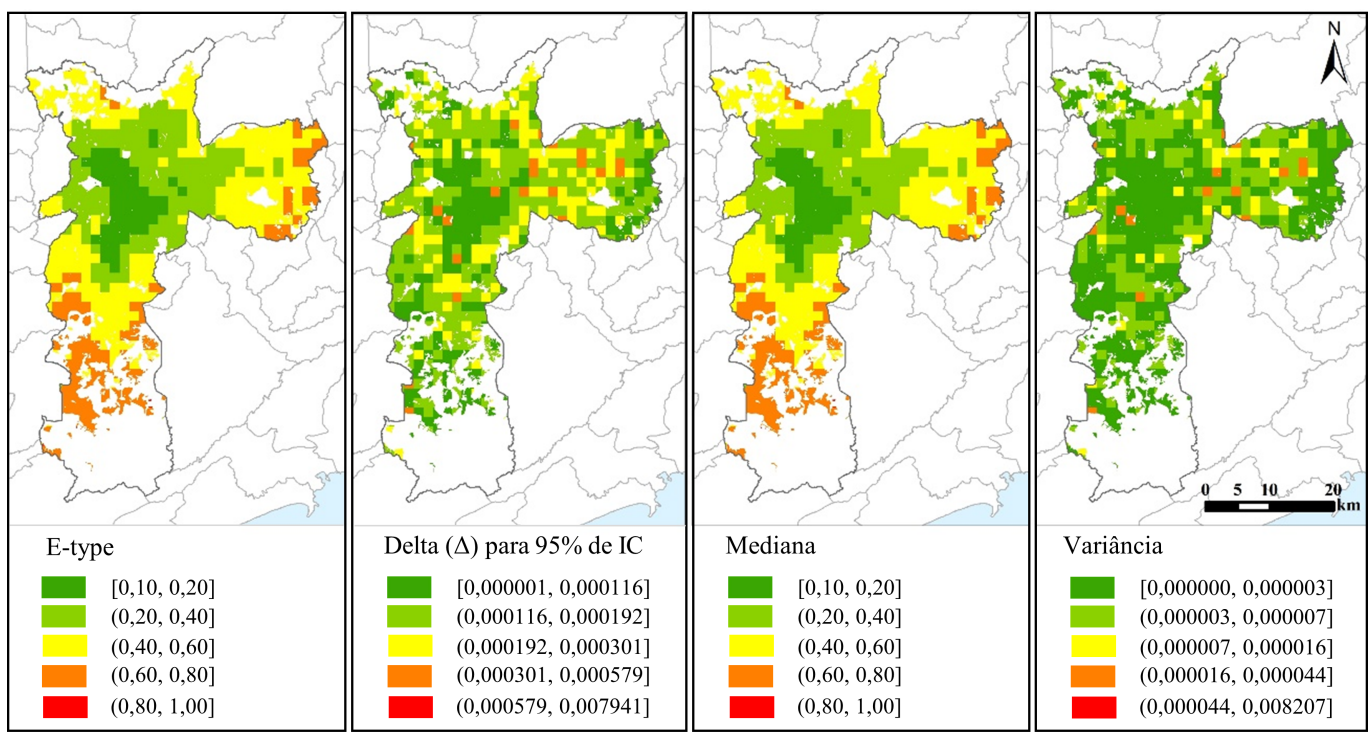

Os mapas e-type e de mediana, apesar dos aspectos de suavização mais acentuados no mapa agregado, mostram resultados com padrões similares. Os mapas com as medidas de incerteza (intervalo de confiança e de variância) possibilitam identificar valores de grandeza maiores para o mapa mais desagregado, conforme previsto pela análise de semivariogramas. Além disso, observa-se que a intra-variância para o suporte de 250 metros é baixa. Isto é, o mapa de variância é composto por células de valores similares. Os valores maiores de variância, conforme a legenda, referem-se a células dispersas ao sul do município de São Paulo e que, apesar de existirem, não se mostram significantes quando analisada a dimensão da área de estudo. Sob outra perspectiva, o mapa de variância para a malha de 1500 metros apresenta maior variabilidade entre as células. 


\subsubsection{MP2}

As Figuras 5.16 e 5.17 apresentam os mapas estatísticos resultantes da aplicação da SSG ao MP2 para as malhas de suporte 250 e 1500 metros, respectivamente. O Apêndice $F$ contém os mapas estatísticos para as malhas 500 e 1000 metros.

Figura 5.16 - Análise estatística das realizações calculadas por SSG para o MP2 (Malha 250 m)

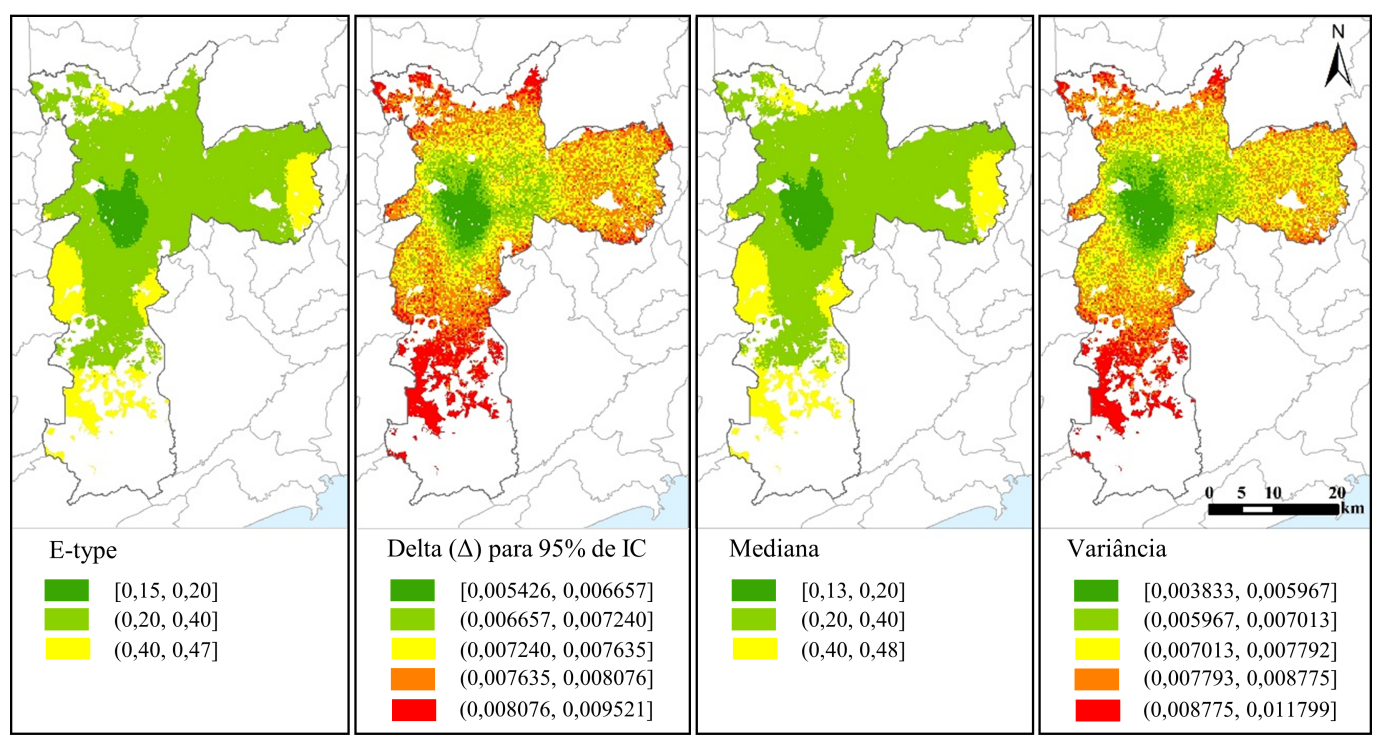

Figura 5.17 - Análise estatística das realizações calculadas por SSG para o MP2 (Malha 1500 m)
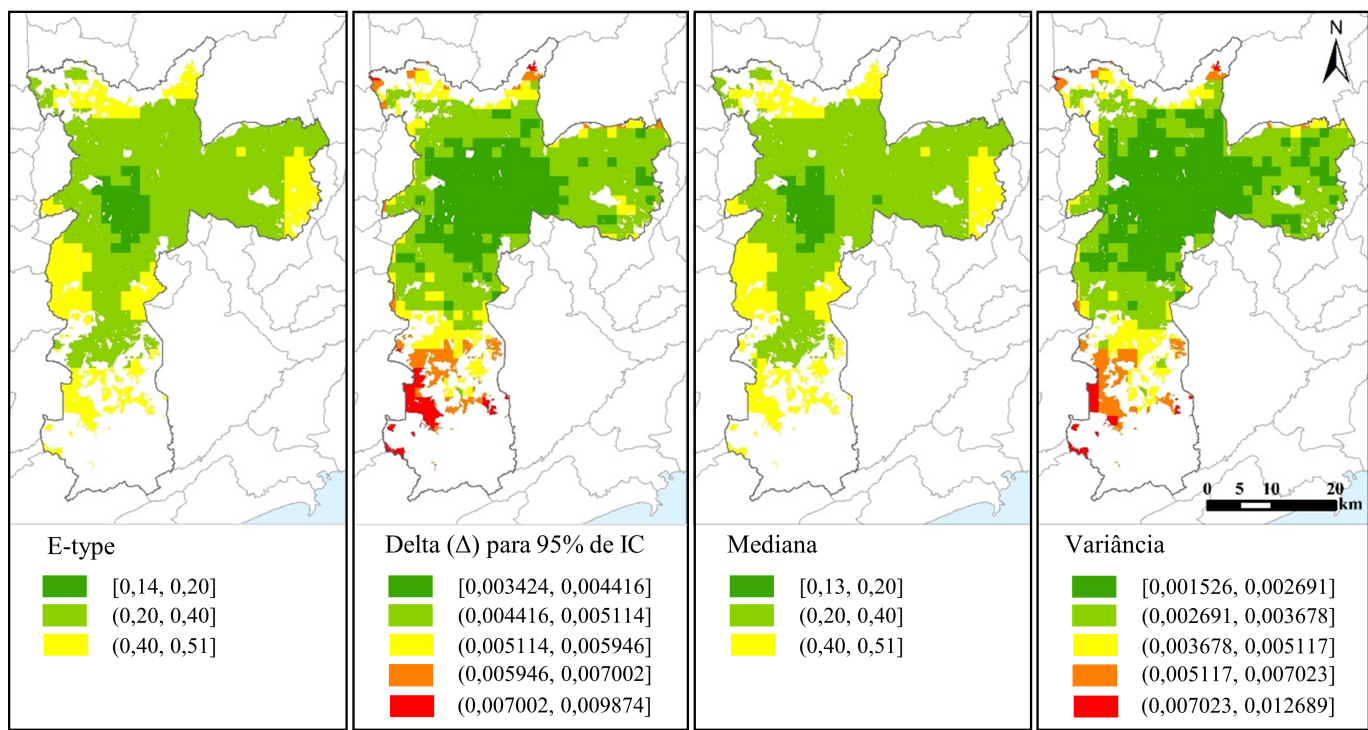

Para o MP2, foram calculadas 500 realizações através dos semivariogramas deconvoluídos e dos dados da Pesquisa O/D por ZT. As médias das realizações (e-type) não atingem os valores extremos, nem ao menos para o caso mais desagregado. Dessa forma, nota-se inconsistência do resultado ao sugerir que não existam células onde sejam realizadas apenas (ou que não sejam realizadas) viagens por transporte público dentre as viagens produzidas. 
Novamente, os mapas indicam maior variância média para o suporte mais desagregado. Levando em conta apenas a desagregação de suporte 250 metros, nota-se que existe grande quantidade de áreas com maiores variâncias e maiores intervalos de confiança quando comparadas aos resultados do suporte de 1500 metros. Este efeito é contrário aos resultados obtidos para o MP1. Ou seja, as intra-variâncias do suporte de 250 metros são superiores às intra-variâncias obtidas pelo suporte de 1500 metros.

\subsection{MÉTODOS COMPARATIVOS}

As subseções seguintes apresentam os mapas estatísticos resultantes do MC1 e da SSG pelo MC2.

\subsubsection{MC1}

Os mapas do MC1 para cada malha estudada são exibidos pela Figura 5.18. Podese observar que, os valores da Pesquisa $O / D$, mesmo agregados em malhas de suporte maior, não abrangem toda a área de estudo. Isto acontece, devido à restrição no número de observações da amostra, que compõe 15.759 domicílios pesquisados - enquanto a amostra obtida pelos microdados compreende informações sobre 172.627 domicílios.

Figura 5.18-MC1 (Malhas 250, 500, 1000 e 1500 m)

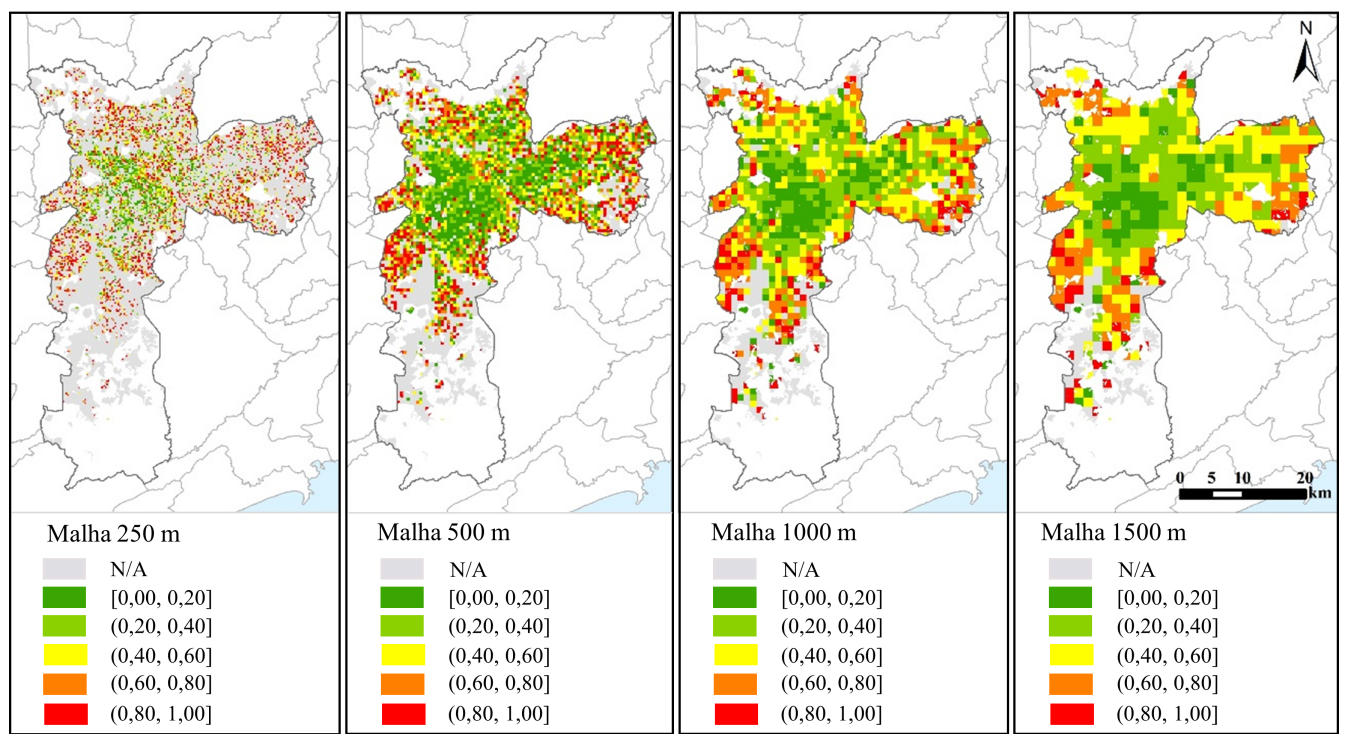




\subsubsection{MC2}

O MC2 utiliza os dados do MC1 e o semivariograma obtido pela agregação (em malhas) dos dados domiciliares da Pesquisa O/D. As Figuras 5.19 e 5.20 mostram os mapas estatísticos resultantes da SSG para o MC2, considerando os suportes de 250 e de 1500 metros, respectivamente. O Apêndice G mostra os resultados para as malhas 500 e 1000 metros.

Figura 5.19 - Análise estatística das realizações calculadas por SSG para o MC2 (Malha 250 m)

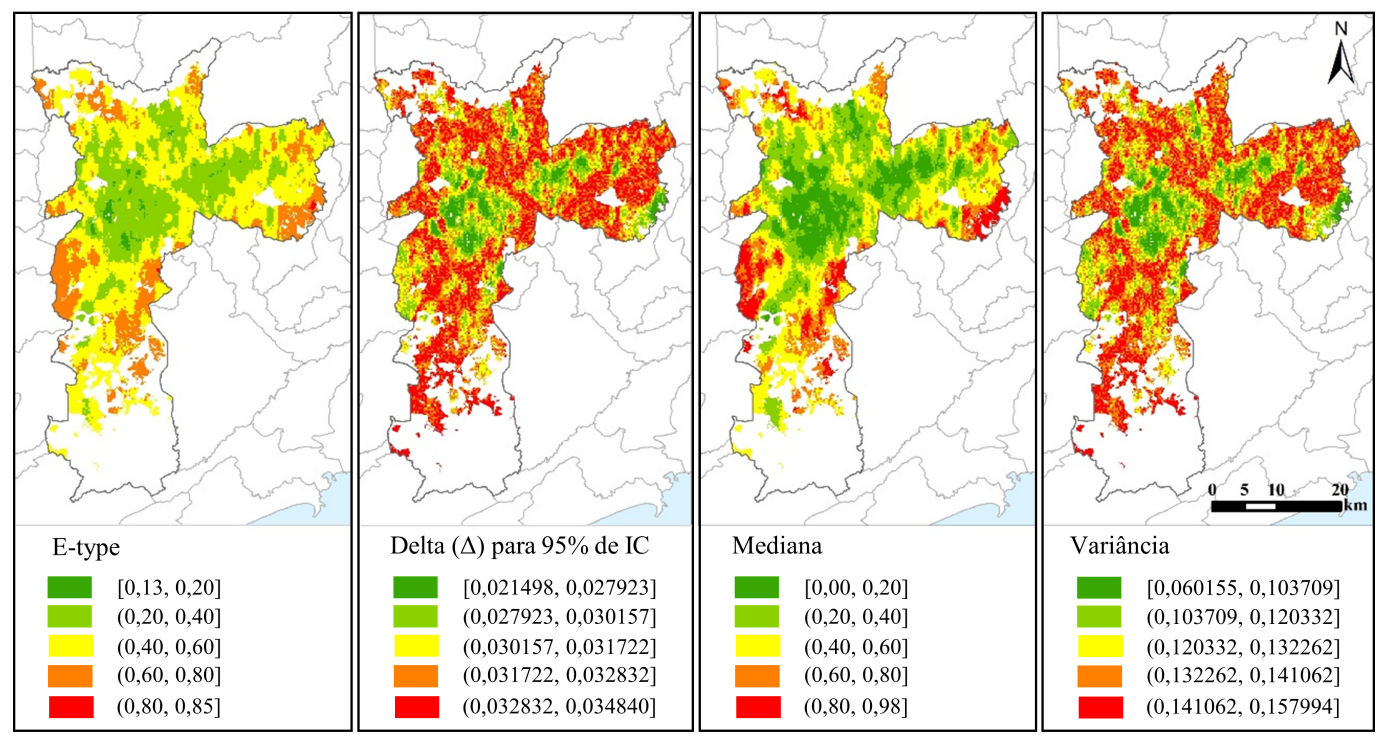

Figura 5.20 - Análise estatística das realizações calculadas por SSG para o MC2 (Malha 1500 m)

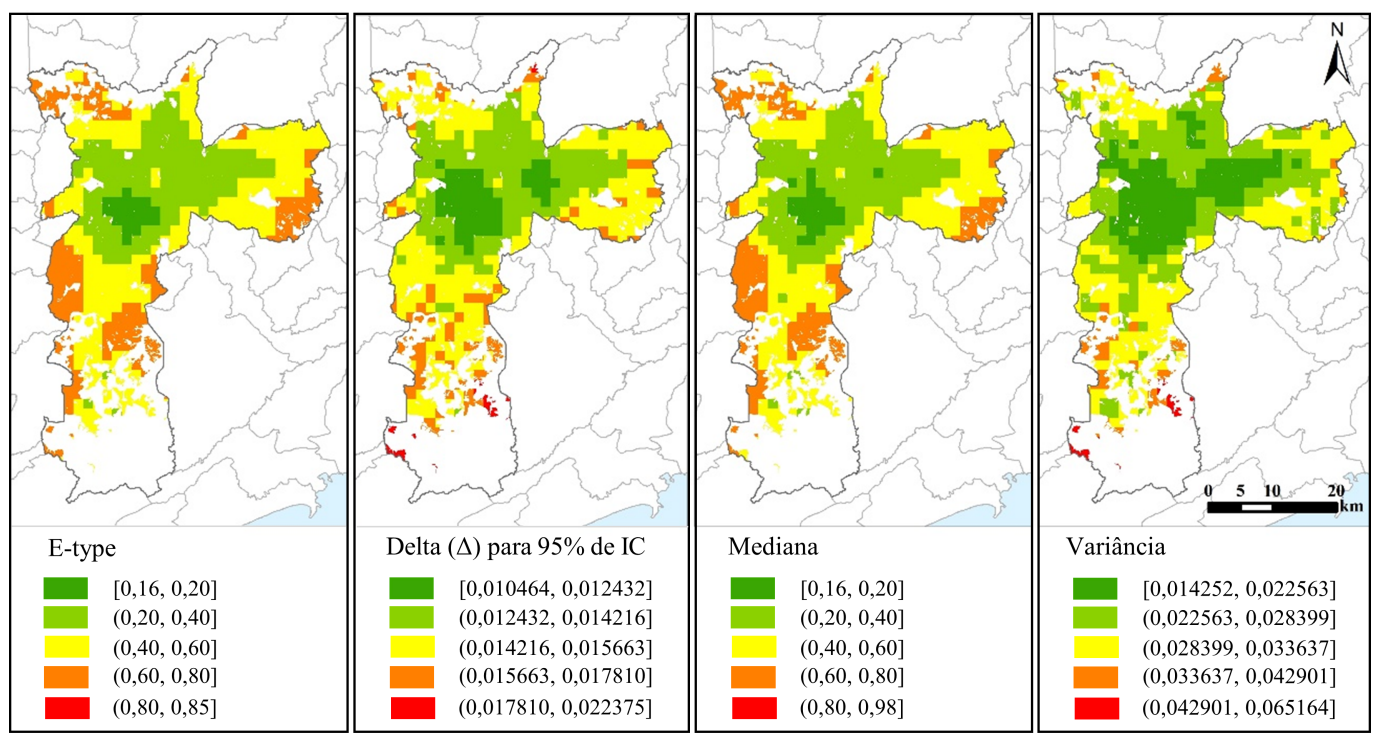

As células dos mapas e-type e mediana não atingem os valores extremos de 0 ou 1 , independentemente do suporte utilizado. Os mapas são similares, com exceção aos 
mapas de mediana, que, para o suporte de 250 metros, apresentam maiores quantidades de células com representatividade de taxas de transporte público acima de $80 \%$.

Ao avaliar os resultados de incerteza, nota-se que as malhas de maior suporte possuem intra-variâncias inferiores às malhas de menor suporte. Da mesma forma, as variâncias entre os diferentes suportes é maior para as malhas mais desagregadas. Este padrão foi previamente observado nos mapas do MP2.

\subsection{MAPAS E ESTATÍSTICAS UNIVARIADAS}

A Tabela 5.2 exibe as estatísticas univariadas de todos os grupos de informações calculados nesta pesquisa.

Tabela 5.2 - Análise estatística univariada dos resultados (considerando 500 realizações)

\begin{tabular}{|c|c|c|c|c|c|c|c|c|c|}
\hline \multirow{2}{*}{$\begin{array}{l}\text { Malha } \\
(\mathrm{m})\end{array}$} & \multirow[b]{2}{*}{ Método } & \multirow{2}{*}{$\begin{array}{c}\# \\
\text { Registros* }\end{array}$} & \multicolumn{7}{|c|}{ Medida Estatística } \\
\hline & & & Média & $\begin{array}{l}\text { Desvio } \\
\text { Padrão }\end{array}$ & Mínimo & $\begin{array}{l}\text { Primeiro } \\
\text { Quartil }\end{array}$ & Mediana & $\begin{array}{c}\text { Terceiro } \\
\text { Quartil }\end{array}$ & Máximo \\
\hline \multirow{4}{*}{250} & $M P 1$ & 18944 & 0,43 & 0,20 & 0 & 0,28 & 0,43 & 0,57 & 1 \\
\hline & MP2 & 18944 & 0,34 & 0,11 & 0,07 & 0,26 & 0,34 & 0,43 & 0,62 \\
\hline & $M C 1$ & 6619 & 0,44 & 0,39 & 0 & 0 & 0,35 & 1 & 1 \\
\hline & MC2 & 18944 & 0,49 & 0,39 & 0 & 0,09 & 0,49 & 0,96 & 1 \\
\hline \multirow{4}{*}{500} & $M P 1$ & 5076 & 0,45 & 0,19 & 0 & 0,30 & 0,45 & 0,58 & 1 \\
\hline & MP2 & 5076 & 0,35 & 0,11 & 0,07 & 0,28 & 0,35 & 0,43 & 0,62 \\
\hline & $M C 1$ & 2999 & 0,46 & 0,33 & 0 & 0,18 & 0,41 & 0,70 & 1 \\
\hline & MC2 & 5076 & 0,49 & 0,32 & 0 & 0,22 & 0,47 & 0,76 & 1 \\
\hline \multirow{4}{*}{1000} & MP1 & 1398 & 0,46 & 0,18 & 0 & 0,32 & 0,47 & 0,60 & 1 \\
\hline & MP2 & 1398 & 0,36 & 0,10 & 0,07 & 0,29 & 0,36 & 0,44 & 0,62 \\
\hline & MC1 & 1002 & 0,47 & 0,26 & 0 & 0,26 & 0,44 & 0,64 & 1 \\
\hline & MC2 & 1398 & 0,50 & 0,25 & 0 & 0,31 & 0,48 & 0,67 & 1 \\
\hline \multirow{4}{*}{1500} & $M P 1$ & 663 & 0,47 & 0,17 & 0,10 & 0,33 & 0,49 & 0,60 & 1 \\
\hline & MP2 & 663 & 0,36 & 0,10 & 0,07 & 0,29 & 0,36 & 0,44 & 0,62 \\
\hline & MC1 & 503 & 0,47 & 0,24 & 0 & 0,29 & 0,46 & 0,62 & 1 \\
\hline & MC2 & 663 & 0,47 & 0,17 & 0,10 & 0,33 & 0,49 & 0,60 & 1 \\
\hline
\end{tabular}

*registros não nulos

Dados obtidos pela SSG (MP1, MP2 e MC2) possuem maior quantidade de registros. Em contrapartida, o $M C 1$, que utiliza os dados da Pesquisa $O / D$ associados às diferentes malhas, possui menor quantidade de observações.

O método MP2 possui células de valores mínimos de taxa de transporte público iguais a $7 \%$ e máximos de $62 \%$, enquanto o MP1 e os métodos comparativos possuem valores mínimos de $0 \%$ e máximos de $100 \%$.

Em geral, nota-se que as estatísticas dos métodos tendem a ser mais similares, à medida em que o suporte seja mais agregado. 
Os histogramas dos valores e-type para as quatro malhas estão representados pela Figura 5.21.

Figura 5.21 - Histograma dos valores e-type das 500 realizações para cada SSG

E-type das 500 realizações por Simulação Sequencial Gaussiana
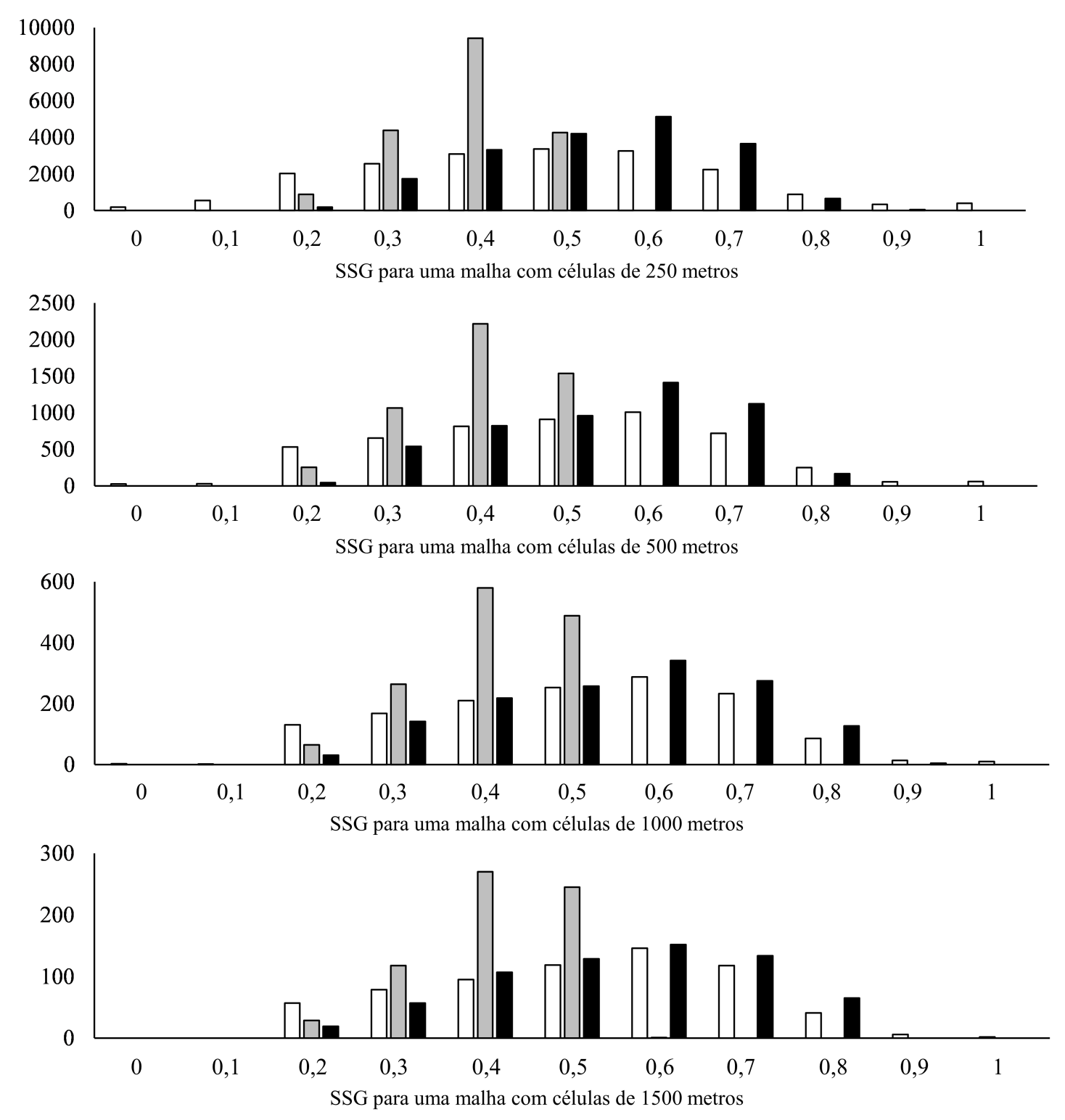

MP1: SSG dos dados sintéticos + semivariograma deconvoluído

$\square$ MP2: SSG dos dados agregados por Zonas de Tráfego + semivariograma deconvoluído

- MC2: SSG dos dados da Pesquisa O/D

Percebe-se que a distribuição dos valores para o MP2 possui maior divergência em relação à distribuição para o $M C 2$. Em contrapartida, a distribuição do $M P 1$ se mostra mais similar à distribuição do $M C 2$, que tende a se aproximar mais da curva normal. 
Com relação aos dados utilizados como input às simulações, a Figura 5.22 apresenta o número de observações por célula para cada grupo de informações utilizado nesta pesquisa. Os microdados são relacionados a Áreas de Ponderação; os dados sintéticos estão agregados por célula; e os dados da Pesquisa O/D estão associados a domicílios, que, por sua vez, foram agregados: por ZTs e por células. São apresentados os valores médios dos dados sintéticos e dos dados agregados da Pesquisa O/D para a malha de 1500 metros.

Figura 5.22 - Quantidade de domicílios entrevistados por célula

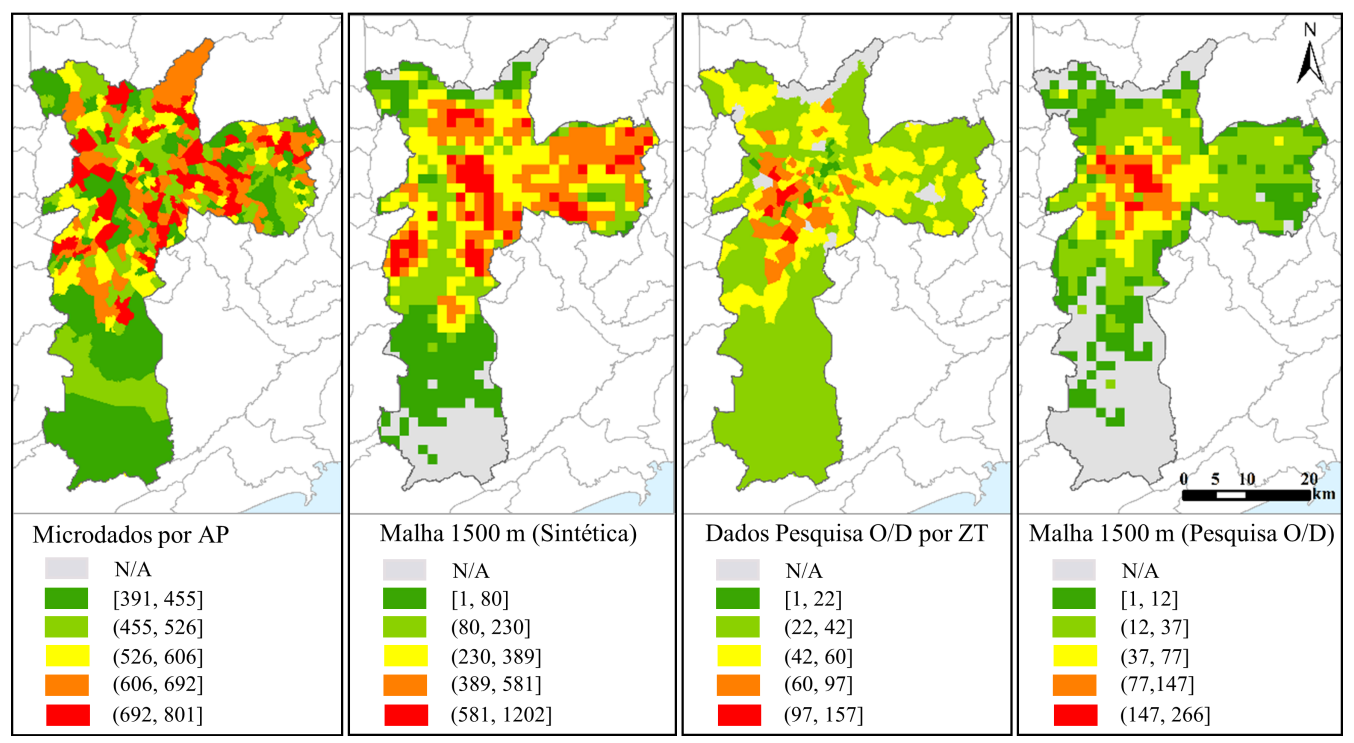

Os mapas dos domicílios por células mostram que os agrupamentos de domicílios são distintos para as duas bases. Enquanto os dados provenientes da Pesquisa O/D concentram a maior quantidade de domicílios pesquisados no miolo do município de São Paulo; os microdados possuem informações de domicílios em regiões mais esparsas. Além disso, salienta-se, novamente, que os microdados possuem maior quantidade de observações e que os dados associados a unidades de áreas maiores apresentam maiores efeitos de suavização das informações.

\subsection{ESTATÍSTICAS COMPARATIVAS}

A Tabela 5.3 resume as medidas estatísticas de desempenho entre os métodos $M P 1 / M P 2$ versus $M C 1 / M C 2$.

O MC2 fornece a melhor métrica comparativa, uma vez que as medidas de desempenho sugerem menores erros e maiores correlações. Ao analisar os resultados 
estatísticos por malha, o MP1 vs. MC2 produz, em geral, os menores erros, principalmente em termos de erro quadrático médio e de erro percentual médio absoluto - medidas estas que avaliam a acurácia; enquanto a análise MP2 vs. MC2 apresenta as maiores correlações, com exceção para a malha de 1000 metros.

Ao analisar os resultados em busca da malha mais adequada e com melhor desempenho, pode-se concluir que não houve associação entre nível de desagregação e maiores correlações para o MP2 vs. MC2, tendo em vista que todas as correlações variaram entre 0,7 e 0,8. No caso da relação MP1 vs. MC2, as malhas com suporte 250 e 500 metros apresentaram as menores correlações, apesar de serem também consideradas satisfatórias. A maior correlação foi de 0,806 , para a malha de 1000 metros.

Tabela 5.3 - Análise estatística comparativa entre valores e-type das 500 realizações

\begin{tabular}{|c|c|c|c|c|c|}
\hline $\begin{array}{c}\text { Malha } \\
(\mathrm{m})\end{array}$ & Medida Estatística & $\begin{array}{c}\text { MP1 vs. } \\
\text { MC1 }\end{array}$ & $\begin{array}{c}\text { MP1 vs. } \\
\text { MC2 }\end{array}$ & $\begin{array}{c}M P 2 \text { vs. } \\
\text { MC1 }\end{array}$ & $\begin{array}{c}\text { MP2 vs. } \\
\text { MC2 }\end{array}$ \\
\hline \multirow{7}{*}{250} & Desvio Médio & 0,094 & 0,054 & 0,135 & 0,145 \\
\hline & Desvio Médio Absoluto & 0,313 & 0,139 & 0,328 & 0,152 \\
\hline & Erro Quadrático Médio & 0,145 & 0,031 & 0,157 & 0,031 \\
\hline & Raiz do Erro Quadrático Médio & 0,381 & 0,177 & 0,396 & 0,175 \\
\hline & Erro Percentual Médio & 0,099 & 0,107 & 0,119 & 0,267 \\
\hline & Erro Percentual Médio Absoluto & 0,423 & 0,302 & 0,443 & 0,293 \\
\hline & Correlação & 0,347 & 0,553 & 0,362 & 0,705 \\
\hline \multirow{7}{*}{500} & Desvio Médio & 0,076 & 0,046 & 0,134 & 0,142 \\
\hline & Desvio Médio Absoluto & 0,243 & 0,113 & 0,265 & 0,146 \\
\hline & Erro Quadrático Médio & 0,094 & 0,021 & 0,112 & 0,028 \\
\hline & Raiz do Erro Quadrático Médio & 0,306 & 0,144 & 0,335 & 0,167 \\
\hline & Erro Percentual Médio & $-0,085$ & 0,098 & $-0,012$ & 0,263 \\
\hline & Erro Percentual Médio Absoluto & 0,531 & 0,244 & 0,545 & 0,282 \\
\hline & Correlação & 0,455 & 0,684 & 0,444 & 0,800 \\
\hline \multirow{7}{*}{1000} & Desvio Médio & 0,131 & 0,040 & 0,059 & 0,144 \\
\hline & Desvio Médio Absoluto & 0,202 & 0,104 & 0,172 & 0,148 \\
\hline & Erro Quadrático Médio & 0,070 & 0,018 & 0,052 & 0,031 \\
\hline & Raiz do Erro Quadrático Médio & 0,264 & 0,134 & 0,228 & 0,175 \\
\hline & Erro Percentual Médio & 0,040 & 0,255 & $-0,096$ & 0,077 \\
\hline & Erro Percentual Médio Absoluto & 0,461 & 0,077 & 0,464 & 0,255 \\
\hline & Correlação & 0,554 & 0,806 & 0,551 & 0,714 \\
\hline \multirow{7}{*}{1500} & Desvio Médio & 0,051 & 0,032 & 0,133 & 0,140 \\
\hline & Desvio Médio Absoluto & 0,143 & 0,100 & 0,185 & 0,144 \\
\hline & Erro Quadrático Médio & 0,038 & 0,017 & 0,057 & 0,030 \\
\hline & Raiz do Erro Quadrático Médio & 0,194 & 0,129 & 0,239 & 0,173 \\
\hline & Erro Percentual Médio & $-0,024$ & 0,059 & 0,120 & 0,247 \\
\hline & Erro Percentual Médio Absoluto & 0,347 & 0,209 & 0,383 & 0,260 \\
\hline & Correlação & 0,610 & 0,710 & 0,596 & 0,776 \\
\hline
\end{tabular}

Apesar da inconstância dos resultados de correlação em comparação ao tamanho do suporte, nota-se que, em geral, malhas mais agregadas apresentam maior acurácia ao avaliar as medidas de raiz do erro quadrático médio e de erro percentual médio absoluto.

Ao avaliar os resultados de desvio médio e de erro percentual médio, que permitem detectar possíveis tendências de superestimação ou subestimação, nota-se que não existe relação entre enviesamento e tamanho dos suportes. 
Ao final, pode-se afirmar que a análise estatística comparativa entre as malhas, mostrada na Tabela 5.3, não permite avaliar, com solidez, qual método proposto indica melhor desempenho. À vista disso, a escolha do método de desagregação deve ser baseada na disponibilidade de informações, uma vez que os métodos propostos apresentam resultados similares.

A Figura 5.23 apresenta graficamente os desvios médios entre valores e-type através de histogramas.

Figura 5.23 - Histograma dos erros (desvios médios) dos valores e-type das 500 realizações para cada SSG

Erro absoluto dos valores e-type das 500 realizações por Simulação Sequencial Gaussiana
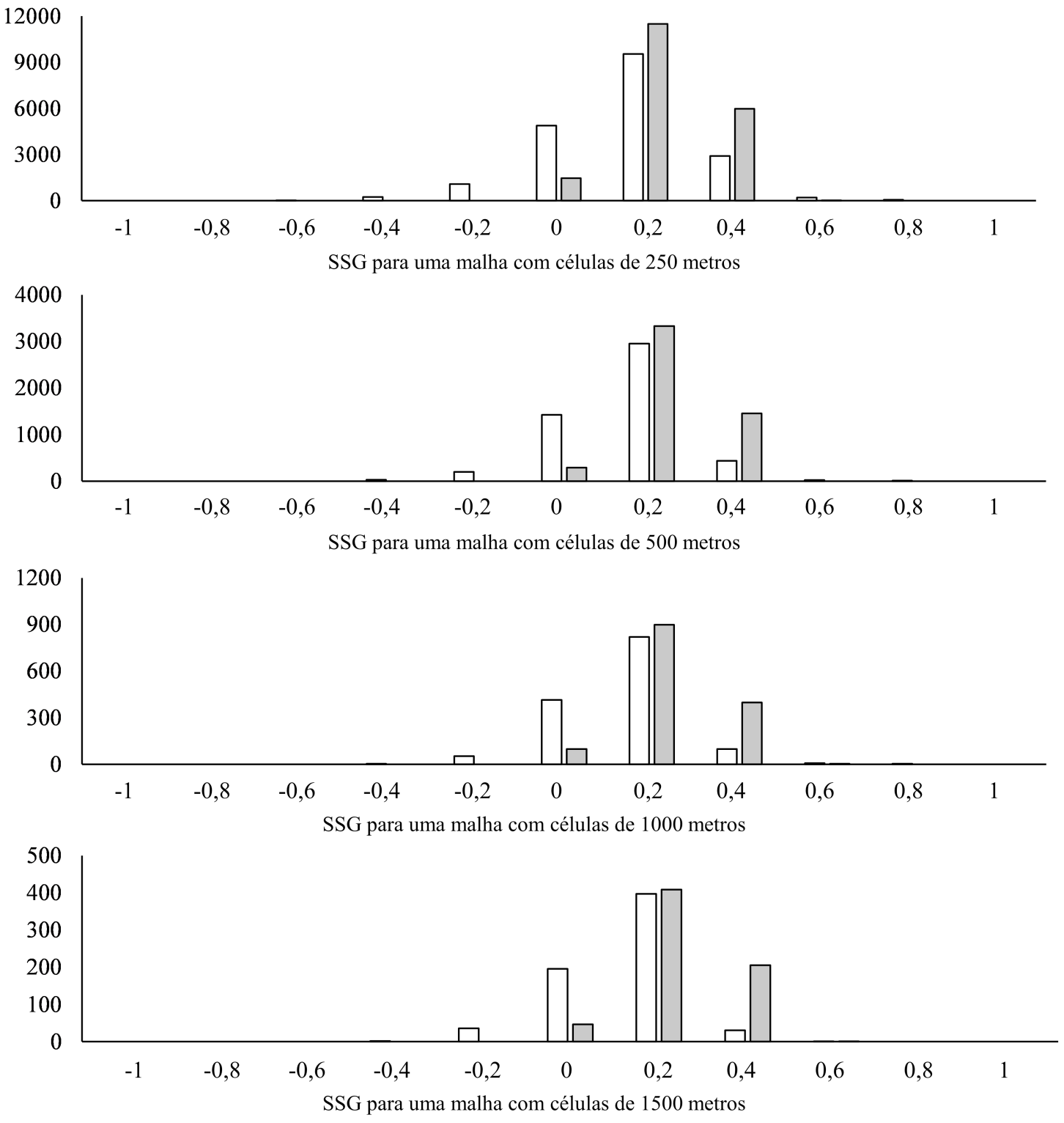

MP1 vs. MC2: Erro absoluto da SSG dos dados sintéticos + semivariograma deconvoluído em relação à SSG dos dados da Pesquisa O/D MP2 vs. MC2: Erro absoluto da SSG dos dados agregados por Zonas de Tráfego + semivariograma deconvoluído
em relação à SSG dos dados da Pesquisa O/D 
Apesar de as comparações serem similares, os erros são relativamente inferiores ao utilizar o MP1, que convenientemente também possui maior quantidade de erros nulos. Ao levar em consideração esta análise e o fato de não utilizar como input os dados da Pesquisa O/D; o MP1 se destaca como método de desagregação mais pertinente aos propósitos desta tese.

Vale salientar ainda que, para os dados sintéticos e procedimento de deconvolução, faz-se necessário o modelo linear calibrado para estimativa da variável de demanda por transportes, uma vez que esta informação não é disponibilizada pelo IBGE.

\subsection{TESTES NÃO PARAMÉTRICOS}

Os testes não paramétricos de distribuição de duas amostras foram realizados considerando os critérios Mann-Whitney e Kolmogorov-Smirnov. A Tabela 5.4 mostra os resultados destes testes.

Tabela 5.4 - Testes não paramétricos de distribuição com valores e-type das 500 realizações

\begin{tabular}{|c|c|c|c|c|c|c|c|}
\hline \multirow{2}{*}{\multicolumn{3}{|c|}{$\begin{array}{c}\text { Métodos } \\
\text { Comparados }\end{array}$}} & \multirow{2}{*}{ Teste } & \multicolumn{4}{|c|}{ Significâncias } \\
\hline & & & & $250 \mathrm{~m}$ & $500 \mathrm{~m}$ & $1000 \mathrm{~m}$ & $1500 \mathrm{~m}$ \\
\hline \multirow{2}{*}{ MP1 } & \multirow[b]{2}{*}{ vs. } & \multirow{2}{*}{ MC1 } & Mann-Whitney & 0 & 0 & 0 & 0,003 \\
\hline & & & Kolmogorov-Smirnov & 0 & 0 & 0 & 0 \\
\hline \multirow{2}{*}{ MP1 } & \multirow[b]{2}{*}{ vs. } & \multirow{2}{*}{ MC2 } & Mann-Whitney & 0 & 0 & 0 & 0,001 \\
\hline & & & Kolmogorov-Smirnov & 0 & 0 & 0 & 0,002 \\
\hline \multirow{2}{*}{$M P 2$} & \multirow[b]{2}{*}{ vs. } & \multirow{2}{*}{ MC1 } & Mann-Whitney & 0 & 0 & 0 & 0 \\
\hline & & & Kolmogorov-Smirnov & 0 & 0 & 0 & 0 \\
\hline \multirow{2}{*}{ MP2 } & \multirow{2}{*}{ vs. } & \multirow{2}{*}{ MC2 } & Mann-Whitney & 0 & 0 & 0 & 0 \\
\hline & & & Kolmogorov-Smirnov & 0 & 0 & 0 & 0 \\
\hline
\end{tabular}

Apesar de as análises apresentadas nas subseções anteriores demonstrarem os aspectos relevantes dos métodos propostos, o teste de hipótese de distribuição entre as amostras não fornece resultados positivos.

Conforme os testes não paramétricos Mann-Whitney e Kolmogorov-Smirnov, as distribuições entre os métodos propostos versus os métodos comparativos não são análogas, uma vez que a hipótese nula (de similaridade entre distribuições populacionais) é rejeitada em todos os casos, considerando um nível de significância de 5\%.

Finalmente, encerra-se este capítulo de resultados e discussões através de um quadro-resumo (Quadro 5.1) dos resultados entre os métodos propostos versus os métodos comparativos, levando-se em conta os quatro critérios considerados (MP1 vs. MC1; MP1 vs. MC2; MP2 vs. MC1; MP2 vs. MC2). 
Quadro 5.1 - Resumo de resultados dos métodos propostos versus métodos comparativos

\begin{tabular}{|c|c|c|c|}
\hline & & MP1 & MP2 \\
\hline \multirow[b]{2}{*}{ 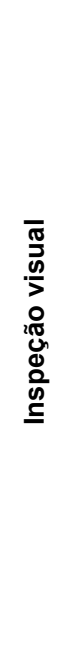 } & 乡 & $\begin{array}{l}\text { O MP1 permite gerar mapas com valores simulados e } \\
\text { calcular incerteza associada (e.g. intervalo de } \\
\text { confiança e variância condicional). O MC1 apresenta } \\
\text { apenas valores médios (suavizados) da amostra, que } \\
\text { não cobre toda a área de estudo. }\end{array}$ & $\begin{array}{c}\text { O MP2 permite gerar mapas com valores simulados e } \\
\text { permite calcular incerteza associada (e.g. intervalo de } \\
\text { confiança e variância condicional). O MC1 apresenta } \\
\text { apenas valores médios (suavizados) da amostra, que } \\
\text { não cobre toda a área de estudo. }\end{array}$ \\
\hline & ญี & $\begin{array}{l}\text { No } M P 1 \text {, os valores de média e mediana possuem } \\
\text { tendências similares, independentemente da malha. } \\
\text { As variâncias e intervalos de confiança são menores. } \\
\text { A variância apresentou-se constante no mapa. No } \\
M C 2 \text {, os valores de média e mediana são } \\
\text { representados por intervalos menores. A malha de } \\
\text { menor suporte tem medianas com valores maiores em } \\
\text { algumas regiões próximas aos limites no município. As } \\
\text { variâncias e intervalos de confiança possuem } \\
\text { grandezas maiores e os maiores valores foram } \\
\text { observados fora do miolo do município de São Paulo. }\end{array}$ & $\begin{array}{l}\text { O MP2 possui valores de média e mediana com } \\
\text { tendências similares, independentemente da malha. } \\
\text { As variâncias e intervalos de confiança possuem } \\
\text { valores menores. A malha de menor suporte } \\
\text { demonstra maiores valores de intervalo de confiança e } \\
\text { de variância fora do miolo de São Paulo. No } M C 2 \text {, os } \\
\text { valores de média e mediana possuem intervalos } \\
\text { menores. A malha de menor suporte tem medianas } \\
\text { com valores maiores em algumas regiões próximas } \\
\text { aos limites no município. As variâncias e intervalos de } \\
\text { confiança possuem grandezas maiores e os maiores } \\
\text { valores foram observados fora do miolo do município. }\end{array}$ \\
\hline \multirow{2}{*}{ 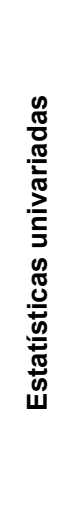 } & $\bar{\Sigma}$ & $\begin{array}{l}\text { O MP1 possui maior número de registros, médias } \\
\text { similares e menores valores de desvio padrão em } \\
\text { comparação ao } M C 1 \text {. O resultado do } M C 1 \text { contém } \\
\text { maior quantidade de valores extremos ( } 0 \text { e } 1) \\
\text { especialmente considerando malhas mais } \\
\text { desagregadas. Quanto mais agregada a malha, mais } \\
\text { similares são as métricas estatísticas. }\end{array}$ & $\begin{array}{c}\text { O MP2 possui maior número de registros, e médias e } \\
\text { valores de desvio padrão inferiores em comparação ao } \\
M C 1 \text {. Os quartis não variam significativamente entre } \\
\text { os suportes no } M P 2 \text {. No } M C 1 \text {, nota-se maior } \\
\text { quantidade de valores extremos }(0 \text { e } 1) \text {, especialmente } \\
\text { considerando malhas mais desagregadas. Quanto } \\
\text { mais agregada a malha, mais similares são as } \\
\text { métricas estatísticas. }\end{array}$ \\
\hline & ญิ & $\begin{array}{c}\text { O MP1 apresenta valores inferiores de média e desvio } \\
\text { padrão, principalmente ao considerar suportes } \\
\text { menores. As medidas estatísticas se tornam mais } \\
\text { similares, à medida em que o suporte analisado seja } \\
\text { mais agregado. }\end{array}$ & $\begin{array}{c}\text { O MP2 apresenta valores inferiores de média e desvio } \\
\text { padrão. As medidas estatísticas se tornam mais } \\
\text { similares, à medida em que o suporte analisado seja } \\
\text { mais agregado. }\end{array}$ \\
\hline \multirow{2}{*}{ 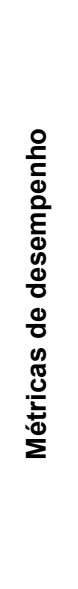 } & 乡 & $\begin{array}{l}\text { A correlação é maior em suportes mais agregados. } \\
\text { Não existe relação entre o suporte e a tendência de } \\
\text { enviesamento. Observa-se maior acurácia para } \\
\text { suportes maiores - com exceção do erro percentual } \\
\text { médio absoluto para a malha de } 250 \text { m (42\%), que é } \\
\text { inferior ao valor da malha de } 500(53 \%) \text {. }\end{array}$ & $\begin{array}{l}\text { A correlação é maior em suportes mais agregados. } \\
\text { Não existe relação entre o suporte e a tendência de } \\
\text { enviesamento. Observa-se maior acurácia para } \\
\text { suportes maiores - com exceção do valor de desvio } \\
\text { médio absoluto para a malha de } 1500 \text { m }(0,185) \text {, que é } \\
\text { superior ao valor da malha de } 1000(0,172) \text {. }\end{array}$ \\
\hline & ญั & $\begin{array}{c}\text { A correlação tende a aumentar ao considerar malhas } \\
\text { mais agregadas. Essa tendência se altera com a } \\
\text { malha de } 1500 \mathrm{~m} \text {, que apresenta correlação inferior à } \\
\text { de } 1000 \mathrm{~m} \text {. Não existe relação entre o suporte e a } \\
\text { tendência de enviesamento. Observa-se maior } \\
\text { acurácia para suportes maiores - com exceção do } \\
\text { resultado de erro percentual médio absoluto para a } \\
\text { malha de } 1500 \text { m (21\%), que é superior ao valor da } \\
\text { malha de } 1000(8 \%) \text {. }\end{array}$ & $\begin{array}{c}\text { A correlação apresenta valores similares (entre } 70 \text { e } \\
80 \%) \text { para as quatro malhas. Não existe relação entre } \\
\text { o suporte e a tendência de enviesamento. Observa-se } \\
\text { maior acurácia para suportes mais agregados - com } \\
\text { exceção do valor de desvio médio absoluto para a } \\
\text { malha de } 250 \text { m }(0,152) \text { que é superior ao valor da } \\
\text { malha de } 500(0,146) .\end{array}$ \\
\hline \multirow{2}{*}{ 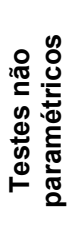 } & $\bar{\Xi}$ & $\begin{array}{l}\text { A hipótese nula (de similaridade entre distribuições } \\
\text { populacionais) é rejeitada para } \alpha=0,05 \text {. }\end{array}$ & $\begin{array}{l}\text { A hipótese nula (de similaridade entre distribuições } \\
\text { populacionais) é rejeitada para } \alpha=0,05 \text {. }\end{array}$ \\
\hline & ญิ & $\begin{array}{l}\text { A hipótese nula (de similaridade entre distribuições } \\
\text { populacionais) é rejeitada para } \alpha=0,05 \text {. }\end{array}$ & $\begin{array}{l}\text { A hipótese nula (de similaridade entre distribuições } \\
\text { populacionais) é rejeitada para } \alpha=0,05 .\end{array}$ \\
\hline
\end{tabular}




\section{Conclusões e Recomendações}

O Capítulo 6 disserta sobre as conclusões obtidas a partir da aplicação dos métodos heurísticos propostos. Para embasamento das conclusões, os Capítulos 1 e 2 são recapitulados. Desta forma, as conclusões são comentadas com base nas problemáticas levantadas, hipóteses de pesquisa, objetivos e questões indagadas. Ao final do capítulo, são realizadas recomendações para o desenvolvimento de futuros estudos correlatos.

\subsection{PROBLEMÁTICAS, HIPÓTESES E OBJETIVOS: PRINCIPAIS CONCLUSÕES E CONTRIBUIÇÕES}

A formulação das hipóteses desta tese de doutorado se baseou nas problemáticas voltadas para o acesso restrito de informações desagregadas (especialmente de dados de demanda por transportes), além da ausência da consideração da dependência espacial nos métodos tradicionais de simulação de dados e modelagem de demanda por transportes. Assim, este trabalho foi concebido com base nas duas hipóteses:

- É possível gerar amostras desagregadas de dados de demanda por transportes, de modo a suprir a ausência de dados provenientes de pesquisa domiciliar ou individual; e

- É possível usar a Geoestatística, que considera a autocorrelação espacial, para desagregar dados de demanda por transportes.

A partir dos resultados obtidos neste trabalho, pode-se corroborar as duas hipóteses formuladas. Os métodos heurísticos aqui propostos permitiram gerar amostras desagregadas de dados de demanda por transportes. Além disso, foram consideradas ferramentas de simulação geoestatística - Simulação Sequencial Gaussiana (SSG); que levam em conta a dependência espacial de variáveis de demanda por transportes na desagregação de informações. Para a verificação de ambas as hipóteses, foi necessário determinar o objetivo geral e os objetivos secundários, bem como determinar um meio para alcançar as finalidades propostas (método). Assim, essas conclusões refletem o sucesso dos métodos e objetivos alcançados, listados em seguida:

Objetivo principal: propor dois métodos heurísticos de desagregação de dados de demanda por transportes, através de procedimentos geoestatísticos.

Foram propostos o Método 1 (MP1), baseado na desagregação de Áreas de Ponderação (APs) e o Método 2 (MP2), baseado na desagregação de Zonas de Tráfego 
(ZTs). Ambas as abordagens possuem etapas comuns (sobretudo àquelas que envolvem o procedimento para deconvolução de semivariograma) e aplicação de Simulação Sequencial Gaussiana. A diferença principal entre os métodos é que o primeiro não necessita de nenhuma informação proveniente de Pesquisa Origem/Destino (O/D), com exceção de um modelo, previamente calibrado, para obtenção da variável de demanda por transportes. Em caso de regiões com ausência de qualquer Pesquisa $O / D$, sugere-se uma análise de transferibilidade espacial de modelos para uso de modelo calibrado para outra região, com características similares.

A simulação geoestatística, em essência, permite a obtenção de valores da variável, associados a áreas menores (desagregação). No procedimento padrão, são considerados os valores da variável e semivariogramas associados à unidade de área inicial, dada como input ao modelo. Em contrapartida, são obtidos, através das simulações, valores associados a centroides de células menores e regulares. Desta forma, tanto a distribuição populacional da variável, quanto a estrutura espacial são provenientes dos dados mais agregados. A contribuição metodológica principal deste trabalho, em ambos os métodos propostos, está relacionada à obtenção de semivariogramas mais desagregados, provenientes do processo alternativo de deconvolução de semivariograma.

Ambos métodos propostos apresentaram desempenhos similares com relação às análises estatísticas comparativas. Os resultados dos mapas, por outro lado, apresentaram algumas variações: a) na grandeza das variâncias e intervalos de confiança, em função do suporte utilizado; e b) nos valores máximos e mínimos das médias e das medianas das simulações, conforme os dados utilizados como input. Apesar dos resultados promissores, é importante levar em consideração possíveis propagações de erros nas sequências metodológicas do processo de desagregação, tendo em vista as diferentes tomadas de decisão.

Objetivo secundário 1: Analisar os obstáculos enfrentados pela aplicação de modelos tradicionais e espaciais (encontrados na literatura atual) a dados de demanda por transportes;

Parte deste objetivo foi alcançado no Capítulo 2, que destaca os trabalhos tradicionais de Transportes e a carência de estudos que considerem, como fator crucial a estimativas, a associação espacial de variáveis. Além disso, A Seção 6.2 formaliza as principais conclusões acerca das questões relativas à aplicação da variável de demanda por transportes, aqui utilizada, para os problemas da Geoestatística, levando em conta os obstáculos apresentados no Capítulo 2. 
Objetivo secundário 2: Propor um procedimento alternativo de deconvolução de semivariogramas para gerar dados sintéticos.

O procedimento proposto neste trabalho para deconvolução de semivariogramas foi uma das contribuições metodológicas, além de ser um dos objetivos secundários. Sabe-se que, através da aplicação direta da SSG a dados desagregados, é possível calcular valores de simulações, em unidades de áreas menores quando comparadas aos dados de entrada. No entanto, neste caso, seriam considerados, como dados de entrada, dados agregados associados a centroides e semivariogramas dos mesmos dados. O procedimento alternativo para deconvolução variográfica, formado por sete etapas descritas anteriormente trabalho, propicia a entrada, na aplicação da SSG, de características da estrutura espacial de dados mais desagregados (por malhas regulares), a partir dos semivariogramas teóricos, obtidos para cada um dos suportes analisados (relativos a unidades de áreas menores e homogêneas, quando comparadas às APs e ZTs). Tendo em vista que os dados de entrada ao método estariam associados a unidades de área diferentes das malhas geradas pela simulação, o emprego da técnica alternativa de deconvolução de semivariogramas foi pertinente. Dessa forma, o suporte utilizado em todos os processos geoestatísticos foi constante, permitindo a compatibilidade entre as técnicas de cálculo de semivariogramas (experimentais e ajustados) e de Krigagem Simples (KS), associadas à SSG.

Ainda em termos metodológicos, destaca-se a importância da etapa de sorteio da posição espacial de microdados, que, agora georreferenciado sinteticamente, pode ser utilizado para outros fins de planejamento de transportes. Além disso, o procedimento proposto para deconvolução de semivariograma, o qual visa calcular um semivariograma desagregado a partir de um agregado, pode ser replicado, não somente para uso em simulações geoestatísticas, mas para qualquer outro caso que se necessite da obtenção de semivariogramas associados a suportes menores e regulares.

Objetivo secundário 3: Propor uma abordagem que combine a desagregação de dados e a Geoestatística para gerar mapas que representem os fenômenos espaciais de uma variável de demanda por transportes, levando em conta o/a: 1) Problema da Unidade de Área Modificável (MAUP); 2) não suavização dos resultados; 3) geração de valores críticos através de intervalos de confiança; e 4) incerteza associada.

O uso de SSG é conveniente a estudos de transportes que visam reproduzir diversas configurações espaciais (cenários). Desta forma, é possível detectar valores extremos da variável em estudo (valores máximos e mínimos), imprescindíveis para o adequado planejamento da oferta de transportes. Destaca-se ainda que, o uso de SSG em 
demanda por transportes não foi encontrado, até o momento, na literatura e espera-se que o presente trabalho forneça uma contribuição acadêmica neste sentido.

Associadas ao objetivo principal e objetivos específicos 1, 2 e 3, destacam-se as principais contribuições deste trabalho. Vale ressaltar que esta tese traz, essencialmente, contribuições metodológicas e acadêmicas com relação à:

(1) Obtenção de dados mais desagregados a partir de áreas irregulares (APs e ZTs), de modo a suprir a ausência de dados domiciliares e/ou individuais;

(2) Proposta de procedimento alternativo para deconvolução de semivariogramas a partir de dados obtidos mais facilmente (por exemplo, microdados do censo demográfico);

(3) Obtenção de diversos cenários, com valores simulados da variável de interesse; estabelecendo-se assim a distribuição de diversos valores possíveis e um mapa de intervalo de confiança, bem como a análise da incerteza associada à SSG.

\subsection{USO DA GEOESTATÍSTICA PARA DEMANDA POR TRANSPORTES}

As questões indagadas no Capítulo 2 são arguidas a partir dos resultados obtidos nesta pesquisa.

a) Qual o melhor nível de desagregação para modelos espaciais? Com relação à Geoestatística e a dados contínuos de escolha modal, nota-se que as variâncias entre observações são diretamente proporcionais ao nível de desagregação. Essa conjuntura justifica o processo de desagregação na Geoestatística. No entanto, é importante avaliar a limitação do nível de desagregação de dados através dos resultados do método para as diferentes malhas. Variáveis de escolha modal, associadas ao indivíduo, podem gerar semivariogramas com efeito pepita puro de $76 \%$ (LINDNER, 2015). Isto é, a variabilidade é tão alta entre observações próximas, que o valor da variância é muito similar aos valores das variâncias entre observações mais afastadas entre si. O nível de agregação ideal para cada variável de estudo não é o foco deste trabalho. Contudo, do ponto de vista da Geoestatística, pôde-se concluir, na presente pesquisa, que dados não pontuais produzem semivariogramas com melhores estruturas espaciais. Em geral, as malhas com agregação superior a 500 metros produziram semivariogramas satisfatórios e os resultados das SSGs foram coerentes para todas as malhas analisadas. Apesar de a malha com suporte de 500 metros já possuir um nível de agregação significativo, ao considerar o município de São Paulo e a variável em estudo, nota-se que este é o menor suporte que permite satisfazer as 
características de efeito pepita razoável e estacionariedade de semivariogramas. No entanto, salienta-se que os métodos propostos neste trabalho podem ser aplicáveis para a desagregação de células de qualquer tamanho.

b) É possível calcular estimativas/simulações coerentes considerando que as observações estão relacionadas a unidades com áreas, formas e tamanhos distintos? Sabe-se que os valores das variâncias entre pares de observações para os dados da Pesquisa O/D agregados por Zonas de Tráfego (ZTs) são inferiores aos valores dos semivariogramas dos dados sintéticos e dos próprios dados da Pesquisa O/D agregados em diferentes malhas. $\mathrm{E}$, por isso, o uso de semivariogramas associados a áreas irregulares acarreta perda de informação. Contudo, os resultados gerados pelo MP2, que utiliza uma base de dados associados a ZTs e o semivariograma deconvoluído, permitiram a geração de cenários correlacionados entre 70 e $80 \%$ com o MC2. Isso demonstra que, como input em processos de krigagem, os dados podem estar associados a áreas irregulares - uma vez que estes se aproximem dos valores reais; e estes podem ainda permitir a geração de modelos satisfatórios que reproduzam os valores reais. Dessa forma, o uso de semivariogramas deconvoluídos permite que sejam reproduzidas as variâncias entre os pares de observações, que, a depender do suporte utilizado no método de krigagem, possuem grandezas diferentes.

c) Sabendo da diversidade de tipos de uso de solo em uma determinada área de estudo, os agrupamentos de observações devem ser apontados como empecilhos nas estimativas espaciais? Um aspecto que pode interferir nos resultados da simulação é a diferença, tanto em termos quantitativos quanto qualitativos, na amostragem de ambas pesquisas domiciliares. A Pesquisa O/D contou com $23 \%$ dos domicílios sendo de renda baixa. Os microdados, por outro lado, mostravam que, dos domicílios pesquisados, 39\% possuíam renda inferior a $\mathrm{R} \$ 1.541$. Além disso, a quantidade amostrada era discrepante para ambas pesquisas. Enquanto na Pesquisa O/D, 15.759 domicílios foram entrevistados no município de São Paulo, para os microdados, foram contabilizados 172.627 registros de domicílios. Apesar de os microdados apresentarem uma quantidade maior de agrupamentos do que os dados da Pesquisa O/D, não se pode inferir conclusões acerca dos efeitos dos agrupamentos, tendo em vista que as amostragens possuíam tamanho e fonte distintas. Além destes aspectos, a taxa de viagens produzidas por transporte público para os dados sintéticos foi calculada através de um modelo calibrado, o que pode gerar erros acumulados à simulação.

d) Visto que as técnicas de krigagem necessitam de dados com continuidade espacial, como é possível adaptar os dados de demanda por transportes para que 
áreas não habitadas não sejam um problema nos modelos geoestatísticos? A solução adotada neste trabalho se deu pela classificação de áreas não habitadas e pela análise do uso do solo. Os processos de krigagem utilizaram apenas as áreas com densidade demográfica maior que 0,5 habitantes por hectare. Essa solução é abordada com ineditismo no uso da Geoestatística para dados de demanda por transportes, visto que, até o momento, não foram encontrados trabalhos que selecionassem áreas, em função do uso do solo, no processo de krigagem e nem no processo de amostragem artificial.

\section{e) Qual o efeito que existe ao associar o valor de uma área ao seu respectivo} centroide? O efeito de associar valores de uma área com respectivos centroides é visto pela suavização das informações. Este trabalho visa solucionar esta problemática através da desagregação de dados. No entanto, é importante avaliar a limitação do nível de desagregação de dados para cada estudo de caso. Neste trabalho, notou-se que malhas com células inferiores a 250 metros não produzem estruturas espaciais coerentes, do ponto de vista da Geoestatística.

\subsection{RECOMENDAÇÕES}

Incentiva-se a reprodução dos métodos propostos nesta pesquisa a outros estudos de caso, principalmente no campo das Ciências Sociais. Dados associados a fatores humanos possuem grande variabilidade, mesmo a curtas distâncias entre observações. Contudo, nota-se também a tendência do aumento das variâncias entre observações mais distantes entre si. A Geoestatística permite a mensuração desta variabilidade. Além disso, o método permite que sejam estimados ou simulados valores em superfícies. $O$ desenvolvimento de técnicas geoestatísticas às Ciências Sociais gera também o aperfeiçoamento do entendimento do comportamento espacial das variáveis e proporciona diferentes ferramentas para a tomada de decisão.

Sugere-se que sejam feitos estudos que analisem, com maior ênfase, a relação entre padrões de imagens e uso da geoestatística. Áreas não habitadas podem variar ao longo dos anos em função de novos planos diretores e novas políticas de zoneamento urbano, por exemplo. Assim sendo, é importante que imagens de uso de solo sejam datadas do mesmo período dos dados utilizados para reprodução geoestatística. Além disso, a análise de padrões de imagens permitiria que fossem levados em conta assentamentos irregulares. 
Considerando estudos que adotem o método aqui proposto para diferentes variáveis de demanda por transportes, recomenda-se testar, como suporte, a grade estatística, preparada pelo IBGE em 2016 (com base no censo demográfico de 2010). Esta base de dados fornece informações associadas a uma grade de 200 metros para regiões urbanas e 1000 metros para áreas rurais. Para a variável e área de estudo desta tese, no entanto, a grade estatística não foi suficiente para assegurar os pressupostos da Geoestatística acerca da hipótese intrínseca de estacionariedade de segunda ordem.

Recomenda-se, também, que trabalhos sucessivos avaliem diferentes modelos de regressão para previsão de dados de escolha modal em diferentes municípios. A escolha de um modelo melhor calibrado possibilita a geração de modelos espaciais mais acurados. Para áreas sem qualquer dado de demanda por transportes ou Pesquisa Origem/Destino, sugere-se uma análise de transferibilidade espacial de modelos.

A deconvolução de semivariogramas se mostra relevante a estudos de demanda por transportes, pois, em geral, os dados divulgados estão associados a áreas irregulares. Sugere-se, para próximas pesquisas, que o método de deconvolução proposto por Journel e Huijbregts (1978) seja aplicado aos dados de transportes e comparado às técnicas heurísticas aqui propostas.

Outro enfoque interessante pode ser dado a análises geoestatísticas espaçotemporais. Estes métodos podem auxiliar no entendimento de comportamentos de demanda por transportes e servir de subsídio para previsões espaciais dos dados.

Finalmente, recomenda-se o uso de SSG para dados de demanda por transporte público em rede, como dados de embarques e desembarques em pontos de parada, por exemplo. Neste caso, o suporte é evidentemente regular e os dados provenientes de simulações relevantes ao operador, sobretudo para dimensionamento de oferta nos períodos de pico e entre-pico. 


\section{Referências Bibliográficas}

ABEP - Associação Brasileira de Empresas de Pesquisa (2010) Critério Brasil 2010. In: http://www.abep.org/criterio-brasil (último acesso em 05.06.2018)

ATKINSON, PM (2013) Downscaling in remote sensing. International. Journal of Applied Earth Observation and Geoinformation, v.22, p.106-114. doi: 10.1016/j.jag.2012.04.012

ATKINSON, PM; PARDO-IGÚZQUIZA, E; CHICA-OLMO, M (2008) Downscaling cokriging for superresolution mapping of continua in remotely sensed images. IEEE Transactions on Geoscience and Remote Sensing, v.46, pp. 573-580. doi: 10.1109/TGRS.2007.909952

ATKINSON, PM; TATE, NJ (2000) Spatial scale problems and geostatistical solutions: a review. Professional Geographer. v.52, n.4, 607-623. doi: 10.1111/0033-0124.00250

BEN-AKIVA, ME (1973) Structure of Passenger Travel Demand Models. Tese de Doutorado. Massachusetts Institute of Technology, Cambridge.

BEN-AKIVA, ME; RAMMING, MS; BEKHOR, S (2004) Route choice models. Human Behaviour and Traffic Networks, Springer Berlin Heidelberg, p.23-45.

BHAT, C; ZHAO, H (2002) The spatial analysis of activity stop generation. Transportation Research Part B. v.36, n.6, p.557-575. doi: 10.1016/S0191-2615(01)00019-4

BOLUWADE, A; MADRAMOOTOO, CA (2015) Geostatistical independent simulation of spatially correlated soil variables. Computers \& Geosciences, v.85, p.3-15. doi: 10.1016/j.cageo.2015.09.002.

BOUCHER, A; KYRIAKIDIS, PC (2006) Super-resolution land cover mapping with indicator geostatistics. Remote Sensing of Environment, v.104, n.3, p.264-282. doi: 10.1016/j.rse.2006.04.020

BOULOS, MNK (2004) Towards evidence-based, GIS-driven national spatial health information infrastructure and surveillance services in the United Kingdom. International Journal of Health Geographics, v.3, n.1, p.1. doi: 10.1186/1476-072X-3-1

BRAXMEIER, H; SCHMIDT, V; SPODAREV, E (2009) Kriged road-traffic maps. Interfacing Geostatistics and GIS. Springer Berlin Heidelberg, p.105-119. doi: 10.1007/978-3-540-332367_9

CAMARGO, ECG; FUCKS, SD; CÂMARA, G (2004) Análise espacial de superfícies. Análise espacial de dados geográficos. Planaltina: Embrapa Cerrados, $1^{\text {a }}$ ed, p.79-122. In: http://www.dpi.inpe.br/gilberto/livro/analise (último acesso em 09.01.2019)

CERVERO, R; RADISCH, C (1996) Pedestrian versus automobile oriented neighborhoods. Transport Policy, v.3, p.127-141. doi: 10.1016/0967-070X(96)00016-9

CHEN, XM; HE, X; XIONG, C; ZHANG, L (2015) A bayesian stochastic kriging metamodel for simultaneous optimization of travel behavioral responses and traffic management. Transportation Research Board. 94th Annual Meeting Compendium of Papers. Washington. doi:10.1016/j.trpro.2015.06.056 
CHILĖS, JP; DELFINER, P (1999) Geostatistics Modeling Spatial Uncertainty. John Wiley \& Sons. Nova lorque, 695p.

CIUFFO, BF; PUNZO, V; QUAGLIETTA, E (2011) Kriging Meta-Modelling to Verify Traffic MicroSimulation Calibration Methods. Transportation Research Board 90th Annual Meeting Compendium of Papers. Washington, D.C.

CRONER, CM; DE COLA, L (2001) Visualization of disease surveillance data with geostatistics. UNECE (United Nations Economic Commission for Europe) work session on methodological issues involving integration of statistics and geography, Tallinn, Setembro.

DA COSTA, ASG; PITOMBO, CS; SALGUEIRO, AR (2013) Estimação de escolha modal através da geoestatística. Anais do XXVII Congresso de Pesquisa e Ensino em Transportes (ANPET). Belém, Pará. 04 a 08 de Novembro de 2013.

DE SÁ, JPM (2007) Applied statistics using SPSS, STATISTICA, MATLAB and R, $2^{\mathrm{a}}$ ed. Springer, Nova lorque, 505p.

DEMING, WE; STEPHAN, FF (1940) On a least squares adjustment of a sampled frequency table when the expected marginal totals are known. Mathematical Statistics, v.11, n.4, p.427-444.

DEUTSCH, CV; JOURNEL AG (1998) GSLIB: Geostatistical Software Library and User's Guide, Oxford University Press, 370p.

DOMENCICH, T; MCFADDEN, D (1975) Urban Travel Demand. North-Holland Press, Amsterdam, Netherlands, 215p.

DU J; AULTMAN-HALL, L (2006) Using spatial analysis to estimate link travel times on local roads. 85 Transportation Research Board (TRB), n.06-0676.

DUGUNDJI, E; WALKER, J (2005) Discrete choice with social and spatial network interdependencies: an empirical example using mixed generalized extreme value models with field and panel effects. Transportation Research Record: Journal of the Transportation Research Board. v.1921: p.7078. doi: 10.3141/1921-09

EMPLASA - Empresa Paulista de Planejamento Metropolitano (2002) Mapa digital de uso do solo. In: https://www.emplasa.sp.gov.br/ (último acesso em 15.03.2018)

FISCHER, MM (2006) Spatial analysis and geocomputation: selected essays. Springer-Verlag Berlin Heidelberg, 336p.

FLOWERDEW, R; GREEN, M (1993) Developments in areal interpolation methods and GIS. In: Geographic Information Systems, Spatial Modelling and Policy Evaluation. Springer, Berlin, Heidelberg, p.73-84. doi: 10.1007/978-3-642-77500-0_5

FOSU, MO; JACKSON, OAY; TWUM, SB (2016) Application of Area to Point Kriging to Low Birth Weight Incidence in Ghana. British Journal of Applied Science \& Technology, v.15, n.5, p.1-9. doi: 10.9734/BJAST/2016/25752

FOTHERINGHAM, AS; WONG, DWS (1991) The modifiable areal unit problem in multivariate statistical analysis. Environment and planning A. v.23, n.7, p.1025-1044. doi: 10.1068/a231025

GELFAND, AE; ZHU, L; CARLIN, BP (2001) On the change of support problem for spatio-temporal data. Biostatistics, v.2, n.1, p. 31-45. doi: 10.1093/biostatistics/2.1.31 
GEOSAMPA - Base de dados (2010) Mapa Digital da Cidade de São Paulo, Secretaria Municipal de Urbanismo e Licenciamento, Prefeitura de São Paulo. In: http://geosampa.prefeitura.sp.gov.br (último acesso em 16.12.2018)

GONÇALVES, ACA; FOLEGATTI, MV; MATA, JDV (2001) Análise exploratória e geoestatística da variabilidade de propriedades físicas de um Argissolo Vermelho. Acta Scientiarum. Maringá, v.23, n.5, p.1149-1157

GOODCHILD, M F; LAM, NSN (1980) Areal interpolation: a variant of the traditional spatial problem.

Geo-Processing, v.1, p.297-312. Elsevier, Amsterdam

GOODCHILD, MF; ANSELIN, L; DEICHMANN, U (1993) A framework for the areal interpolation of socioeconomic data. Environment and planning A, v.25, n.3, p.383-397. doi: 10.1068/a250383

GOOVAERTS, P (1997) Geostatistics for Natural Resources Evaluation. Applied Geostatistics.

Oxford University Press on Demand, Nova lorque, 496p. doi: 10.1080/00401706.2000.10485733

GOOVAERTS, P (1999) Impact of the simulation algorithm, magnitude of ergodic fluctuations and number of realizations on the spaces of uncertainty of flow properties. Stochastic Environmental Research and Risk Assessment, v.13, n.3, p.161-182. doi: 10.1007/s004770050037

GOOVAERTS, P (2001) Geostatistical modelling of uncertainty in soil science. Geoderma, v.103, n.1, p.3-26. doi: 10.1016/S0016-7061(01)00067-2

GOOVAERTS, P (2006) Geostatistical analysis of disease data: accounting for spatial support and population density in the isopleth mapping of cancer mortality risk using area-to-point Poisson kriging. International Journal of Health Geographics, v.5, n.1, p.52.

GOOVAERTS, P (2008) Kriging and semivariogram deconvolution in the presence of irregular geographical units. Mathematical Geosciences, v.40, n.1, p.101-128. doi: 10.1007/s11004-0079129-1

GOOVAERTS, P (2009) Medical geography: a promising field of application for geostatistics.

Mathematical Geosciences, v.41, n.3, p.243-264. doi: 10.1007/s11004-008-9211-3

GOOVAERTS, P (2011) A coherent geostatistical approach for combining choropleth map and field data in the spatial interpolation of soil properties. European journal of soil science, v.62, n.3, p.371-380. doi: 10.1111/j.1365- 2389.2011.01368.x.

GOOVAERTS, P; JACQUEZ, GM (2004) Accounting for regional background and population size in the detection of spatial clusters and outliers using geostatistical filtering and spatial neutral models: the case of lung cancer in Long Island, New York. International Journal of Health Geographics, v.3, n.14, p.14. doi:10.1186/1476-072X-3-14

GOTWAY, CA; YOUNG, LJ (2002) Combining incompatible spatial data. Journal of the American Statistical Association, v.97, p.632-648. doi: 10.1198/016214502760047140

GRIFO, ARL; DA SILVA, JRM (2016) Stochastic simulation of maize productivity: spatial and temporal uncertainty in order to manage crop risks. Precision agriculture, v.16, n.6, p.668-689. doi:10.1007/s11119-015-9401-1

GUNDOGDU, IB (2014) Risk governance for traffic accidents by Geostatistical Analyst methods. International Journal of Research in Engineering and Science (IJRES), v.2, n.9 p.35-40. 
GUO, J; BHAT, C (2007) Population synthesis for microsimulating travel behavior. Transportation

Research Record: Journal of the Transportation Research Board, n.2014, p.92-101. doi:

10.3141/2014-12

HOLLANDER, M (1999) Nonparametric statistical method, $2^{a}$ ed. New York: John Wiley \& Sons.

IBGE - Instituto Brasileiro de Geografia e Estatística (2010) Censo e Microdados. In:

https://www.ibge.gov.br (último acesso em 16.12.2018)

ISAAKS, EH (1990) The Application of Monte Carlo Methods to the Analysis of Spatially

Correlated Data. Tese de Doutorado. Universidade Stanford, 213p.

JEANNÉE, N; NEDELLEC, V; BOUALLALA, S; DERAISME, J; DESQUEYROUX, H (2005)

Geostatistical assessment of long term human exposure to air pollution. Geostatistics for

Environmental Applications, p.161-172, Springer, Berlin, Heidelberg.

JEGA, IM (2015) Estimating population surfaces in areas where actual distributions are unknown: dasymetric mapping and pycnophylactic interpolation across different spatial scales. Tese (Doutorado em Filosofia)- Departamento de Geografia, Universidade de Leicester.

JOURNEL, AG; HUIJBREGTS, CJ (1978) Mining geostatistics, Academic press. Reimpresso (1991). The Blackburn Press, EUA. 600p.

KASSTEELE, JV; STEIN, A (2006) A model for external drift kriging with uncertain covariates applied to air quality measurements and dispersion model output. Environmetrics, v.17, n.4, p.309-322. doi: 10.1002/env.771

KASSTEELE, JV; VELDERS, GJM (2006) Uncertainty assessment of local NO2 concentrations derived from error-in-variable external drift kriging and its relationship to the 2010 air quality standard. Atmospheric Environment, v.40, n.14, p.2583-2595. doi:

10.1016/j.atmosenv.2005.12.023.

KAYGISIZ, Ö; DÜZGÜN, Ş; YILDIZ, A; SENBIL, M (2015) Spatio-temporal accident analysis for accident prevention in relation to behavioral factors in driving: The case of South Anatolian Motorway. Transportation Research Part F: Traffic Psychology and Behaviour, v.33, p.128-140. doi: 10.1016/j.trf.2015.07.002

KITAMURA, R; MOKHTARIAN, PL; LAIDET, L (1997) A micro-analysis of land use and travel in five neighborhoods in the San Francisco Bay Area. Transportation, v.24, p.125-158. doi:

10.1023/A:1017959825565

KRIGE, DG (1951) A statistical approach to some basic mine valuation problems on the Witwatersrand. Journal of the Southern African Institute of Mining and Metallurgy, v.52, n.6, p.119-139.

KYRIAKIDIS, PC (2004) A geostatistical framework for area-to-point spatial interpolation. Geographical Analysis, v.36, n.3, p.259-289. doi: 10.1111/j.1538-4632.2004.tb01135.x

LAM, NS (1983) Spatial Interpolation Methods: A Review, The American Cartographer, v.10, n.2, p.129-150. doi: 10.1559/152304083783914958

LANDIM, PMB (2003) Análise Estatística de Dados Geológicos, $2^{\mathrm{a}}$ ed. Universidade Estadual Paulista. São Paulo, 254p.

LEE, SY; CARLE, SF; FOGG, GE (2007) Geologic heterogeneity and a comparison of two geostatistical models: Sequential Gaussian and transition probability-based geostatistical 
simulation. Advances in Water Resources, v.30, n.9, p.1914-1932. doi:

10.1016/j.advwatres.2007.03.005

LINDNER, A (2015) Análise desagregada de dados de demanda por transportes através de modelagem geoestatística e tradicional. 106p. Dissertação (Mestrado em Ciências) - Escola de Engenharia de São Carlos, Universidade de São Paulo, 106p.

LINDNER, A; PITOMBO, CS (2018) A Conjoint Approach of Spatial Statistics and a Traditional Method for Travel Mode Choice Issues. Journal of Geovisualization and Spatial Analysis, v.2, n.1, p.1. doi: 10.1007/s41651-017-0008-0

LINDNER, A; PITOMBO, CS; ROCHA, SS; QUINTANILHA, JA (2016) Estimation of transit trip production using Factorial Kriging with External Drift: an aggregated data case study. Geo-spatial Information Science, v.19, n.4, p.245-254. doi: 10.1080/10095020.2016.1260811

LOPES, SB (2005) Efeitos da dependência espacial em modelos de previsão de demanda por transporte (Tese de Doutorado) - Escola de Engenharia de São Carlos, Universidade de São Paulo,137p.

MANEPALLI, URR; BHAM, GH (2011) Crash Prediction: Evaluation of Empirical Bayes and Kriging Methods. 3rd International Conference on Road Safety and Simulation, Indianapolis.

MARQUES, SF; PITOMBO, CS (2018) Estimativa do volume de passageiros ao longo de linhas de transporte público por ônibus a partir da geoestatística. Anais do XXXII Congresso de Pesquisa e Ensino em Transportes (ANPET). Gramado, Rio Grande do Sul. 4 a 7 de Novembro de 2018.

MASSEY, FJ (1952) Distribution table for the deviation between two sample cumulatives.

Mathematical Statistics, v.23, n.3, p.435-441. doi:10.1214/aoms/1177729388

MATHERON, G (1963) Principles of Geostatistics, Economic Geology, v.58, p.1246-1266. doi: 10.2113/gsecongeo.58.8.1246

MATHERON, G (1965) Les Variables Régionalisées et leur estimation, Masson et Cie, Paris, 306p. MATHERON, G (1971) The theory of regionalized variables and its applications, Cahiers du Centre de Morphologie Mathématique, 5, ENSMP, Paris, 212p.

MAZZELLA, A; PIRAS, C; PINNA, F (2011) Use of kriging technique to study roundabout performance. Transportation Research Record: Journal of the Transportation Research Board, v.2241: p.78-86. doi: 10.3141/2241-09

MCFADDEN, D (1974) The measurement of urban travel demand. Journal of Public Economics, v.3, n.4, p.303-328.

MENNIS, J (2003) Generating surface models of population using dasymetric mapping. The

Professional Geographer, v.55, n.1, p.31-42. doi: 10.1111/0033-0124.10042

METRÔ - Companhia do Metropolitano de São Paulo (2007) Pesquisa Origem-Destino 2007 -

Região Metropolitana de São Paulo: Resumo de Informações. In:

http://www.metro.sp.gov.br/metro/numeros-pesquisa/pesquisa-origem-destino- 2007.aspx (último acesso em 28.06.2017)

MILTON, RC (1964) An extended table of critical values for the Mann-Whitney (Wilcoxon) Two-

Sample Statistic. Journal of the American Statistical Association, v.59, n.307, p.925-934. doi: 10.1080/01621459.1964.10480740 
MIURA, H (2010) A study of travel time prediction using universal kriging. Sociedad de Estadística e Investigación Operativa, p.257-270. doi:10.1007/s11750-009-0103-6

MIYAMOTO, K; VICHIENSAN, V; SHIMOMURA, N; PÁEZ, A (2004) Discrete choice model with structuralized spatial effects for location analysis. Transportation Research Record, v.1898, p.183-190. doi: 10.3141/1898-22

MOLLA, MM; STONE ML; LEE, E (2014) Geostatistical Approach to Detect Traffic Accident Hot Spots and Clusters in North Dakota. Upper Great Plains Transportation Institute. DP-276.

MÜLLER, K; AXHAUSEN, W (2010) Population synthesis for microsimulation: State of the art. Arbeitsberichte Verkehrs-und Raumplanung, v.638. doi: 10.3929/ethz-a-006127782

OLEA, RA (2006) A six step practical approach to semivariogram modeling. Stochastic Environmental Research and Risk Assessment, v.20. p.307-318. doi: 10.1007/s00477-0050026-1

OMRAN, ESE (2016) A stochastic simulation model to early predict susceptible areas to water table level fluctuations in North Sinai, Egypt. The Egyptian Journal of Remote Sensing and Space Science, v.19, n.2, p.235-257. doi: 10.1016/j.ejrs.2016.03.001

OPENSHAW, $S$ (1984). The modifiable areal unit problem. Concepts and techniques in modern geography, n.38, 40p. Geo Books, Norwich, Inglaterra.

ORTÚZAR JD; WILLUMSEN LG (2011) Modeling Transport. London: Wiley. $4^{\text {a }}$ Edição. 586p.

PACHEPSKY, Y; ACOCK, B (1998) Stochastic imaging of soil parameters to assess variability and uncertainty of crop yield estimates. Geoderma, v.85, n.2, p.213-229. doi: 10.1016/S00167061(98)00021-4

PÁEZ, A (2007) Spatial perspectives in urban systems: developments and directions. Journal of Geographical Systems, v.9, n.1, p.1-6. doi: 10.1007/s10109-007-0041-5

PÁEZ, A; LÓPEZ, FA; RUIZ, M; MORENCY, C (2013) Development of an indicator to assess the spatial fit of discrete choice models. Transportation Research Part B: Methodological, v.56, p.217-233. doi: 10.1016/j.trb.2013.08.009

PÁEZ, A; SCOTT, DM (2005) Spatial statistics for urban analysis: a review of techniques with examples. GeoJournal, v.61, n.1, p.53-67. doi: 10.1007/s10708-005-0877-5

PARDO-IGÚZQUIZA, E; CHICA-OLMO, M (2008) Geostatistical simulation when the number of experimental data is small: an alternative paradigm. Stochastic Environmental Research and Risk Assessment, v.22, n.3, p.325-337. doi: 10.1007/s00477-007-0118-1

PARK, NW (2013) Spatial downscaling of TRMM precipitation using geostatistics and fine scale environmental variables. Advances in Meteorology, v.2013. doi: 10.1155/2013/237126

PEARCE, JL; RATHBUN, SL; AGUILAR-VILLALOBOS, M; NAEHER, LP (2009) Characterizing the spatiotemporal variability of PM2.5 in Cusco, Peru using kriging with external drift. Atmospheric Environment, v.43, n.12, p.2060-2069. doi: 10.1016/j.atmosenv.2008.10.060

PITOMBO, CS; DA COSTA, ASG; SALGUEIRO, AR (2015b) Proposal of a sequential method for spatial interpolation of mode choice. Boletim de Ciências Geodésicas, v.21, n.2, p.274-289. doi: 10.1590/S1982-21702015000200016

PITOMBO, CS; FERNANDES, VO; ALIXANDRINI JR, MJ; SANTOS, DVC; TEIXEIRA, TCS (2010) Aplicação conjunta de técnicas de análise multivariada de dados e análise espacial exploratória 
para avaliação do desempenho de transporte público por ônibus. Anais do XXIV Congresso de Pesquisa e Ensino em Transportes (ANPET). Salvador, Bahia. 29 de Novembro a 3 de Dezembro de 2010.

PITOMBO, CS; ROCHA, SS; SALGUEIRO, AR; BITTENCOURT, DC (2014) Uso de krigagem para estimação de geração de viagens. $6^{\circ}$ Congresso Luso-Brasileiro para Planejamento Urbano, Regional, Integrado e Sustentável, 2014, Lisboa. PLURIS 2014.

PITOMBO, CS; SALGUEIRO, AR; DA COSTA, ASG; ISLER, CA (2015a) A Two-step method for mode choice estimation with socioeconomic and spatial information. Spatial Statistics. v.11, p.45-64. doi: 10.1016/j.spasta.2014.12.002

PITOMBO, CS; SOUSA, AJ (2009) Aplicação de conceitos geoestatísticos para análise de geração de viagens urbanas. Anais do XXIII Congresso de Pesquisa e Ensino em Transportes (ANPET). Vitória, Espírito Santo. 9 a 13 de novembro de 2009.

REMY, N; BOUCHER, A; WU, J (2009) Applied Geostatistics with SGeMS: A User's Guide, Cambridge University Press, Cambridge, 2009.

ROCHA, SS (2014) Análise de geração de viagens urbanas por transporte coletivo através de técnicas de geoestatística. Dissertação (Mestrado em Engenharia Ambiental Urbana) - Escola Politécnica da Universidade Federal da Bahia.

ROCHA, SS; LINDNER, A; PITOMBO, CS (2014) Modelagem geoestatística aplicada à amostra sistemática desagregada: estimação de geração de viagens. Anais do XXVIII Congresso de

Pesquisa e Ensino em Transportes (ANPET). Curitiba, Paraná. 24 a 28 de novembro de 2014.

ROCHA, SS; LINDNER, A; PITOMBO, CS (2017) Proposal of a geostatistical procedure for transportation planning field. Boletim de Ciências Geodésicas, v.23, n.4, p.636-653. doi: 10.1590/S1982-21702017000400042

SHESKIN, DJ (2007) Handbook of parametric and nonparametric statistical procedures. $4^{\mathrm{a}} \mathrm{ed}$. Chapman \& Hall/CRC.

SMIRNOV, NV (1948) Table for estimating the goodness of fit of empirical distributions. Mathematical Statistics, v.19, p.279-281. doi: 10.1214/aoms/1177730256

SOARES, A (2006) Geoestatística para as Ciências da Terra e do Ambiente. $2^{a}$ ed. IST Press. Lisboa, 214p.

SOUZA, ZM; MARQUES JR, J; PEREIRA, GT (2004) Variabilidade espacial da estabilidade de agregados e matéria orgânica em solos de relevos diferentes. Pesquisa Agropecuária Brasileira, Brasília, v.39, n.5, p.491-499, Maio de 2004.

SPTRANS (2018) Relatório diário do número de passageiros transportados. In: http://www.prefeitura.sp.gov.br/ (último acesso em 17.12.2018)

TAMAYO-MAS, E; MUSTAPHA, H; DIMITRAKOPOULOS, R (2016) Testing geological heterogeneity representations for enhanced oil recovery techniques. Journal of Petroleum Science and Engineering, v.146, p.222-240. doi: 10.1016/j.petrol.2016.04.027.

TEIXEIRA, GL (2003) Uso de dados censitários para identificação de zonas homogêneas para planejamento de transportes utilizando estatística espacial, Dissertação (Mestrado em Transportes). Faculdade de Tecnologia da Universidade de Brasília, Brasília. 
TOBLER, WR (1979) Smooth pycnophylactic interpolation for geographical regions. Journal of the American Statistical Association, v. 74, n. 367, p. 519-530. doi: 10.1080/01621459.1979.10481647

VAN MEIRVENNE, M; GOOVAERTS, P (2001) Evaluating the probability of exceeding a site-specific soil cadmium contamination threshold. Geoderma, v.102, n.1, p.75-100. doi: 10.1016/S00167061(00)00105-1

VERLY, G (1993) Sequential Gaussian simulation: a Monte Carlo method for generating models of porosity and permeability. Generation, Accumulation and Production of Europe's Hydrocarbons III. Berlin, Heidelberg, Springer, p.345-356. doi: 10.1007/978-3-642-77859-9_28 WACKERNAGEL, H (2003) Multivariate Geostatistics. $3^{\mathrm{a}}$ ed. 388p., Berlin, Heidelberg: Springer.

XIE, Z; YAN, J (2013) Detecting traffic accident clusters with network kernel density estimation and local spatial statistics: an integrated approach. Journal of Transport Geography, v.31, p.64-71. doi: 10.1016/j.jtrangeo.2013.05.009

YAMADA, I; THILL, JC (2004) Comparison of planar and network K-functions in traffic accident analysis. Journal of Transport Geography, v.12, n.2, p.149-158. doi: 10.1016/j.jtrangeo.2003.10.006

YAMAGUCHI, FY; FERNANDES, VO; ALIXANDRINI JR, MJ (2018) Correlação de métodos de desagregação de setores censitários com a grade estatística do IBGE. Anais do $8^{\circ}$ Congresso Luso-Brasileiro para o Planeamento Urbano, Regional, Integrado e Sustentável (PLURIS). Coimbra, Portugal. 23 a 26 de Outubro de 2018.

YAO, RJ; YANG, JS; SHAO, HB (2013) Accuracy and uncertainty assessment on geostatistical simulation of soil salinity in a coastal farmland using auxiliary variable. Environmental monitoring and assessment, v.185, n.6, p.5151-5164. 10.1007/s10661-012-2932-2

YOON, SY; RAVULAPARTHY, SK; GOULIAS, KG (2014) Dynamic diurnal social taxonomy of urban environments using data from a geocoded time use activity-travel diary and point-based business establishment inventory. Transportation Research Part A: Policy and Practice, v.68, p.3-17. doi: org/10.1016/j.tra.2014.01.004

ZHANG, S; SHAO, M; LI, D (2017) Prediction of soil moisture scarcity using sequential Gaussian simulation in an arid region of China. Geoderma, v.295, p.119-128. doi: 10.1016/j.geoderma.2017.02.003

ZOU, H; YUE, Y; LI, Q; YEH, AGO (2012) An improved distance metric for the interpolation of linkbased traffic data using kriging: a case study of a large-scale urban road network. International Journal of Geographic Information Science, v.26, n.4, p.667-689. doi: 10.1080/13658816.2011.60948 
Apêndices e Anexos 


\section{Apêndice A}

Semivariogramas dos dados sintéticos criados a partir de oito sorteios (Malha de $500 \mathrm{~m}$ )

Semivariogramas omnidirecionais para oito sorteios dos microdados (IBGE, 2010)
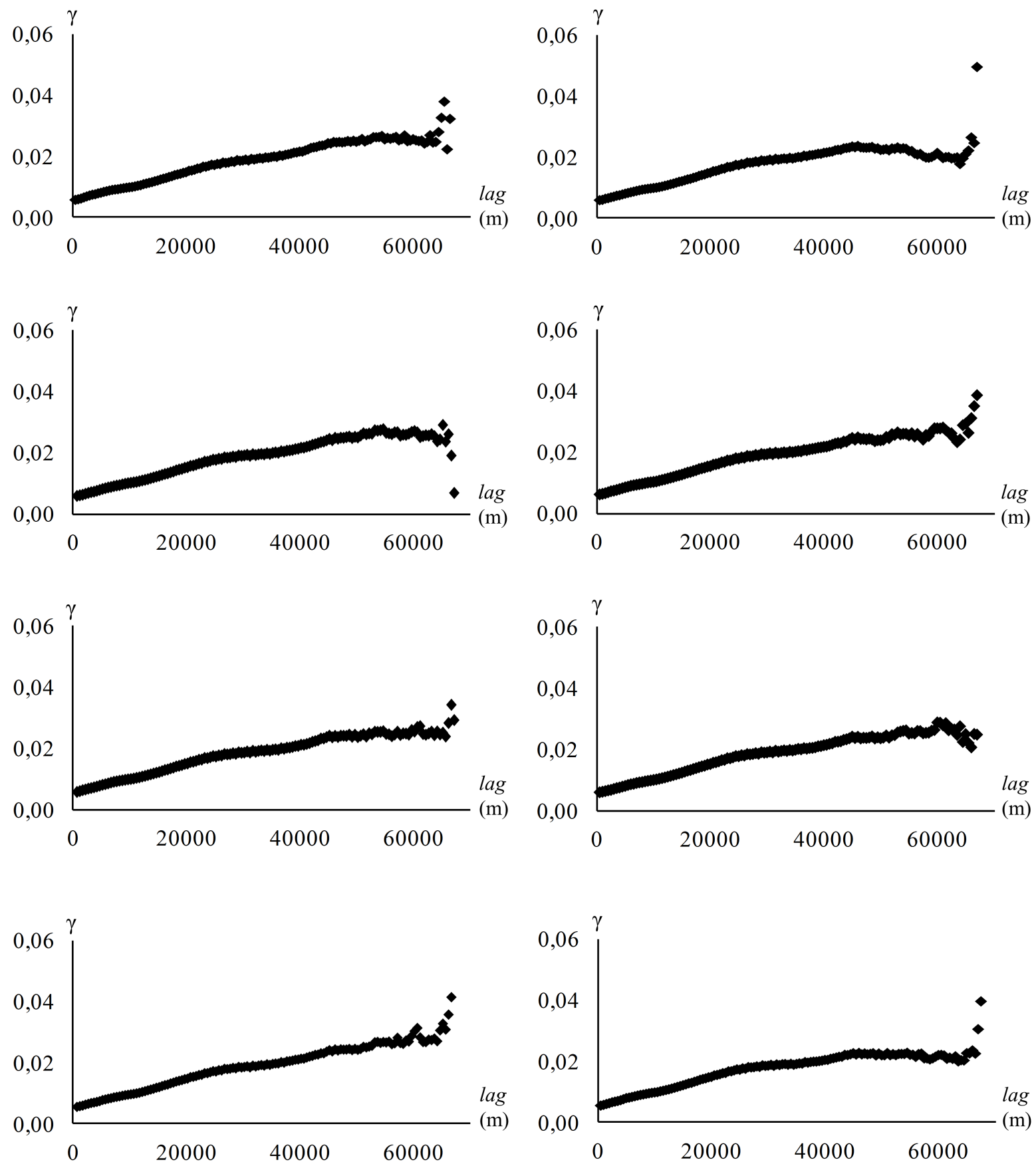

Dados agregados em uma malha com células de 500 metros 


\section{Apêndice B}

Semivariogramas dos dados sintéticos criados a partir de oito sorteios (Malha de $1000 \mathrm{~m}$ )

Semivariogramas omnidirecionais para oito sorteios dos microdados (IBGE, 2010)
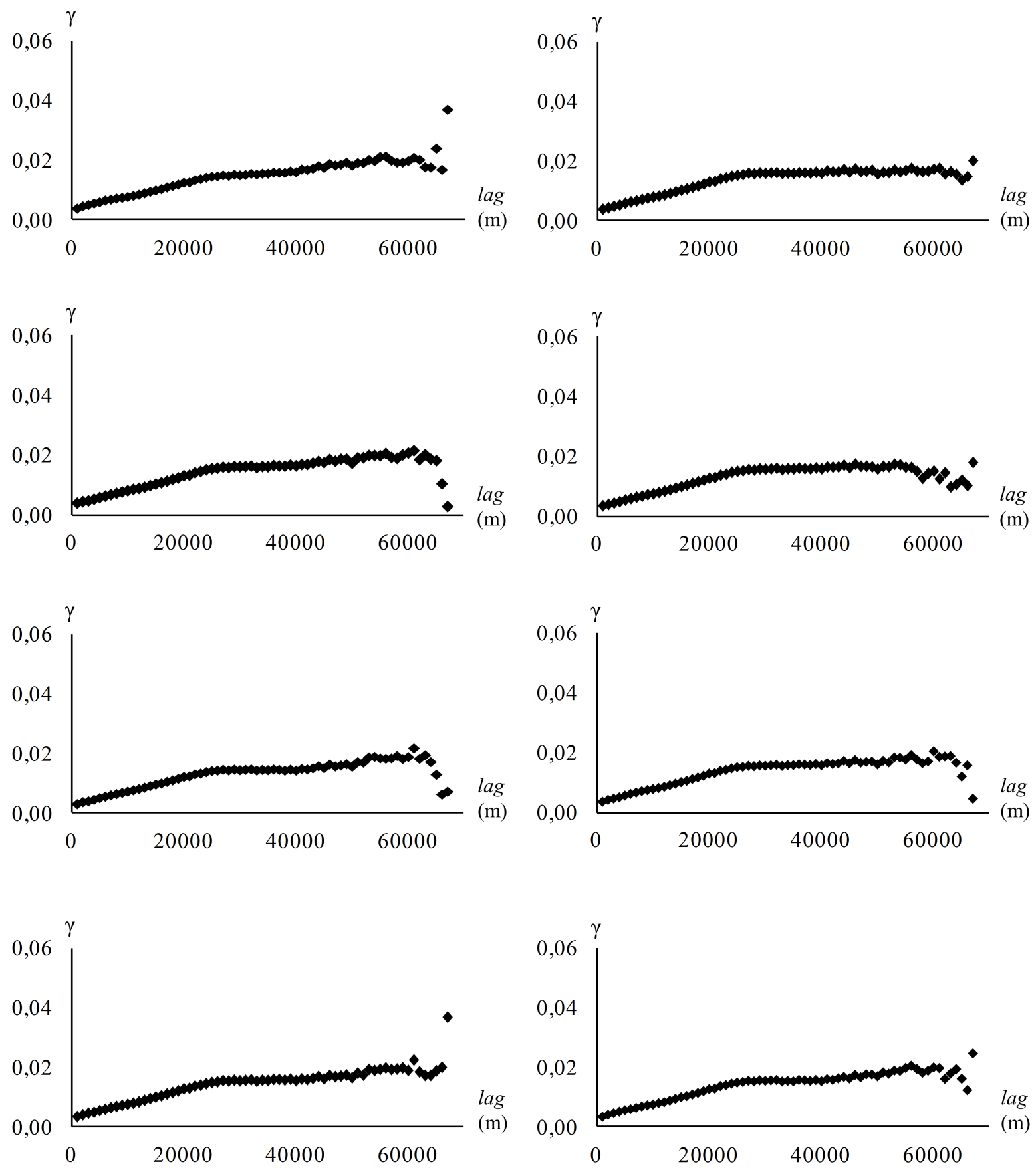

Dados agregados em uma malha com células de 1000 metros 


\section{Apêndice C}

Semivariogramas dos dados sintéticos criados a partir de oito sorteios (Malha de $1500 \mathrm{~m}$ )

Semivariogramas omnidirecionais para oito sorteios dos microdados (IBGE, 2010)
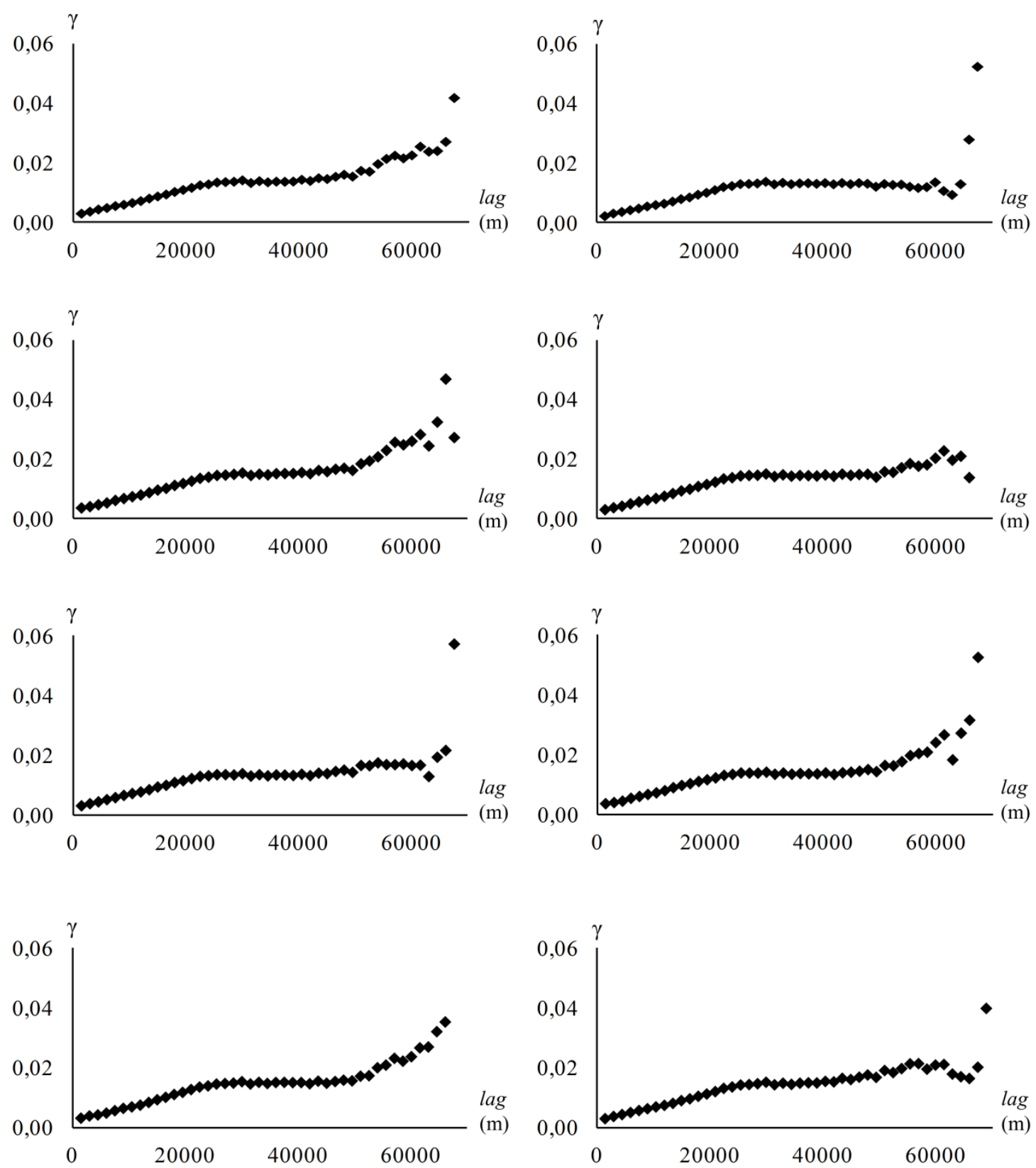

Dados agregados em uma malha com células de 1500 metros 


\section{Apêndice D}

Gráficos de variabilidade (variância média vs. o número de realizações calculadas) para cada SSG

MP1

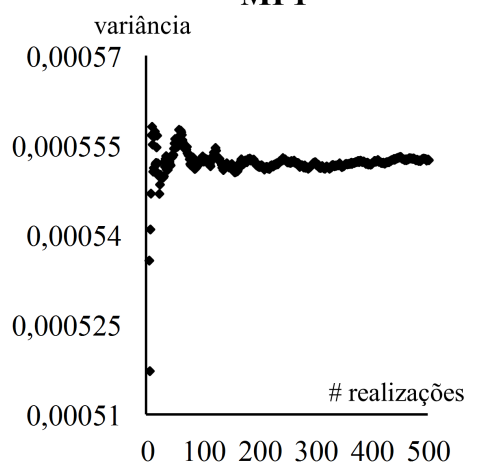

MP2

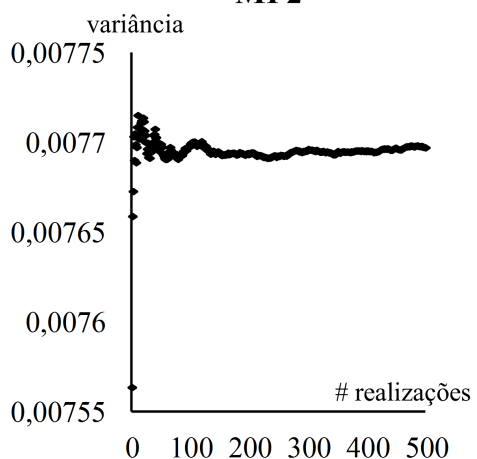

MC2

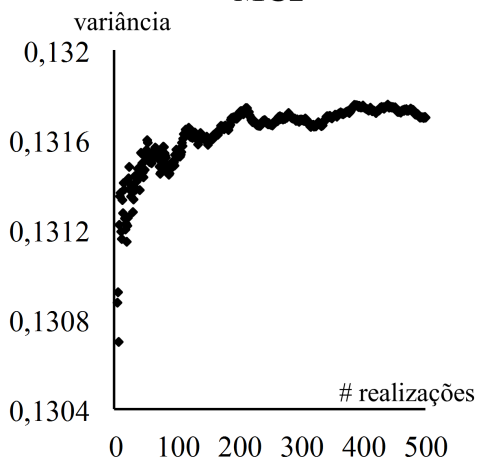

Dados agregados em uma malha com células de 250 metros
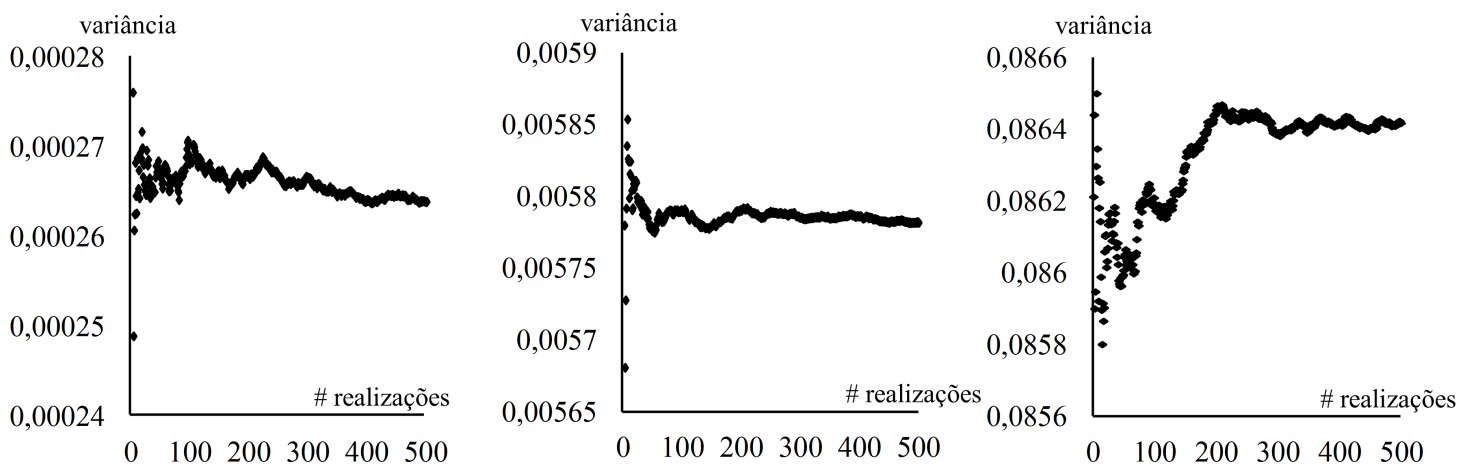

Dados agregados em uma malha com células de 500 metros
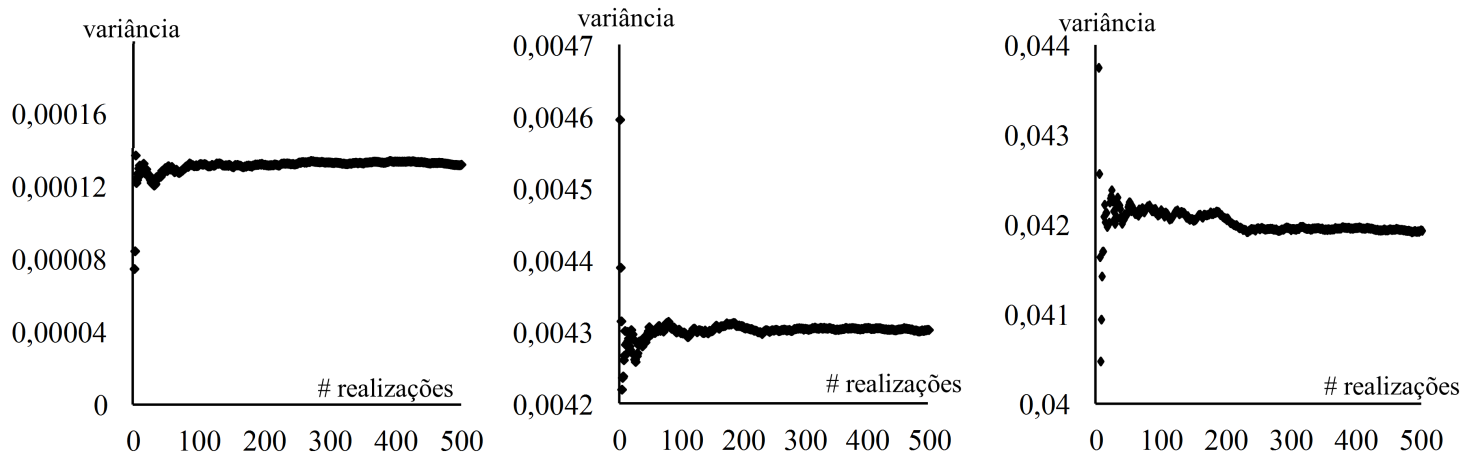

Dados agregados em uma malha com células de 1000 metros
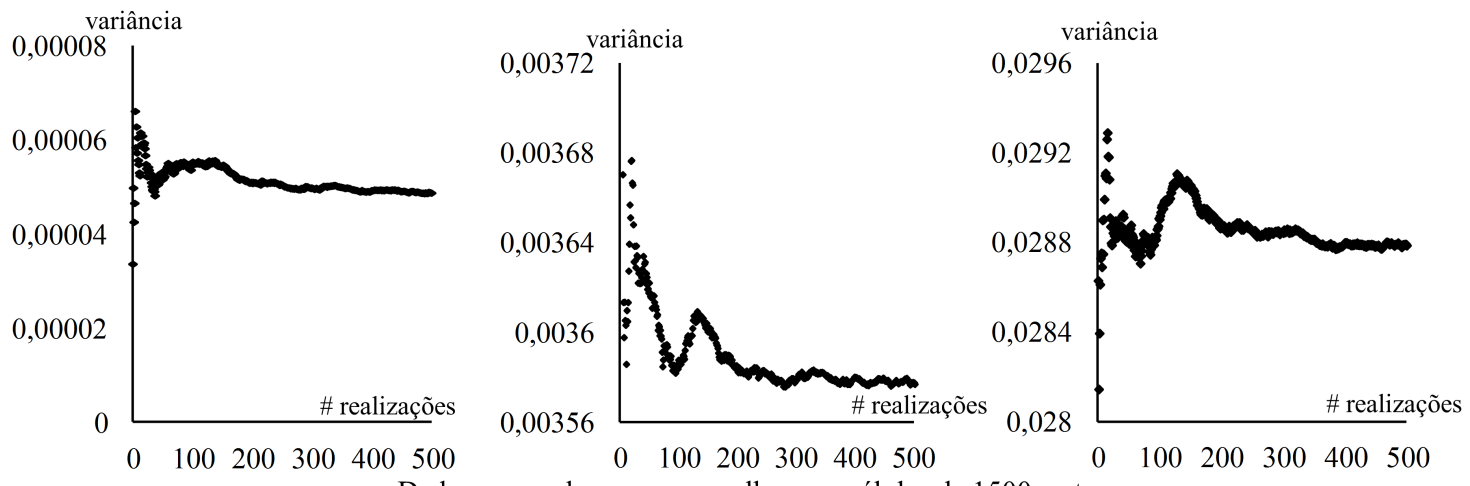

Dados agregados em uma malha com células de 1500 metros 


\title{
Apêndice E
}

\author{
Mapas resultantes da SSG para o MP1 (Malhas 500 e 1000 m)
}

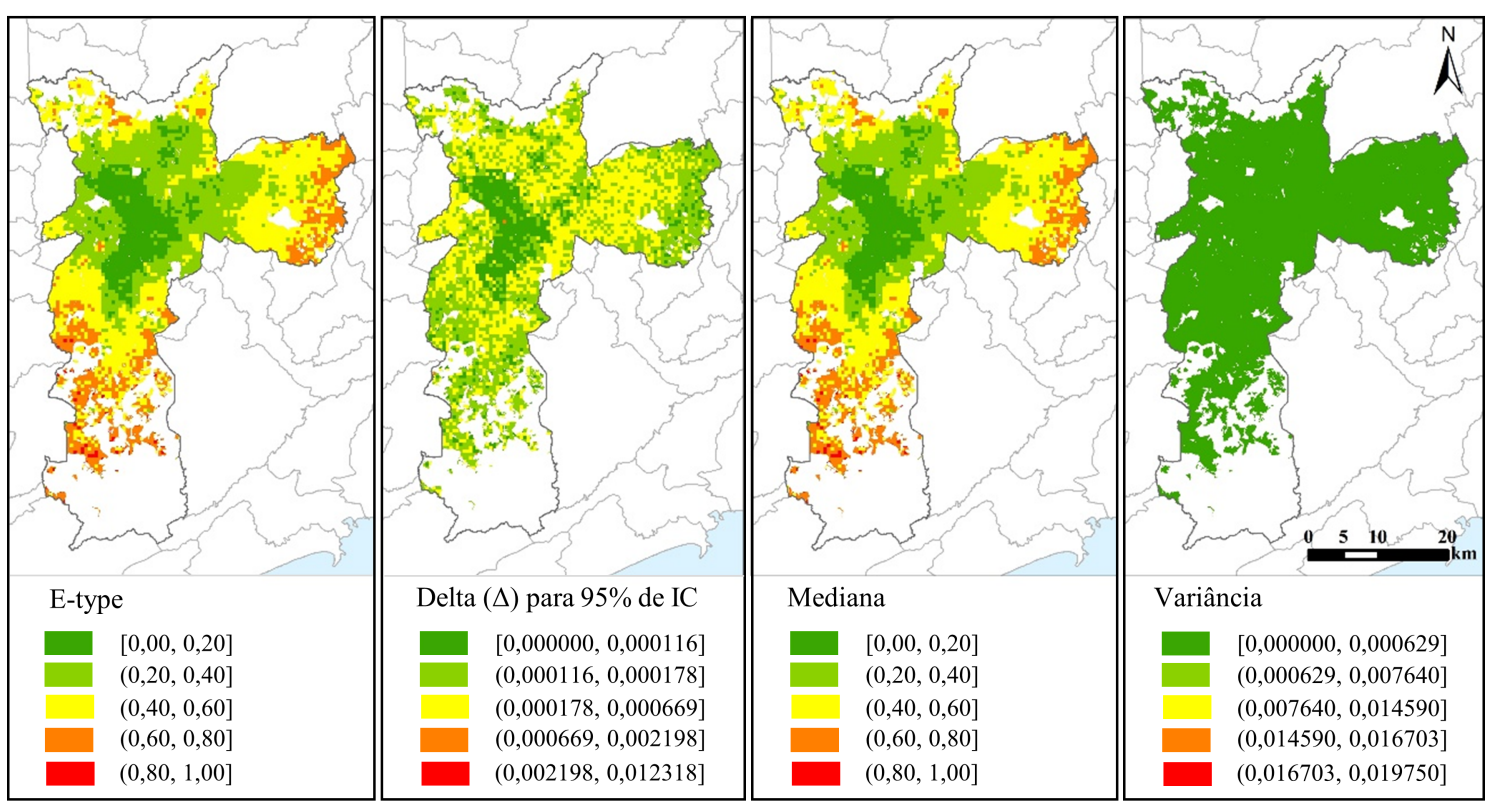

Simulação Sequencial Gaussiana do MP1 uma malha com células de 500 metros

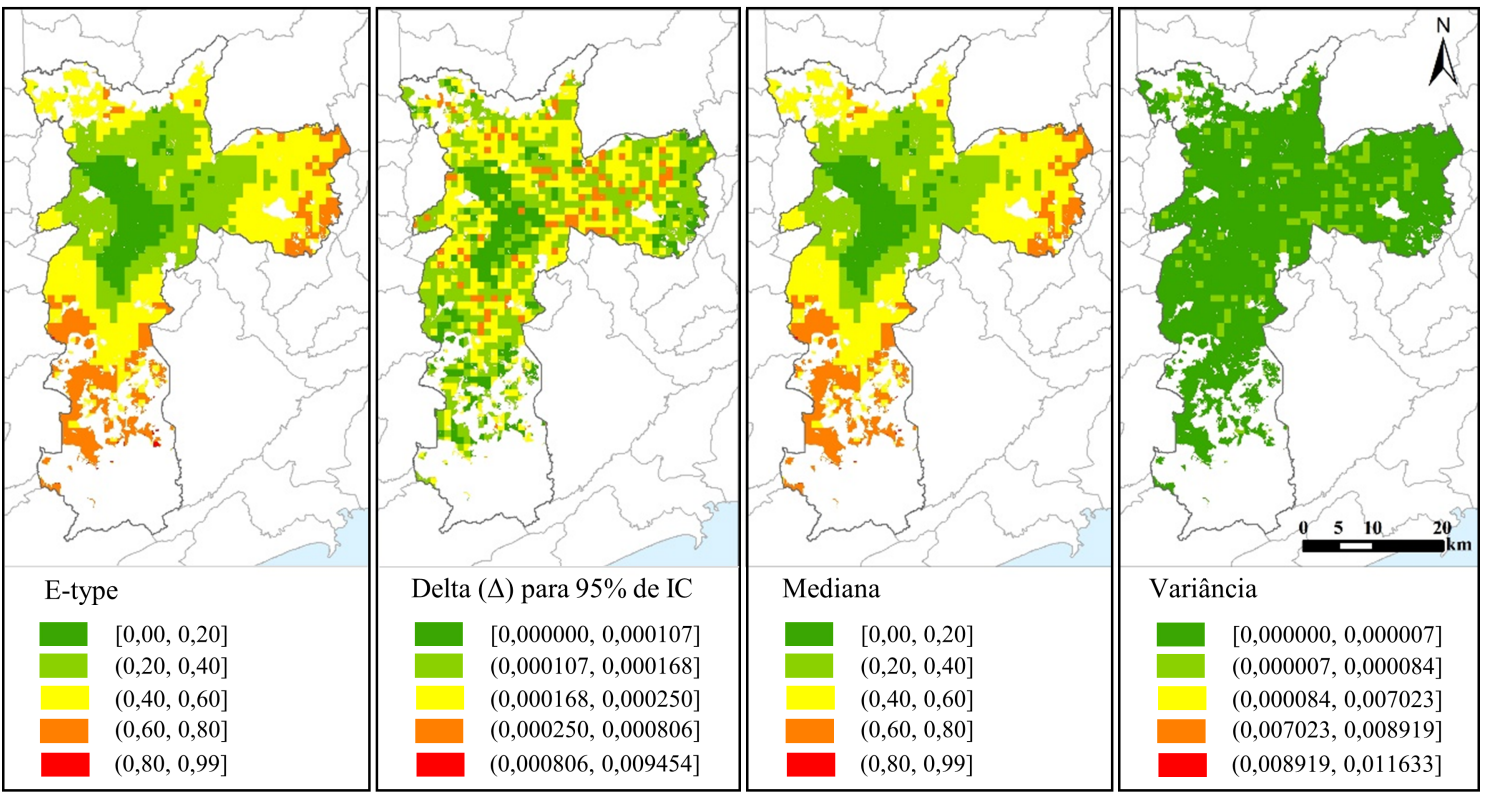

Simulação Sequencial Gaussiana do MP1 uma malha com células de 1000 metros 


\section{Apêndice F}

Mapas resultantes da SSG para o MP2 (Malhas 500 e 1000 m)

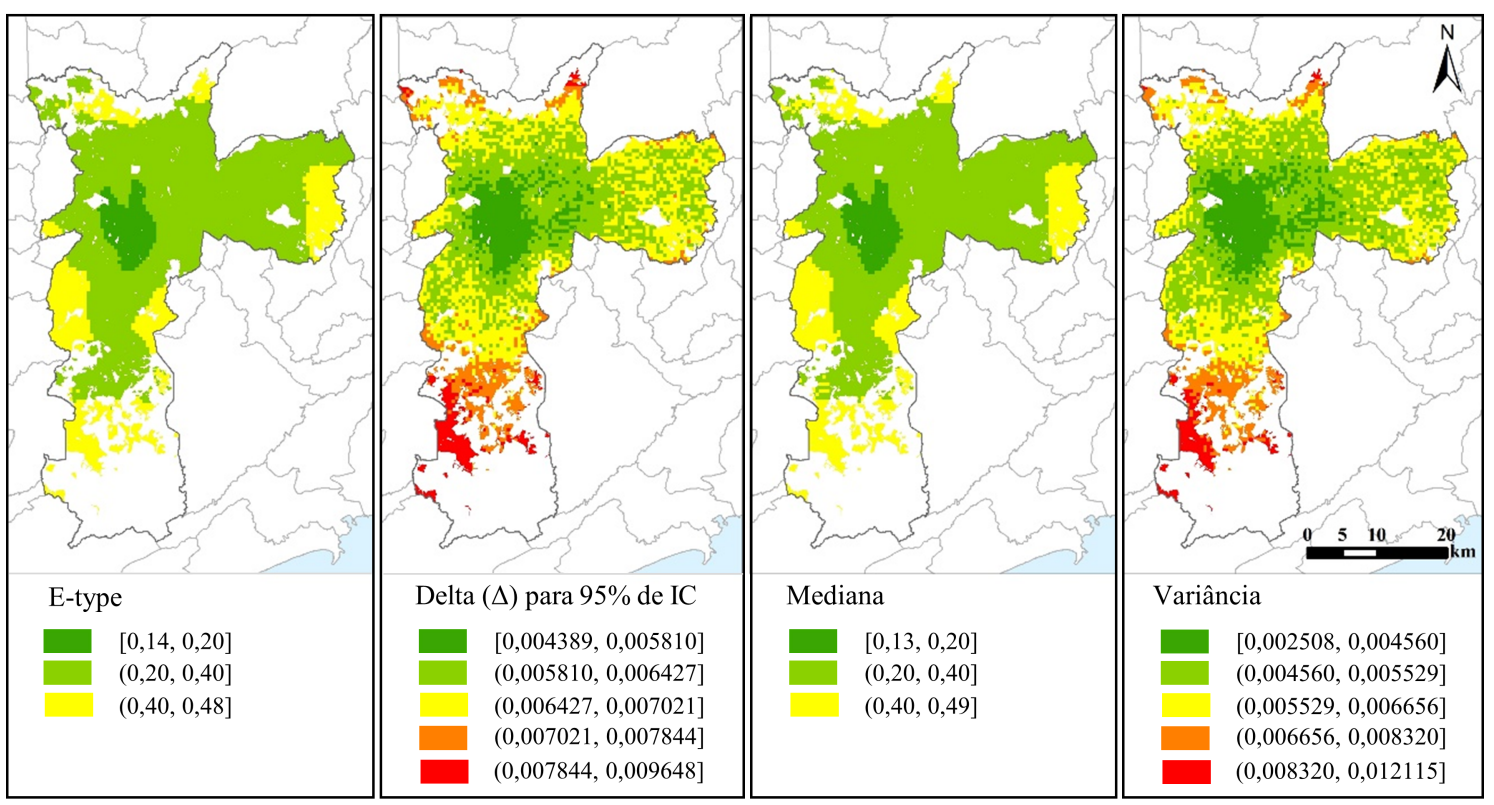

Simulação Sequencial Gaussiana do MP2 uma malha com células de 500 metros

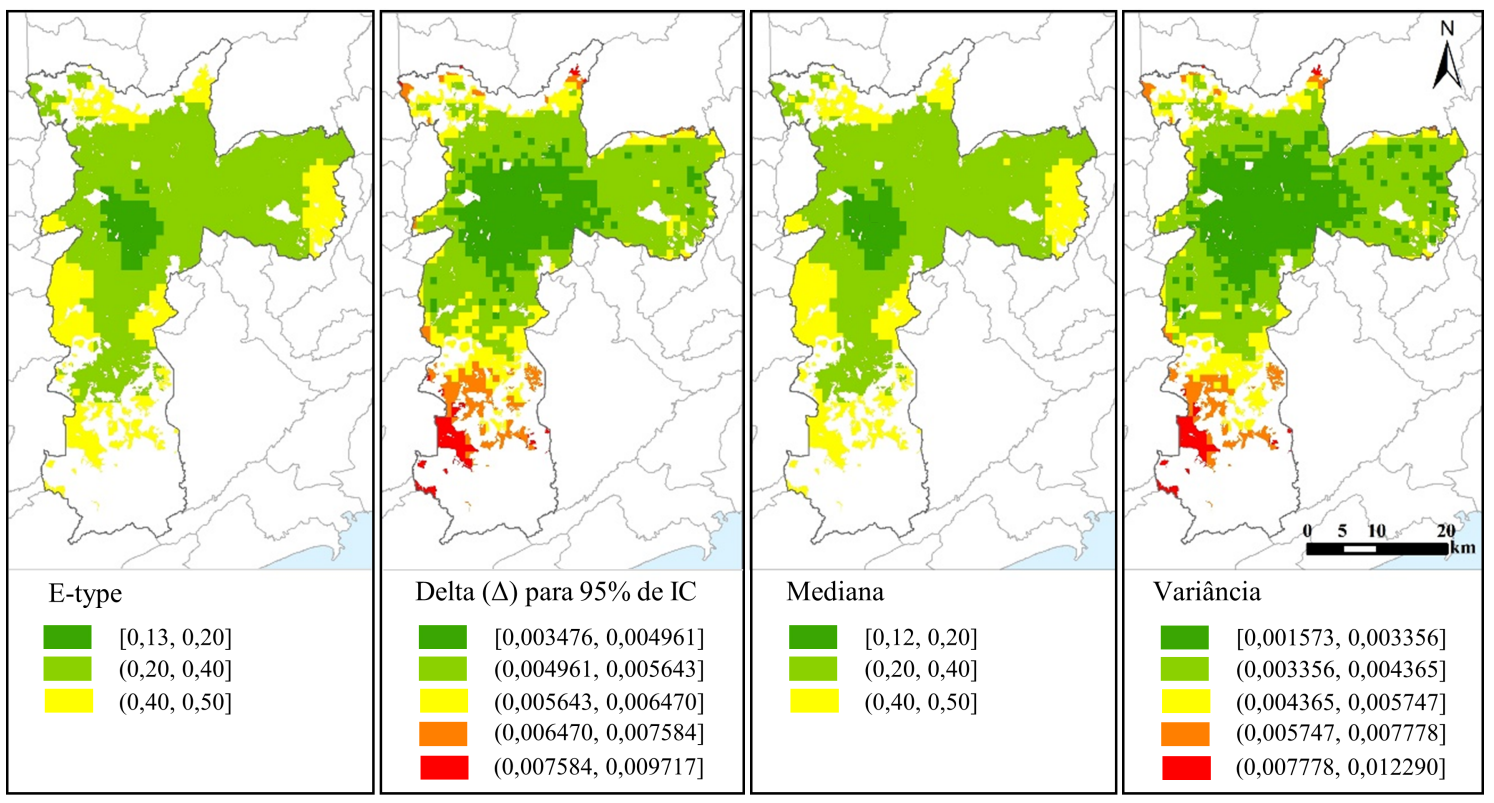

Simulação Sequencial Gaussiana do MP2 uma malha com células de 1000 metros 


\section{Apêndice G}

Mapas resultantes da SSG para o MC2 (Malhas 500 e $1000 \mathrm{~m}$ )

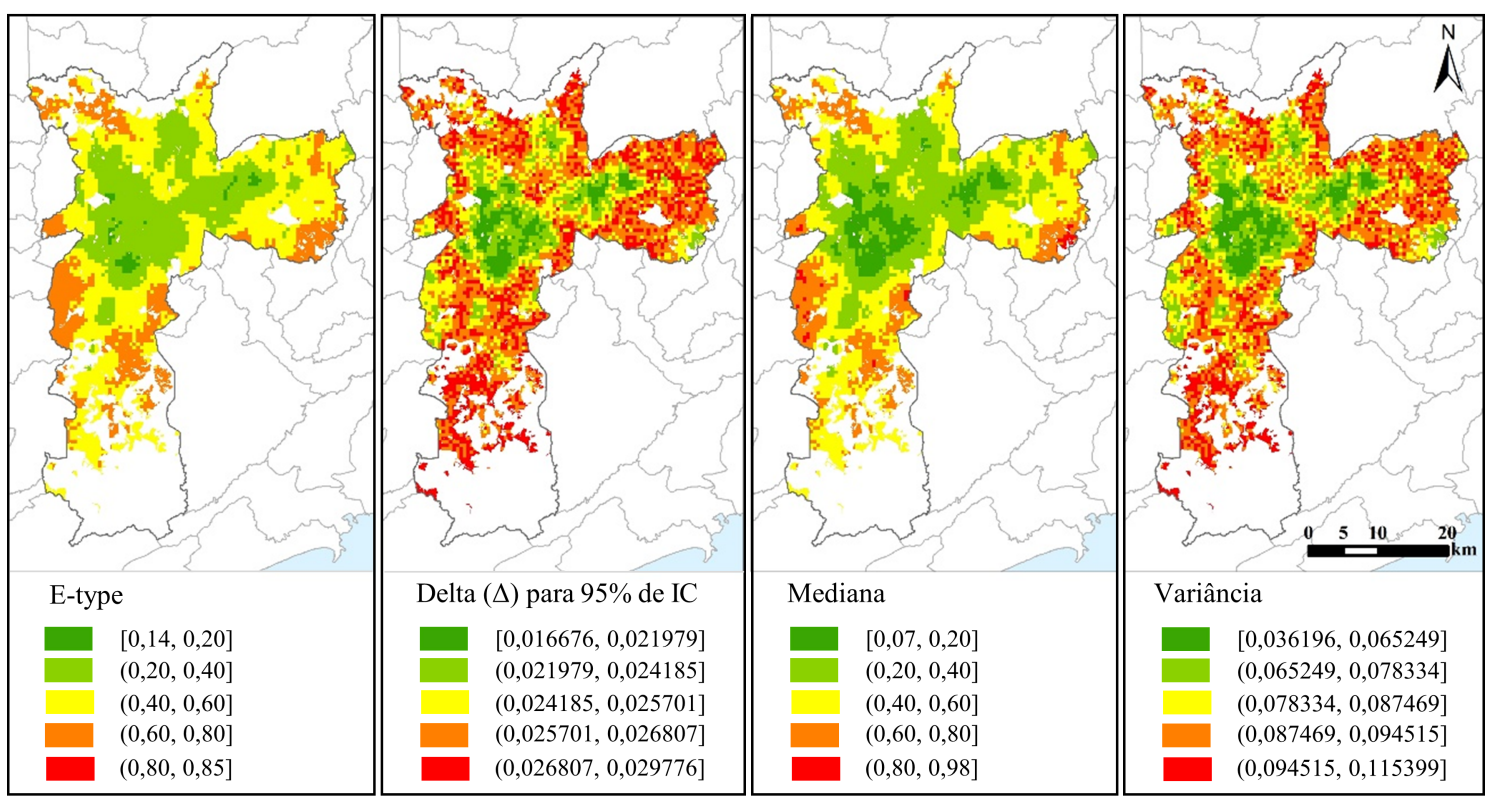

Simulação Sequencial Gaussiana do MC2 uma malha com células de 500 metros

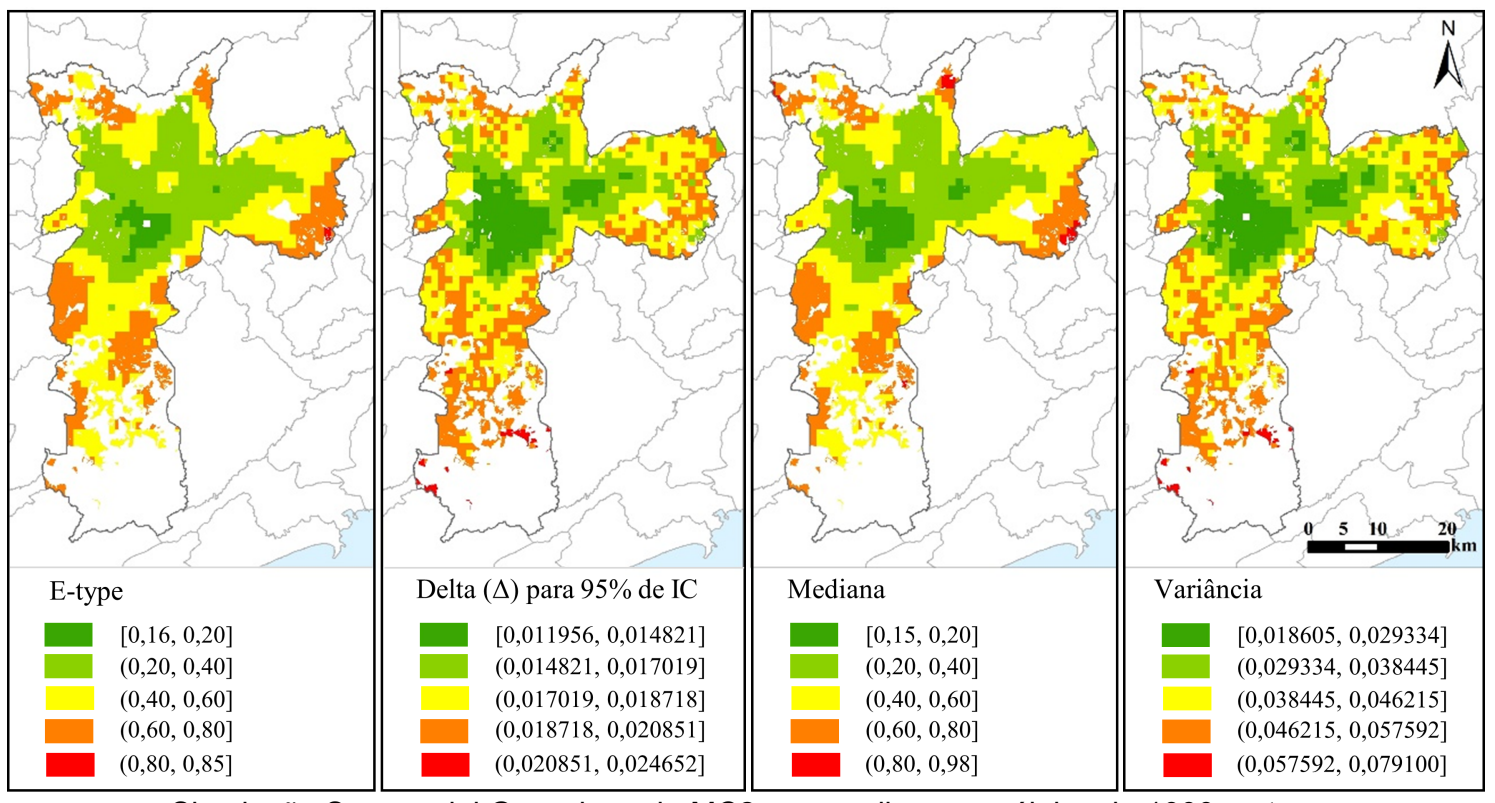

Simulação Sequencial Gaussiana do MC2 uma malha com células de 1000 metros 


\section{Anexo A}

Representação do mapa das Zonas de Tráfego do município de São Paulo

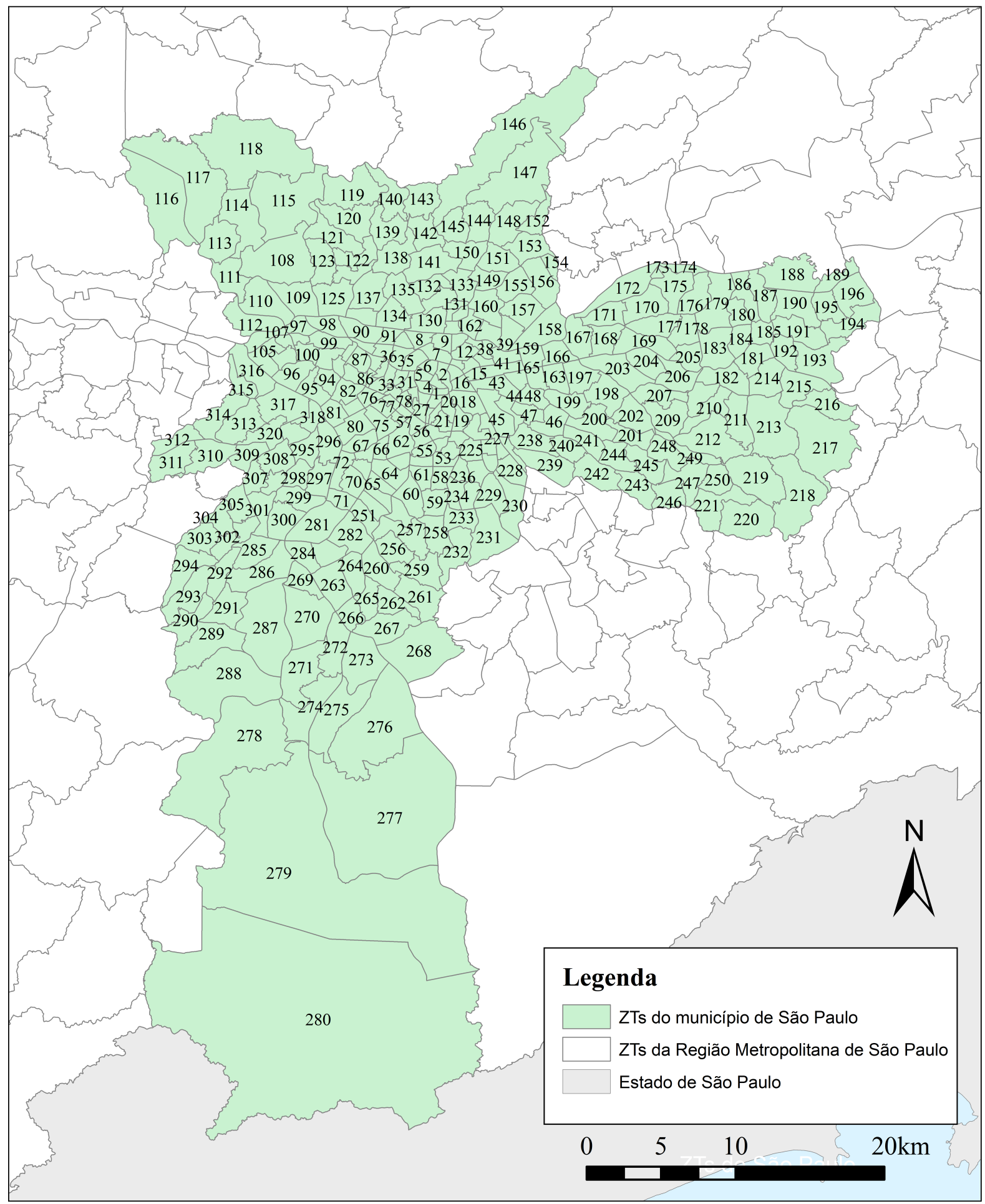




\section{Anexo B}

Legenda das Zonas de Tráfego do município de São Paulo

\begin{tabular}{|c|c|}
\hline ID & Zona de Tráfego \\
\hline 1 & Sé \\
\hline 2 & Parque Dom Pedro \\
\hline 3 & Praça João Mendes \\
\hline 4 & Ladeira da Memória \\
\hline 5 & República \\
\hline 6 & Santa Ifigênia \\
\hline 7 & Luz \\
\hline 8 & Bom Retiro \\
\hline 9 & Ponte Pequena \\
\hline 10 & Canindé \\
\hline 11 & Bom Jardim \\
\hline 12 & Pari \\
\hline 13 & João Teodoro \\
\hline 14 & Oriente \\
\hline 15 & Bresser \\
\hline 16 & Brás \\
\hline 17 & Gasômetro \\
\hline 18 & Independência \\
\hline 19 & Cambuci \\
\hline 20 & Glicério \\
\hline 21 & Aclimação \\
\hline 22 & Pires da Mota \\
\hline 23 & Centro Cultural \\
\hline 24 & Liberdade \\
\hline 25 & Treze de Maio \\
\hline 26 & Bexiga \\
\hline 27 & Bela Vista \\
\hline 28 & São Carlos do Pinhal \\
\hline 29 & Masp \\
\hline 30 & Higienópolis \\
\hline 31 & Vila Buarque \\
\hline 32 & Consolação \\
\hline 33 & Pacaembu \\
\hline 34 & FAAP \\
\hline 35 & Santa Cecília \\
\hline 36 & Marechal Deodoro \\
\hline 37 & Rudge \\
\hline 38 & Catumbi \\
\hline 39 & Belém \\
\hline 40 & Quarta Parada \\
\hline 41 & Belenzinho \\
\hline 42 & Celso Garcia \\
\hline 43 & Moóca \\
\hline 44 & Alto da Moóca \\
\hline 45 & Parque da Moóca \\
\hline 46 & Água Rasa \\
\hline 47 & Vila Bertioga \\
\hline 48 & Regente Feijó \\
\hline 49 & Ana Rosa \\
\hline 50 & Jardim da Glória \\
\hline 51 & Chácara Klabin \\
\hline 52 & Vila Mariana \\
\hline 53 & Santa Cruz \\
\hline 54 & Vila Clementino \\
\hline 55 & França Pinto \\
\hline 56 & Rodrigues Alves \\
\hline 57 & Paraíso \\
\hline 58 & Bosque da Saúde \\
\hline 59 & Saúde \\
\hline 60 & Planalto Paulista \\
\hline 61 & Mirandópolis \\
\hline 62 & Parque Ibirapuera \\
\hline 63 & Jardim Luzitânia \\
\hline 64 & Moema \\
\hline 65 & Bandeirantes \\
\hline 66 & Vila Nova Conceição \\
\hline 67 & Chácara Itaim \\
\hline 68 & Vila Olímpia \\
\hline 69 & Hélio Pelegrino \\
\hline 70 & Brooklin \\
\hline 71 & Vila Cordeiro \\
\hline 72 & Berrini \\
\hline 73 & Campinas \\
\hline 74 & Pamplona \\
\hline 75 & Jardins \\
\hline 76 & Clínicas \\
\hline 77 & Oscar Freire \\
\hline 78 & Trianon \\
\hline 79 & Jardim Paulistano \\
\hline 80 & Jardim Europa \\
\hline
\end{tabular}

\begin{tabular}{|c|c|}
\hline ID & Zona de Tráfego \\
\hline 81 & Pinheiros \\
\hline 82 & Vila Madalena \\
\hline 83 & PUC \\
\hline 84 & Cardoso de Almeida \\
\hline 85 & Zequinha de Abreu \\
\hline 86 & Sumaré \\
\hline 87 & Perdizes \\
\hline 88 & Vila Anglo Brasileira \\
\hline 89 & Pompéia \\
\hline 90 & Santa Marina \\
\hline 91 & Barra Funda \\
\hline 92 & Francisco Matarazzo \\
\hline 93 & Água Branca \\
\hline 94 & Vila Beatriz \\
\hline 95 & Alto de Pinheiros \\
\hline 96 & Boaçava \\
\hline 97 & Vila Anastácio \\
\hline 98 & Lapa de Baixo \\
\hline 99 & Lapa \\
\hline 100 & Vila Ipojuca \\
\hline 101 & Alto da Lapa \\
\hline 102 & Gavião Peixoto \\
\hline 103 & Bela Aliança \\
\hline 104 & Vila Hamburguesa \\
\hline 105 & CEASA \\
\hline 106 & Vila Leopoldina \\
\hline 107 & Emissário \\
\hline 108 & Vila Zatt \\
\hline 109 & Pirituba \\
\hline 110 & São Domingos \\
\hline 111 & Jardim Mutinga \\
\hline 112 & Vila Jaguara \\
\hline 113 & Jaraguá \\
\hline 114 & Nova Jaraguá \\
\hline 115 & Parada de Taipas \\
\hline 116 & Parque Morro Doce \\
\hline 117 & Anhanguera \\
\hline 118 & Perus \\
\hline 119 & Vista Alegre \\
\hline 120 & Jardim Damasceno \\
\hline 121 & Vila Terezinha \\
\hline 122 & Brasilândia \\
\hline 123 & Vila Morro Grande \\
\hline 124 & Itaberaba \\
\hline 125 & Freguesia do Ó \\
\hline 126 & Carandiru \\
\hline 127 & Santana \\
\hline 128 & Zaki Narchi \\
\hline 129 & Tietê \\
\hline 130 & Parque Anhembi \\
\hline 131 & Alfredo Pujol \\
\hline 132 & Santa Terezinha \\
\hline 133 & Jardim São Paulo \\
\hline 134 & Casa Verde \\
\hline 135 & Parque Peruche \\
\hline 136 & Limão \\
\hline 137 & Casa Verde Alta \\
\hline 138 & Cachoeirinha \\
\hline 139 & Jardim Peri \\
\hline 140 & Reserva da Cantareira \\
\hline 141 & Mandaqui \\
\hline 142 & Horto Florestal \\
\hline 143 & ETA Guaraú \\
\hline 144 & Parque Palmas do Tremembé \\
\hline 145 & Tremembé \\
\hline 146 & Cantareira \\
\hline 147 & Jardim das Pedras \\
\hline 148 & Jardim Guapira \\
\hline 149 & Parada Inglesa \\
\hline 150 & Tucuruvi \\
\hline 151 & Vila Gustavo \\
\hline 152 & Cohab Jova Real \\
\hline 153 & Jaçanã \\
\hline 154 & Parque Edu Chaves \\
\hline 155 & Vila Medeiros \\
\hline 156 & Jardim Brasil \\
\hline 157 & Jardim Japão \\
\hline 158 & Parque Novo Mundo \\
\hline 159 & Vila Maria \\
\hline 160 & Vila Isolina Mazzei \\
\hline
\end{tabular}

\begin{tabular}{|c|c|}
\hline ID & Zona de Tráfego \\
\hline 161 & Vila Guilherme \\
\hline 162 & Coroa \\
\hline 163 & Gomes Cardim \\
\hline 164 & Tatuapé \\
\hline 165 & Chácara do Piqueri \\
\hline 166 & Parque São Jorge \\
\hline 167 & Penha \\
\hline 168 & Tiquatira \\
\hline 169 & Vila Esperança \\
\hline 170 & Rui Barbosa \\
\hline 171 & Cangaíba \\
\hline 172 & Engenheiro Goulart \\
\hline 173 & USP Leste I \\
\hline 174 & USP Leste II \\
\hline 175 & Ermelino Matarazzo \\
\hline 176 & Parque Boturussu \\
\hline 177 & Ponte Rasa \\
\hline 178 & Águia de Haia \\
\hline 179 & Limoeiro \\
\hline 180 & Vila Jacuí \\
\hline 181 & Parada XV \\
\hline 182 & Itaquera \\
\hline 183 & Vila Campanela \\
\hline 184 & Rio Verde \\
\hline 185 & Saudade \\
\hline 186 & São Miguel Paulista \\
\hline 187 & Cidade Nitro-Operária \\
\hline 188 & Jardim Helena \\
\hline 189 & Jardim Romano \\
\hline 190 & Vila Curuçá \\
\hline 191 & Jardim Robru \\
\hline 192 & Lajeado \\
\hline 193 & Fábrica Bandeirantes \\
\hline 194 & Fazenda Itaim \\
\hline 195 & Itaim Paulista \\
\hline 196 & Jardim das Oliveiras \\
\hline 197 & Vila Califórnia \\
\hline 198 & Vila Carrão \\
\hline 199 & Jardim Anália Franco \\
\hline 200 & Vila Formosa \\
\hline 201 & Sapopemba \\
\hline 202 & Aricanduva \\
\hline 203 & Vila Matilde \\
\hline 204 & Vila Guilhermina \\
\hline 205 & Cidade A.E.Carvalho \\
\hline 206 & Artur Alvim \\
\hline 207 & Cidade Líder \\
\hline 208 & Santa Marcelina \\
\hline 209 & Parque Savoy \\
\hline 210 & Vila Carmosina \\
\hline 211 & Fazenda Caguaçu \\
\hline 212 & Parque do Carmo \\
\hline 213 & Gleba do Pessêgo \\
\hline 214 & José Bonifácio \\
\hline 215 & Guaianases \\
\hline 216 & Juscelino Kubitschek \\
\hline 217 & Cidade Tiradentes \\
\hline 218 & Terceira Divisão \\
\hline 219 & Iguatemi \\
\hline 220 & Parque São Rafael \\
\hline 221 & Rodolfo Pirani \\
\hline 222 & Ipiranga \\
\hline 223 & Sacomã \\
\hline 224 & Alto do Ipiranga \\
\hline 225 & Vila São José \\
\hline 226 & Vila Monumento \\
\hline 227 & Vila Independência \\
\hline 228 & Vila Carioca \\
\hline 229 & Moinho Velho \\
\hline 230 & São João Clímaco \\
\hline 231 & Anchieta \\
\hline 232 & Parque do Estado \\
\hline 233 & Água Funda \\
\hline 234 & Jardim da Saúde \\
\hline 235 & Vila Gumercindo \\
\hline 236 & Jardim Previdência \\
\hline 237 & Tamanduateí \\
\hline 238 & Orfanato \\
\hline 239 & Vila Zelina \\
\hline 240 & Linhas Corrente \\
\hline
\end{tabular}

\begin{tabular}{|c|c|}
\hline ID & Zona de Tráfego \\
\hline 241 & Vila Ema \\
\hline 242 & Parque São Lucas \\
\hline 243 & Parque Santa Madalena \\
\hline 244 & Jardim Colorado \\
\hline 245 & Teotônio Vilela \\
\hline 246 & Fazenda da Juta \\
\hline 247 & São Mateus \\
\hline 248 & Cidade IV Centenário \\
\hline 249 & Rio Claro \\
\hline 250 & Cidade Satélite \\
\hline 251 & Joaquim Nabuco \\
\hline 252 & Vieira de Moraes \\
\hline 253 & Campo Belo \\
\hline 254 & Congonhas \\
\hline 255 & Jardim Aeroporto \\
\hline 256 & Vila Santa Catarina \\
\hline 257 & Jabaquara \\
\hline 258 & Cidade Vargas \\
\hline 259 & Jardim Bom Clima \\
\hline 260 & Cupecê \\
\hline 261 & Jardim Miriam \\
\hline 262 & Vila Missionária \\
\hline 263 & Jurubatuba \\
\hline 264 & Vila São Pedro \\
\hline 265 & Campo Grande \\
\hline 266 & Vila Sabará \\
\hline 267 & Mar Paulista \\
\hline 268 & Pedreira \\
\hline 269 & Vila Socorro \\
\hline 270 & Parque Interlagos \\
\hline 271 & Jardim Represa \\
\hline 272 & Rio Bonito \\
\hline 273 & SESC Interlagos \\
\hline 274 & Jardim Presidente \\
\hline 275 & Grajaú \\
\hline 276 & Cocaia \\
\hline 277 & Bororé \\
\hline 278 & Jaceguava \\
\hline 279 & Parelheiros \\
\hline 280 & Marsilac \\
\hline 281 & Granja Julieta \\
\hline 282 & Chácara Flora \\
\hline 283 & Santo Amaro \\
\hline 284 & Vila Miranda \\
\hline 285 & Jardim São Luís \\
\hline 286 & Centro Empresarial \\
\hline 287 & Guarapiranga \\
\hline 288 & Jardim Capela \\
\hline 289 & Riviera \\
\hline 290 & M' Boi Mirim \\
\hline 291 & Jardim Ângela \\
\hline 292 & Capão Redondo \\
\hline 293 & Adventista \\
\hline 294 & Parque Fernanda \\
\hline 295 & Morumbi \\
\hline 296 & Jóquei Clube \\
\hline 297 & Fazenda Morumbi \\
\hline 298 & Real Parque \\
\hline 299 & Paraisópolis \\
\hline 300 & Jardim Vitória Régia \\
\hline 301 & Vila Suzana \\
\hline 302 & Parque Arariba \\
\hline 303 & Jardim Mitsutani \\
\hline 304 & Pirajussara \\
\hline 305 & Jardim Umarizal \\
\hline 306 & Portal do Morumbi \\
\hline 307 & Jardim Jussara \\
\hline 308 & Vila Sônia \\
\hline 309 & Jardim Maria do Carmo \\
\hline 310 & Jardim Cambará \\
\hline 311 & Jardim João XXIII \\
\hline 312 & Raposo Tavares \\
\hline 313 & Rio Pequeno \\
\hline 314 & Jardim Adalgiza \\
\hline 315 & Parque Continental \\
\hline 316 & Jaguaré \\
\hline 317 & Cidade Universitária \\
\hline 318 & Butantã \\
\hline 319 & Jardim Caxingui \\
\hline 320 & Jardim Bonfiglioli \\
\hline
\end{tabular}




\section{Anexo C}

Representação do mapa das Áreas de Ponderação do município de São Paulo

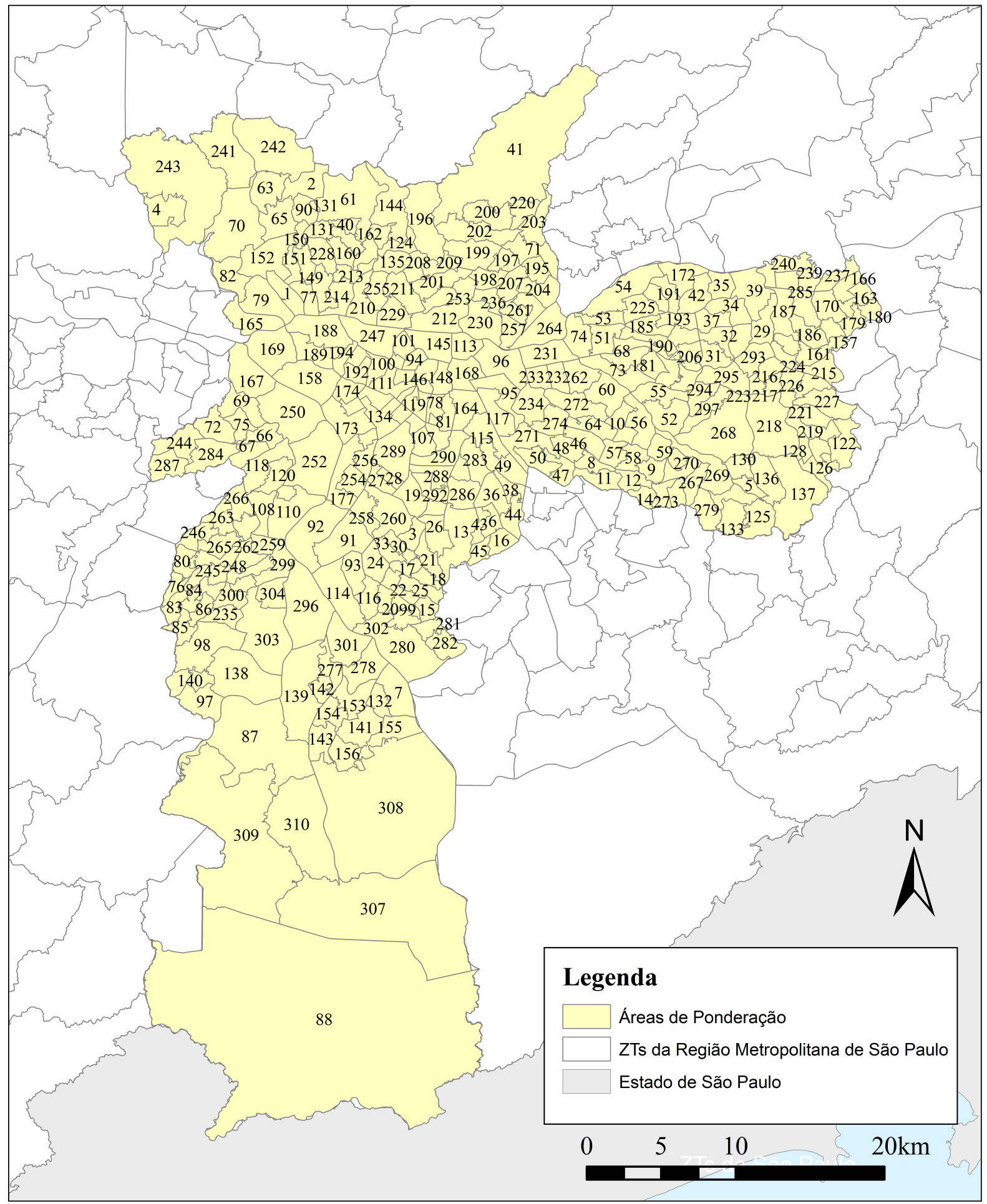




\section{Anexo D}

Legenda das Áreas de Ponderação do município de São Paulo

\begin{tabular}{|c|c|c|}
\hline ID & \# Setores & \# Pontos Aleatórios \\
\hline 1 & 48 & 468 \\
\hline 2 & 54 & 477 \\
\hline 3 & 49 & 447 \\
\hline 4 & 49 & 523 \\
\hline 5 & 42 & 414 \\
\hline 6 & 42 & 401 \\
\hline 7 & 38 & 441 \\
\hline 8 & 33 & 423 \\
\hline 9 & 69 & 743 \\
\hline 10 & 59 & 674 \\
\hline 11 & 59 & 651 \\
\hline 12 & 61 & 703 \\
\hline 13 & 79 & 711 \\
\hline 14 & 47 & 531 \\
\hline 15 & 66 & 705 \\
\hline 16 & $\begin{array}{l}00 \\
41\end{array}$ & 418 \\
\hline 17 & 59 & 409 \\
\hline 18 & 63 & 562 \\
\hline 19 & 45 & 459 \\
\hline 20 & 53 & 599 \\
\hline 21 & 58 & 498 \\
\hline 22 & 72 & 666 \\
\hline 23 & 36 & 403 \\
\hline 24 & 61 & 605 \\
\hline $\begin{array}{l}24 \\
25\end{array}$ & $\begin{array}{ll}61 \\
73\end{array}$ & $\begin{array}{l}605 \\
719\end{array}$ \\
\hline 26 & 71 & 661 \\
\hline 27 & 44 & 403 \\
\hline 28 & 60 & 559 \\
\hline $\begin{array}{l}20 \\
29\end{array}$ & 79 & 765 \\
\hline 30 & 63 & 461 \\
\hline 31 & 58 & 566 \\
\hline 32 & 62 & 602 \\
\hline 33 & 49 & 510 \\
\hline 34 & 85 & 758 \\
\hline 35 & 76 & 660 \\
\hline 36 & 73 & 731 \\
\hline 37 & 72 & 625 \\
\hline 38 & 49 & 641 \\
\hline 39 & 69 & 570 \\
\hline 40 & 45 & 449 \\
\hline 41 & 92 & 685 \\
\hline 42 & 70 & 615 \\
\hline 43 & 42 & 425 \\
\hline 44 & 45 & 567 \\
\hline 45 & 63 & 605 \\
\hline 46 & 58 & 681 \\
\hline 47 & 42 & 488 \\
\hline 48 & 40 & 467 \\
\hline 49 & 68 & 712 \\
\hline 50 & 55 & 576 \\
\hline 51 & 68 & 642 \\
\hline 52 & 59 & 646 \\
\hline 53 & 45 & 408 \\
\hline 54 & 48 & 436 \\
\hline 55 & 64 & 746 \\
\hline 56 & 67 & 714 \\
\hline 57 & 53 & 577 \\
\hline 58 & 65 & 725 \\
\hline 59 & 64 & 670 \\
\hline 60 & 61 & 642 \\
\hline 61 & 94 & 769 \\
\hline 62 & 54 & 656 \\
\hline 63 & 38 & 461 \\
\hline 64 & 65 & $\begin{array}{l}601 \\
6997\end{array}$ \\
\hline 65 & 59 & 439 \\
\hline 66 & 63 & 423 \\
\hline 67 & 84 & 537 \\
\hline 68 & 41 & 453 \\
\hline 69 & 114 & 770 \\
\hline 70 & 86 & 638 \\
\hline 71 & 85 & 781 \\
\hline 72 & 85 & 561 \\
\hline 73 & 69 & 746 \\
\hline 74 & 56 & 498 \\
\hline 75 & 73 & 479 \\
\hline 76 & 47 & 432 \\
\hline 77 & 40 & 413 \\
\hline 78 & 55 & 578 \\
\hline
\end{tabular}

\begin{tabular}{|c|c|c|}
\hline ID & \# Setores & \# Pontos Aleatórios \\
\hline 79 & 76 & 777 \\
\hline 80 & 85 & 744 \\
\hline 81 & 62 & 704 \\
\hline 82 & 50 & 496 \\
\hline 83 & 43 & 487 \\
\hline 84 & 51 & 453 \\
\hline 85 & 65 & 563 \\
\hline 86 & 57 & 618 \\
\hline 87 & 62 & \\
\hline & 73 & 455 \\
\hline 89 & 39 & 434 \\
\hline 90 & 53 & 593 \\
\hline 91 & 53 & 451 \\
\hline 92 & 81 & 729 \\
\hline 93 & $\begin{array}{l}\begin{array}{l}01 \\
61\end{array} \\
6\end{array}$ & 614 \\
\hline 94 & $\begin{array}{l}01 \\
81\end{array}$ & $\begin{array}{l}814 \\
801\end{array}$ \\
\hline 95 & $\begin{array}{l}81 \\
77\end{array}$ & 735 \\
\hline 96 & 79 & $\begin{array}{l}676 \\
676\end{array}$ \\
\hline $\begin{array}{l}90 \\
97\end{array}$ & 39 & $\begin{array}{l}010 \\
435\end{array}$ \\
\hline $\begin{array}{l}91 \\
98\end{array}$ & 75 & $\begin{array}{l}433 \\
573\end{array}$ \\
\hline $\begin{array}{l}98 \\
99\end{array}$ & $\begin{array}{l}13 \\
55\end{array}$ & $\begin{array}{l}573 \\
552\end{array}$ \\
\hline 100 & 55 & 455 \\
\hline 101 & 41 & 408 \\
\hline 102 & 41 & 496 \\
\hline $\begin{array}{l}102 \\
103\end{array}$ & 78 & $\begin{array}{l}496 \\
712\end{array}$ \\
\hline 104 & 44 & 454 \\
\hline 105 & 67 & 562 \\
\hline 106 & 42 & 468 \\
\hline 107 & 69 & 675 \\
\hline 108 & 88 & 478 \\
\hline 109 & 72 & 585 \\
\hline 110 & 98 & 602 \\
\hline 111 & 75 & 634 \\
\hline 112 & 37 & 734 \\
\hline 113 & 28 & 522 \\
\hline 114 & 55 & 472 \\
\hline 115 & 49 & 484 \\
\hline 116 & 62 & 501 \\
\hline 117 & 56 & 519 \\
\hline 118 & 102 & 551 \\
\hline 119 & 59 & 593 \\
\hline 120 & 84 & 507 \\
\hline 121 & 45 & 419 \\
\hline 122 & 52 & 514 \\
\hline 123 & 53 & 423 \\
\hline 124 & 50 & 577 \\
\hline 125 & 49 & 417 \\
\hline 126 & 67 & 568 \\
\hline 127 & 64 & 474 \\
\hline 128 & 49 & 465 \\
\hline 129 & 66 & 623 \\
\hline 130 & $\begin{array}{l}00 \\
43\end{array}$ & 405 \\
\hline 131 & $\begin{array}{l}43 \\
62\end{array}$ & $\begin{array}{l}403 \\
619\end{array}$ \\
\hline 132 & 40 & 433 \\
\hline 133 & 52 & 481 \\
\hline 134 & 71 & 623 \\
\hline 135 & 59 & 554 \\
\hline 136 & 63 & 485 \\
\hline 137 & 70 & 486 \\
\hline 138 & 27 & 431 \\
\hline 139 & 71 & 678 \\
\hline 140 & 43 & 434 \\
\hline 141 & 87 & 783 \\
\hline 142 & 41 & 469 \\
\hline 143 & 70 & 606 \\
\hline 144 & 55 & 424 \\
\hline 145 & 50 & 524 \\
\hline 146 & 83 & 728 \\
\hline 147 & 58 & 520 \\
\hline 148 & 46 & 429 \\
\hline 149 & 70 & 705 \\
\hline 150 & 57 & 565 \\
\hline 151 & 70 & 550 \\
\hline 152 & 53 & 539 \\
\hline 153 & 86 & 785 \\
\hline 154 & 78 & 632 \\
\hline 155 & 48 & 401 \\
\hline 156 & 64 & 514 \\
\hline
\end{tabular}

\begin{tabular}{|c|c|c|}
\hline ID & \# Setores & \# Pontos Aleatórios \\
\hline 157 & 51 & 455 \\
\hline 158 & 79 & 710 \\
\hline 159 & 44 & 404 \\
\hline 160 & 69 & 680 \\
\hline 161 & 80 & 759 \\
\hline 162 & 54 & 498 \\
\hline 163 & 67 & 629 \\
\hline 164 & 56 & 616 \\
\hline 165 & 35 & \\
\hline 166 & 45 & 413 \\
\hline 167 & 105 & 800 \\
\hline 168 & 56 & \\
\hline 169 & 73 & 652 \\
\hline 170 & 80 & 657 \\
\hline 171 & 57 & 565 \\
\hline 172 & 61 & 548 \\
\hline 173 & 60 & 420 \\
\hline 174 & 59 & 438 \\
\hline 175 & 54 & 448 \\
\hline 176 & 55 & 395 \\
\hline 177 & 49 & 430 \\
\hline 178 & 44 & 415 \\
\hline 179 & 63 & $\begin{array}{l}413 \\
591\end{array}$ \\
\hline 180 & 49 & 416 \\
\hline $\begin{array}{l}100 \\
181\end{array}$ & 42 & $\begin{array}{l}410 \\
435\end{array}$ \\
\hline $\begin{array}{l}101 \\
182\end{array}$ & 50 & 426 \\
\hline 183 & 55 & 621 \\
\hline 184 & 40 & 488 \\
\hline 185 & 60 & 551 \\
\hline 186 & 69 & 692 \\
\hline 187 & 70 & 732 \\
\hline 188 & 67 & 470 \\
\hline 189 & 73 & 624 \\
\hline 190 & 40 & 430 \\
\hline 191 & 47 & 419 \\
\hline 192 & 57 & 546 \\
\hline 193 & 59 & 469 \\
\hline 194 & 49 & 500 \\
\hline 195 & 84 & 723 \\
\hline 196 & 60 & 526 \\
\hline 197 & 51 & 435 \\
\hline 198 & 62 & 563 \\
\hline 199 & 62 & 541 \\
\hline 200 & 77 & 610 \\
\hline 201 & 83 & 702 \\
\hline 202 & 85 & 731 \\
\hline 203 & 67 & 549 \\
\hline 204 & 58 & 498 \\
\hline 205 & 37 & 410 \\
\hline 206 & 55 & 516 \\
\hline 207 & 79 & 679 \\
\hline 208 & 67 & 649 \\
\hline 209 & 58 & 543 \\
\hline 210 & 66 & 625 \\
\hline 211 & 78 & 768 \\
\hline 212 & 80 & 513 \\
\hline 213 & 57 & 516 \\
\hline 211 & 50 & 490 \\
\hline 215 & 73 & 667 \\
\hline 2116 & 59 & $\begin{array}{l}501 \\
557\end{array}$ \\
\hline $\begin{array}{l}10 \\
217\end{array}$ & 46 & 410 \\
\hline 218 & $\begin{array}{l}40 \\
69\end{array}$ & $\begin{array}{l}410 \\
484\end{array}$ \\
\hline $\begin{array}{l}118 \\
219\end{array}$ & $\begin{array}{l}69 \\
74\end{array}$ & $\begin{array}{l}484 \\
583\end{array}$ \\
\hline 220 & 71 & 742 \\
\hline 221 & 44 & 429 \\
\hline 222 & 44 & 418 \\
\hline 223 & 40 & 421 \\
\hline 224 & 56 & 461 \\
\hline 225 & 71 & 707 \\
\hline 226 & 48 & 402 \\
\hline 227 & 67 & 631 \\
\hline 228 & 57 & 488 \\
\hline 229 & 55 & 510 \\
\hline 230 & 42 & 403 \\
\hline 231 & 83 & 719 \\
\hline 232 & 51 & 463 \\
\hline 233 & 44 & 416 \\
\hline 234 & 77 & 787 \\
\hline
\end{tabular}

\begin{tabular}{|c|c|c|}
\hline ID & \# Setores & \# Pontos Aleatórios \\
\hline 235 & 4 & 539 \\
\hline 236 & 40 & 423 \\
\hline 237 & 60 & 455 \\
\hline 238 & 51 & 473 \\
\hline 239 & 55 & 430 \\
\hline 240 & 58 & 513 \\
\hline 241 & 77 & 585 \\
\hline 242 & 68 & 506 \\
\hline 243 & 72 & 406 \\
\hline 244 & 70 & 476 \\
\hline 245 & 67 & 689 \\
\hline 246 & 67 & 559 \\
\hline 247 & 37 & 556 \\
\hline 248 & 75 & 732 \\
\hline 249 & 50 & 420 \\
\hline 250 & 83 & 433 \\
\hline 251 & 59 & 541 \\
\hline 252 & 133 & 715 \\
\hline 253 & 68 & 605 \\
\hline 254 & 56 & 504 \\
\hline 255 & 63 & 585 \\
\hline 256 & 49 & 443 \\
\hline 257 & 68 & 630 \\
\hline 258 & 59 & 453 \\
\hline 259 & 39 & 452 \\
\hline 260 & 89 & 681 \\
\hline 261 & 42 & 400 \\
\hline 262 & 64 & 690 \\
\hline 263 & 62 & 553 \\
\hline 264 & 69 & 716 \\
\hline 265 & 81 & 792 \\
\hline 266 & 64 & 638 \\
\hline 267 & 49 & 462 \\
\hline 268 & 44 & 428 \\
\hline 269 & 63 & 655 \\
\hline 270 & 49 & 517 \\
\hline 271 & 65 & 615 \\
\hline 272 & 69 & 739 \\
\hline 273 & 48 & 422 \\
\hline 274 & 53 & 548 \\
\hline 275 & 40 & 474 \\
\hline 276 & 42 & 405 \\
\hline 277 & 41 & 501 \\
\hline 278 & 44 & 485 \\
\hline 279 & 69 & 643 \\
\hline 280 & 76 & 579 \\
\hline 281 & 77 & 564 \\
\hline 282 & 55 & 474 \\
\hline 283 & 50 & 519 \\
\hline 284 & 86 & 552 \\
\hline 285 & 76 & 692 \\
\hline 286 & 64 & 621 \\
\hline 287 & 66 & 413 \\
\hline 288 & 79 & 773 \\
\hline 289 & 73 & 628 \\
\hline 290 & 77 & 786 \\
\hline 291 & 41 & 415 \\
\hline 292 & 64 & 737 \\
\hline 293 & 68 & 692 \\
\hline 294 & 42 & 421 \\
\hline 295 & 48 & 499 \\
\hline 296 & 56 & 589 \\
\hline 297 & 52 & 494 \\
\hline 298 & 49 & 526 \\
\hline 299 & 55 & 625 \\
\hline 300 & 60 & 584 \\
\hline 301 & 64 & 655 \\
\hline 302 & 54 & 391 \\
\hline 303 & 69 & 663 \\
\hline 304 & 47 & 461 \\
\hline 305 & 50 & 446 \\
\hline 306 & 62 & 697 \\
\hline 307 & 99 & 465 \\
\hline 308 & 175 & 405 \\
\hline 309 & 88 & 484 \\
\hline 310 & 87 & 452 \\
\hline
\end{tabular}

